San Jose State University

SJSU ScholarWorks

Master's Theses

Master's Theses and Graduate Research

Spring 2017

\title{
Taxonomic Revision of the Short Nose Chimaeras (Genus Hydrolagus) from the Southern African Region
}

Kristin Walovich

San Jose State University

Follow this and additional works at: https://scholarworks.sjsu.edu/etd_theses

\section{Recommended Citation}

Walovich, Kristin, "Taxonomic Revision of the Short Nose Chimaeras (Genus Hydrolagus) from the Southern African Region" (2017). Master's Theses. 4829.

DOI: https://doi.org/10.31979/etd.27cz-jst2

https://scholarworks.sjsu.edu/etd_theses/4829

This Thesis is brought to you for free and open access by the Master's Theses and Graduate Research at SJSU ScholarWorks. It has been accepted for inclusion in Master's Theses by an authorized administrator of SJSU ScholarWorks. For more information, please contact scholarworks@sjsu.edu. 


\title{
TAXONOMIC REVISION OF THE SHORT NOSE CHIMAERAS (GENUS HYDROLAGUS ) FROM THE SOUTHERN AFRICAN REGION
}

\author{
A Thesis \\ Presented to \\ The Faculty of Moss Landing Marine Laboratories
}

San José State University

In Partial Fulfillment

of the Requirements for the Degree

Master of Science

by

Kristin A. Walovich

May 2017 
(C) 2017

Kristin A. Walovich

ALL RIGHTS RESERVED 
The Designated Thesis Committee Approves the Thesis Titled

TAXONOMIC REVISION OF THE SHORT NOSE CHIMAERAS (GENUS HYDROLAGUS ) FROM THE SOUTHERN AFRICAN REGION

by

Kristin A. Walovich

APPROVED FOR THE DEPARTMENT OF MARINE SCIENCE

SAN JOSÉ STATE UNIVERISTY

May 2017

Dr. Scott Hamilton

Dr. David A. Ebert

Dr. Kenneth Coale
Moss Landing Marine Laboratories

Moss Landing Marine Laboratories

Moss Landing Marine Laboratories 


\title{
Abstract \\ TAXONOMIC REVISION OF THE SHORT NOSE CHIMAERAS (GENUS HYDROLAGUS ) FROM THE SOUTHERN AFRICAN REGION
}

\author{
by Kristin A. Walovich
}

Short-nose chimaeras are an enigmatic and understudied group of deep-sea Chondrichthyan fishes. To resolve decades of confusion and misidentification in the southern African region, morphometric and genetic data were utilized to resolve taxonomic confusion for the genus Hydrolagus. Nearly 100 chimaeroid specimens were examined from numerous national and international museum ichthyology collections. A series of 96 measurements per specimen were recorded and analyzed with multivariate statistics to determine differences among species. Tissue was collected from various southern African species for analysis of the mitochondrial gene NADH2. The resulting genetic information was compared to morphologically similar species and those within the same geographical region. This study re-describes Hydrolagus africanus, officially describes a new species Hydrolagus erithacus sp. nov, identifies a species known as Hydrolagus cf. trolli as Hydrolagus affinis, and provides taxonomic clarification and detailed descriptions for all three species. The morphological and genetic differences between species of this genus are not pronounced, presenting challenges for identification and classification. Species clarification enables improved identification and fisheries statistics, informed management efforts, and the advancement of chimaera genetic and biological research. 


\section{Acknowledgements}

This thesis would not have been possible if not for the guidance and support from numerous people. Sincere thanks are owed to my three thesis advisors, Dr. David Ebert, whose immense knowledge of Chondrichthyans has helped save three more "Lost Sharks”, Dr. Scott Hamilton, whose help extends back to my undergraduate days, and Dr. Kenneth Coale, for his unflagging support and insight. Thank you to Jenny Kemper (Medical University of South Carolina), whose work ethic, productivity and knowledge I strive to emulate. A special thanks goes to Rob Leslie (South African Department of Agriculture, Forestry and Fisheries) who has been instrumental to the success of my thesis.

A number of people were very helpful during this research and I wish to extend a very appreciated thank you to Dominique Didier (Millersville University) and Douglas Long (Saint Mary's College) for their assistance on the Hydrolagus africanus paper, Gavin Naylor (College of Charleston, South Carolina), Mattias Lanas and Mark Dando who contributed their time and immense talent to draw the illustrations for my thesis, and to the staffs at the numerous museum collections and institutions I was privileged to visit including Mark Sabaj-Pérez (Academy of Natural Sciences Philadelphia, Drexel University), Radford Arrindell (American Museum of Natural History, New York), Kris Murphy and Jeffery Williams (National Museum of Natural History, Smithsonian Institute), Roger Bills, Paul Cowley, and Alan Whitfield (South African Institute of Aquatic Biodiversity), Robb Copper, and Larvika Singh (South African Department of 
Agriculture, Forestry and Fisheries), Mike Bougaardt, Dylan Clarke, Liz Hoenson and Candice Untiedt (Izikio South African Museum), and Dave Catania and Jon Fong (California Academy of Sciences).

The Moss Landing Marine Laboratories community has been vital to my success. Thank you to Paul Clerkin for his help at the South African Museum to discover odd, smelly, and wonderful creatures in that dark basement in Cape Town, to all the students, past and present of the Pacific Shark Research Center, especially Matt Jew and Melissa Nehmens to whom I owe most of my sanity, Jason Adelaars for ArcGIS assistance, the 'shop guys' James Cochran, Billy Cochran and Kris Machado who saved the day many times and Joan Parker for her library and research expertise. I am so appreciative to Maria Kanapuu, Murray Stein and John Douglas at Marine Operations and Amy Byington, Wes Heim and Autumn Bonnema at the Marine Pollution Studies Lab for providing a flexible work environment.

This project was supported in part by the National Science Foundation (NSF) Collaborative Research: Jaws and Backbone: Chondrichthyan Phylogeny and a Spine for the Vertebrate Tree of Life (DEB 1132229 and 1036505). Other funding was provided by the Council on Ocean Affairs, Science and Technology (COAST) Travel Award, the American Society of Ichthyologists and Herpetologists Raney Award, the Systematics Research Fund Grant, the Dr. Earl H. Myers and Ethel M. Myers Oceanographic and Marine Biology Trust Grant, the MLML Wave Award, the David and Lucille Packard Research and Travel Award, the San José State University Alumni Association Dean's Scholarship and the South African Institute for Aquatic Biodiversity. 


\section{Table of Contents}

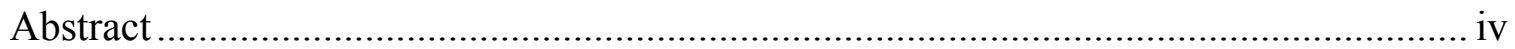

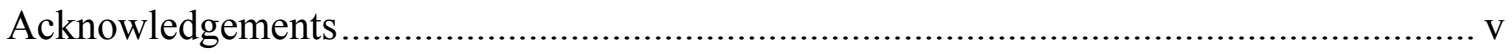

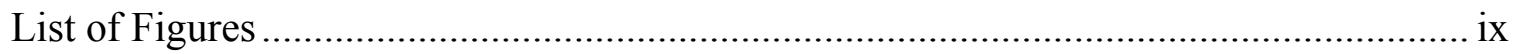

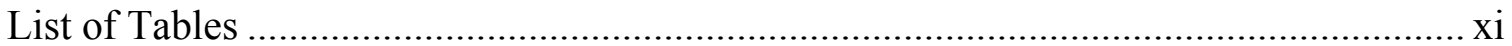

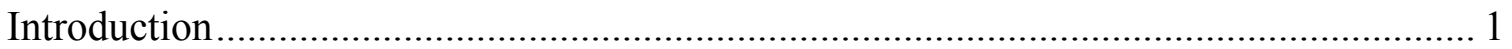

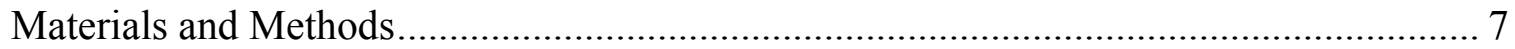

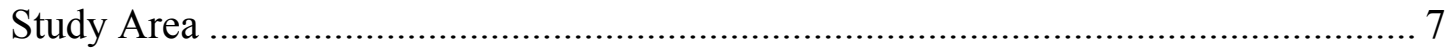

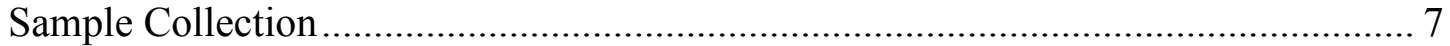

Morphological Measurements ............................................................................... 10

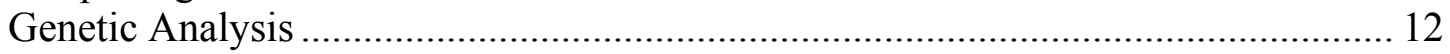

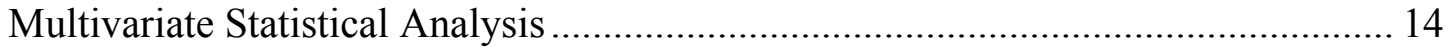

Chapter 1 Re-Description Of Hydrolagus africanus (Gilchrist, 1922)........................... 17

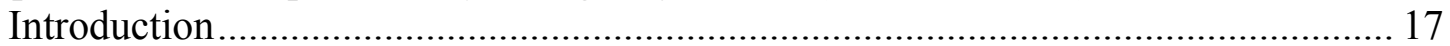

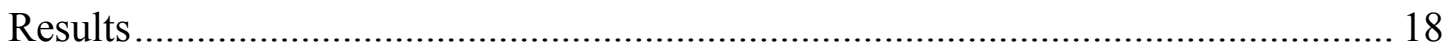

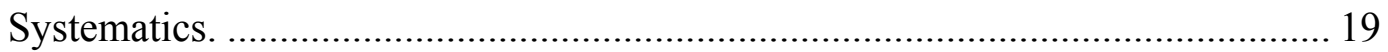

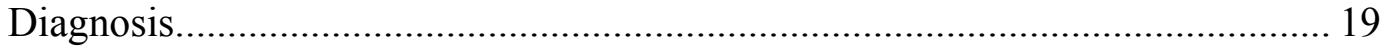

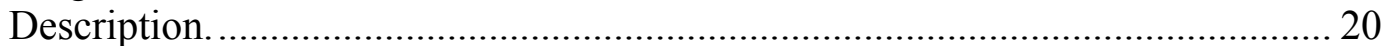

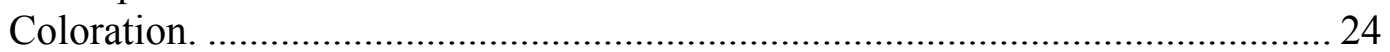

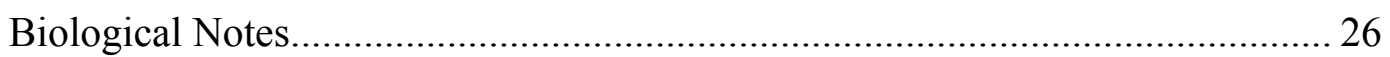

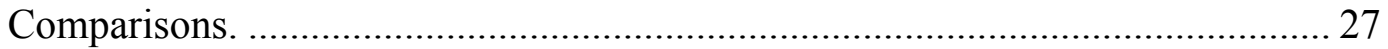

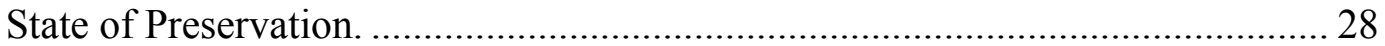

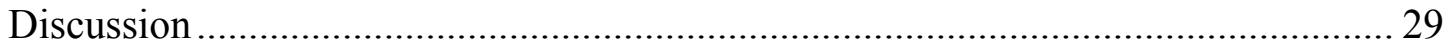

Chapter 2 Description Of Hydrolagus erithacus sp. nov. Walovich, Ebert \& Kemper,

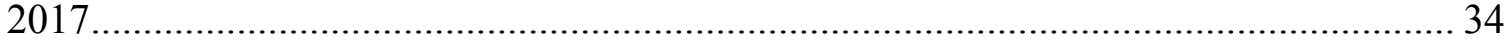

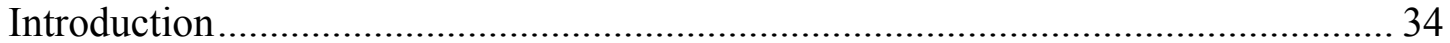

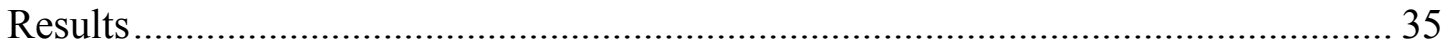

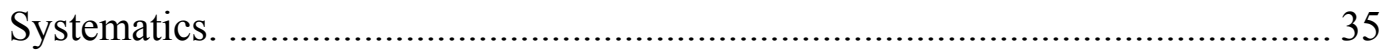

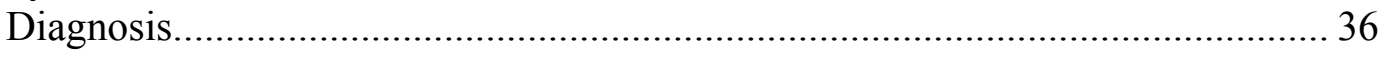

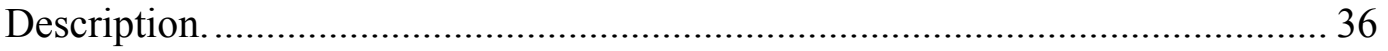




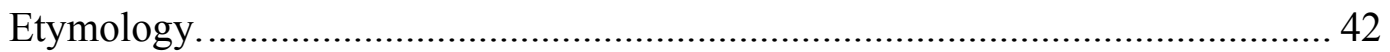

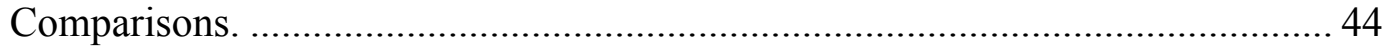

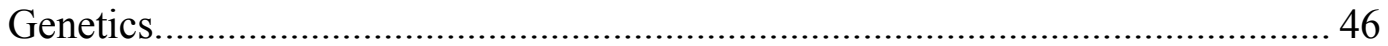

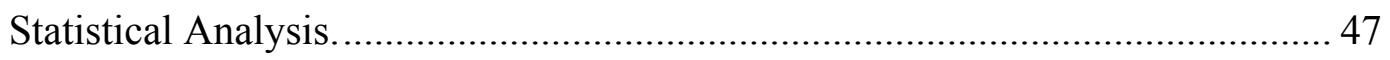

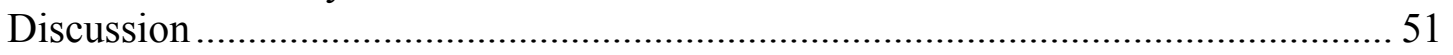

Chapter 3 Identification Of The Southern African Ghost Shark Formerly Known As

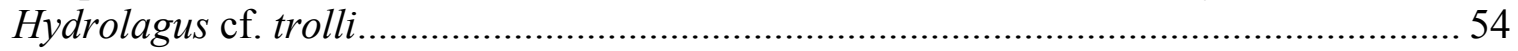

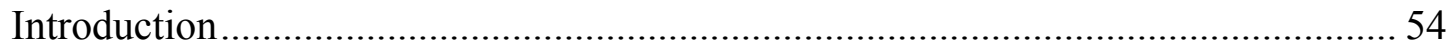

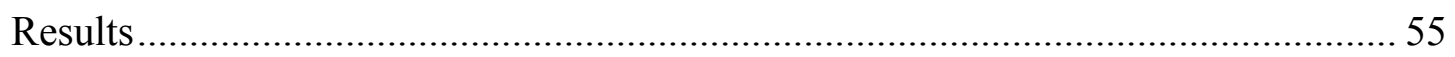

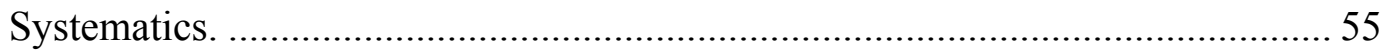

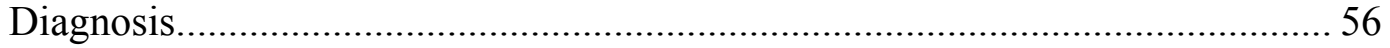

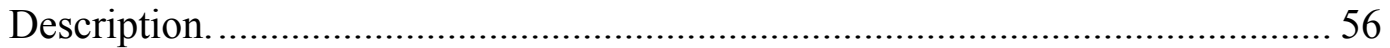

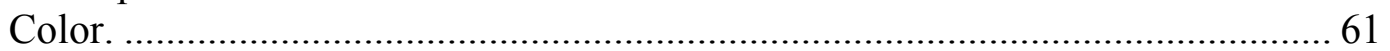

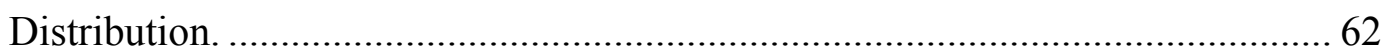

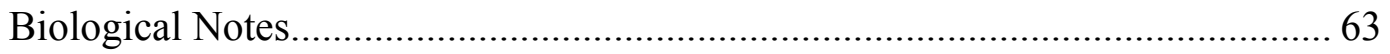

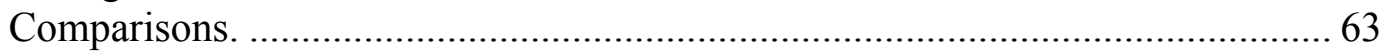

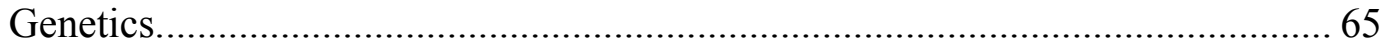

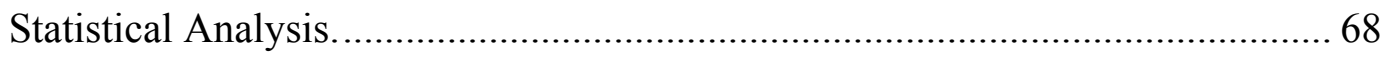

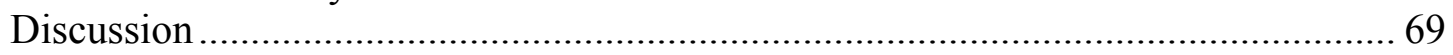

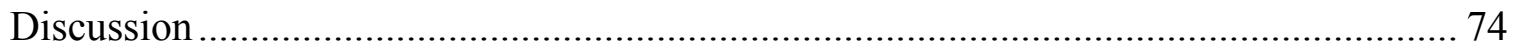

Conservation and Management of Chimaeroid Fishes ......................................... 79

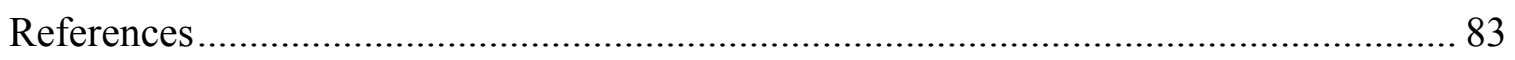

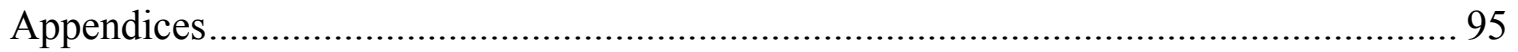

Appendix 1 Key to Southern African Chimaeroid Species .................................... 95

Appendix 2 Material Examined ....................................................................... 97

Appendix 3 Morphological Measurements Definitions and Abbreviations ............. 101 


\section{List of Figures}

Figure 1. Diagram of morphological measurements for Chimaeridae species. Illustrations by Marc Dando (lateral view) and Mattias Lanas (frontal tenaculum).

Figure 2. Hydrolagus africanus (Gilchrist, 1922) neotype, SAM 34420, mature male, $600+\mathrm{mm}$ TL, $388 \mathrm{~mm}$ BDL, collected from the

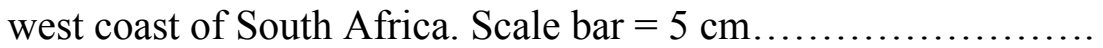

Figure 3. Intraspecific comparison of lateral line canals of (a) Hydrolagus africanus neotype and (b) adult male (SAM 27750); preopercular (POP), oral $(\mathrm{O})$ and intraorbital $(\mathrm{IO})$. Scale bar $=3 \mathrm{~cm}$.

Figure 4. Sexual characters in adult male neotype SAM 34420, (a) lateral view of frontal tenaculum and (b) prepelvic tenaculum with five medial denticles and one lateral denticle (arrow). Scale bar $=3$

Figure 5. Ventral view of neotype SAM 34420 claspers. Scale bar $=3 \mathrm{~cm}$..

Figure 6. Two-dimensional non-Metric Multidimensional Scaling (n-MDS) plots comparing the preserved (orange) and non-preserved (blue) specimens of Hydrolagus africanus.

Figure 7. Hydrolagus erithacus sp. nov. holotype, SAIAB 200578, mature male, $1290 \mathrm{~mm}$ TL, $790 \mathrm{~mm}$ BDL, collected from Discovery Seamount, southeastern Indian Ocean. Scale bar $=5 \mathrm{~cm} \ldots \ldots \ldots \ldots$

Figure 8. Sexual characters of adult H. erithacus holotype including the (A) claspers (B) frontal tenaculum in lateral view (C) frontal tenaculum in dorsal view and (D) pre-pelvic tenaculum in ventral view. Illustration of male reproductiv organs by Mattias Lanas (E) Scale bars $=5 \mathrm{~mm}(\mathrm{~A})$, and $1 \mathrm{~mm}(\mathrm{~B})-(\mathrm{D})$

Figure 9. Distribution of H. erithacus in the southeast Atlantic and southwest Indian Oceans.... 
Figure 10. Maximum likelihood tree estimate using general-time reversible (GTR) + gamma model based on NADH2 sequence data of Hydrolagus erithacus and comparative species. GenBank accession numbers follow species names. Hydrolagus erithacus position indicated in bold; collection number follows GenBank accession number. $*$ holotype ...............................

Figure 11. Two-dimensional non-Metric Multidimensional Scaling (n-MDS) plot comparing the morphological traits of four Hydrolagus species including Hydrolagus affinis (NA) (dark blue), Hydrolagus affinis (SA)(light blue), Hydrolagus africanus (purple), Hydrolagus erithacus (red) and Hydrolagus trolli (green)

Figure 12. Hydrolagus affinis (SA) SAM 33297A, mature male, $935 \mathrm{~mm}$ TL, $613 \mathrm{~mm}$ BDL. Scale bar $=5 \mathrm{~cm}$.

Figure 13. Two color variants of Hydrolagus affinis found in southern Africa including a lighter morph (top; GN 16943) and a darker form (bottom; GN 16944). Scale bar $=5 \mathrm{~cm}$

Figure 14. Maximum likelihood tree estimate using general-time reversible (GTR) + gamma model based on NADH2 sequence data of Hydrolagus affinis (SA and NA) and comparative species

Figure 15. Two-dimensional non-Metric Multidimensional Scaling (n-MDS) plot comparing the morphological traits of the north Atlantic (dark blue) and southern African (light blue) H. affinis populations and $H$. trolli (green). 


\section{List of Tables}

Table 1. List of Specimens used in Genetic Analysis ...................... 9

Table 2. Hydrolagus africanus Morphometric Data......................... 21-22

Table 3. Summary Table of One-Sample T-test for Differences in Hydrolagus africanus Morphological Traits Before (NP) and After (P) preservation................................................ 30

Table 4. Measurements of Hydrolagus erithacus sp. nov. Holotype (SAIAB 200578) and Paratypes ( $n=8)$.

Table 5. Analysis of Similarity (ANOSIM) and Similarity Percentage Analysis (SIMPER) Results for Differences Between Species.........

Table 6. Hydrolagus affinis (NA), H. affinis (SA), and H. trolli Morphometric Data ........................................................... $57-58$

Table 7. Analysis of Similarity (ANOSIM) and Similarity Percentage Analysis (SIMPER) Results for Differences Between $H$. affinis Populations and H.trolli. 


\section{Introduction}

A lack of taxonomic clarity has detrimental and far-reaching implications for many facets of Chondrichthyan research including proper identification, acquisition of basic life history information, and the implementation of fishery management and conservation efforts (Simpfendorfer et al., 2011; White \& Last, 2012). Taxonomic resolution is fundamentally important to the biological sciences for these reasons. A species without a valid binomial name cannot be successfully managed nor can any research concerning that species be placed into context (Blackwelder, 1967). Chondrichthyan taxonomy and systematics, despite its importance, remains an underrepresented and underfunded field of study (Anderson \& Pietsch, 1997; White \& Last, 2012). This phenomenon can be attributed to a common misconception that the taxonomy of Chondrichthyans, collectively sharks, batoids and chimaeras, has been fully resolved. Yet over the last decade and a half, over 275 new species have been described, representing c. $20 \%$ of global Chondrichthyan biodiversity (Ebert \& van Hees, 2015; White \& Last, 2012). Declines in global shark populations, due to habitat loss and overfishing, have increased the need for accurate and consistent species identification. Dulvy et al. (2014) emphasized proper identification where data is lacking and the implementation of appropriate management and conservation decisions for this vulnerable fish group. International organizations like the Food and Agriculture Organization of the United Nations (FAO) International Plan of Action (IPOA) for sharks and the International Union for the Conservation of Nature (IUCN) have prioritized the resolution of 
taxonomic problems in order to improve data on catches, fishing efforts and landings of sharks (FAO, 1999, 2013; IUCN, 2014).

Ambiguous or inconsistent species identification and uncertain species distribution (wide-ranging or regional endemics) yield inaccurate fisheries statistics, hindering subsequent status assessments and proper management. For example, Iglésias et al. (2010) determined that the Critically Endangered Flapper Skate [Dipturus batis (Linnaeus, 1758)] is a species complex, resulting in confounded catch data and elevating the extinction risk for both species. In a second example, the separation of the manta ray into two species: Manta birostris (Walbaum, 1792), a globally distributed and wide ranging species, and Manta alfredi (Krefft, 1868), a smaller and tropically distributed species, highlights two species with differing habitat utilizations and threats (Marshall et al., 2009). These examples emphasize how proper taxonomic identification can alter the strategy and outcome for management and conservation efforts.

The lack of basic taxonomic information is particularly concerning for Chondrichthyan species in the deep ocean, those occurring below 200 meters, where nearly half of all known species reside (Kyne \& Simpfendorfer, 2010). Deep-water sharks are taken as target species or as bycatch in deep-sea fishing operations that are currently expanding into deeper waters in response to the depletion of near shore and shelf species (Didier, Kemper \& Ebert, 2012; Morato et al., 2006; Pauly et al., 2003). These species are frequently discarded or recorded under generic terms like 'shark' or 'other', making assessments of fisheries impacts a challenge. The lack of species specific catch data combined with largely unknown life history characteristics, distribution 
information, and low intrinsic rebound potential (often half that of coastal species) increases the vulnerability of deep-sea Chondrichthyans to expanding fisheries (FAO, 2011; Hoenig \& Gruber, 1990; Kyne \& Simpfendorfer, 2009). The number of species caught, unrecorded and unmonitored by deep-sea operations highlights the need for taxonomic certainty to begin the implementation of appropriate fishery and conservation strategies (Compagno \& Musick, 2005).

The chimaeroid fishes remain an understudied group of deep-sea Chondrichthyans that may be particularly susceptible to the impacts of deep-sea fisheries. Worldwide, the order Chimaeriformes is currently comprised of 50 valid species from three families, Callorhinchidae Garman, 1901, Rhinochimaeridae Garman, 1901 and Chimaeridae Bonaparte, 1831, each characterized by their snout morphology (Angulo et al., 2014; Didier et al., 2012; Kemper et al., 2015). Chimaeroids, commonly referred to as ghost sharks, silver sharks or ratfish, differ from other extant Chondrichthyan fishes (e.g. sharks and batoids) as they possess elongated bodies, long filamentous tails, a single gill opening, smooth, scale-less skin, and paired tooth plates instead of individual teeth (Didier, 1995; Didier et al., 2012). Many of these species were rarely encountered in the past due to the great depths that they inhabit; however as fisheries move into deeper waters and deep-sea research gains support, chimaera species are being encountered and described at a higher rate than ever before. Since 2002, 20 new species have been described, all from the family Chimaeridae (Kemper et al., 2015). The genus Hydrolagus, the most specious genus in the order and family, has increased by $43 \%$ with 10 new species described over the past decade and a half. Despite the surge in new chimaeroid 
species descriptions, there are still many outstanding taxonomic issues remaining within the order. These taxonomic uncertainties and other factors have prompted the IUCN to classify $43 \%$ of chimaeroid species as Data Deficient on its Red List of Threatened Species (IUCN, 2015). The IUCN assesses the conservation status and distribution of species based on published information to provide a foundation for informed conservation and management decisions. However, species categorized as Data Deficient lack the necessary information to make proper assessments. This lack of data negatively impacts how and where conservation resources are invested and introduces uncertainty into estimates of threatened species. Although taxonomic knowledge of chimaeras in some regions is relatively well known, particularly in Australia, Taiwan and the U.S.A., the fauna of most regions, including southern Africa, require further investigation and research (Ebert et al., 2013; White \& Last, 2012).

The taxonomic status of chimaeroid fishes in the southern African region remains somewhat convoluted despite a rich history of ichthyological research (Compagno, 1999; Ebert \& van Hees, 2015). The southern African region has one of the most diverse Chondrichthyan faunas despite its relatively short coastline (Ebert \& van Hees, 2015). Its location between the cold upwelling waters of the Agulhas Current on the west coast and the warmer waters of the Benguela Current to the east fosters more than 200 species representing nearly $20 \%$ of all known species (Compagno, 1999; Ebert \& van Hees, 2015).

Chimaeroid fishes comprise a small percentage of southern African Chondrichthyan biodiversity, but are well represented with species across all three families and six 
genera. Before the initiation of this project, seven species of Chimaeriformes were known: Callorhinchus capensis Duméril, 1865, Rhinochimaera atlantica Holt \& Byrne, 1909, Rhinochimaera africana Compagno, Stehmann \& Ebert, 1990, Harriotta raleighana Goode \& Bean, 1895 and Neoharriotta pinnata (Schnakenbeck, 1929), Chimaera notafricana Kemper, Ebert, Compagno, \& Didier, 2010 and Hydrolagus africanus (Gilchrist, 1922). The taxonomy of the Callorhinchidae and Rhinochimaeridae families has been well established in this region, but the Chimaeridae, comprised of the genera Chimaera Linnaeus, 1758 and Hydrolagus Gill, 1862, has yet to be resolved. Several issues contribute to the complicated status of the Hydrolagus genus, necessitating further investigation.

The Hydrolagus has a rather complex taxonomic history in southern Africa with Hydrolagus africanus having long been considered the only confirmed representative of the genus. The occurrence of additional southern Africa species within this genus has been reported upon in the literature, but not confirmed until this study (Compagno 1986, 1999; Compagno, Ebert \& Smale, 1989; Compagno, Ebert \& Cowley, 1991). The identification of $H$. africanus has been problematic since several other small-bodied (300$350 \mathrm{~mm}$ body length at maturity) brown species have been reported from the region including Hydrolagus mirabilis (Collett, 1904) off Angola and possibly Namibia. Additionally, there have been reports of an unidentified, sympatric species (Compagno et al., 1989, 1991; Walovich et al., 2015).

In addition, several large bodied (550-600+ mm body length at maturity) Hydrolagus have been recovered during both research and commercial trawling operations, including 
a large, black species discovered in 2012 after exploratory demersal trawls from Marion Island, a territory of the South Africa Exclusive Economic Zone (EEZ) located south of the African continent. A second species morphologically similar to Hydrolagus trolli Didier \& Séret, 2002 (Compagno 1999; Ebert \& van Hees, 2015) were recovered on both the west and south coasts of South Africa from depths of 900-1,000 meters. The region requires taxonomic clarification of the Hydrolagus species in order to provide the information necessary for the implementation of proper population monitoring and conservation strategies.

Given the historical and current ambiguity in the taxonomy of Hydrolagus species and its impacts on management and conservation decisions, the primary objective of this study is to provide a qualitative, quantitative and genetic assessment of the diversity of the genus in the southern African region. Improved identification and fisheries statistics will improve the collection of baseline catch data required to understand the impact of expanding deep-sea fisheries and to develop appropriate management and conservation strategies in the future. 


\section{Materials and Methods}

\section{Study Area}

Southern Africa, including Namibia, South Africa and Mozambique, is a rich convergence zone for the warm, fast flowing Agulhas Current on the east coast and the cold, slow flowing upwelled waters of the Benguela Current on the west coast (Briggs, 1995). The junction of two currents and a wide range of habitats, including an extensive coastal shelf and numerous seamounts, contribute to the chondrichthyan diversity and high endemism in southern Africa (Compagno, 1999; Ebert \& van Hess, 2015).

The Prince Edward Islands (PEI) are located 2,000 km south of South Africa, approximately $42^{\circ} 45^{\prime}-50^{\circ} 45^{\prime} \mathrm{S}$ and $32^{\circ} 45^{\prime}-43^{\circ} \mathrm{E}$, at the convergence of three waters masses: the sub-Antarctic surface waters, northern polar front waters and the southern polar front waters. The location of the PEI in the southern Indian Ocean places them within the jurisdiction of the Commission on the Conservation of Antarctic Marine Living Resources (CCAMLR), who together with the South African government has been considering the establishment of a Marine Protected Area (MPA) to help combat the illegal, unreported and unregulated (IUU) fishing to restore the depleted Patagonian toothfish population (Lombart et al., 2007).

\section{Sample Collection}

Twenty-nine specimens were collected during annual demersal surveys conducted by the South African Department of Agriculture, Forestry, and Fisheries (DAFF) along the west and south coasts of South Africa between 2012 and 2015. Specimens were sorted, 
retained, frozen onboard ship and returned to shore where they were subsequently sent to either the Iziko South African Museum (iSAM) or the South African Institute for Aquatic Biodiversity (SAIAB). Additional specimens $(\mathrm{n}=2)$ were collected by a commercial fishing vessel operating near the Prince Edward Islands and returned to Cape Town for further study.

Approximately 100 preserved chimaeroid specimens were examined from numerous museum collections (Appendix 2). These institutions include the American Museum of Natural History, New York (AMNH), Academy of Natural Sciences, Philadelphia Pennsylvania (ANSP), California Academy of Sciences (CAS), National Museum of Natural History, Smithsonian Institution, Washington D.C. (USNM), Iziko South African Museum (iSAM) and South African Institute for Aquatic Biodiversity (SAIAB) (Sabaj, 2016). Identification numbers begin with the institution abbreviation, or in the case of Dr. Gavin Naylor's personal collection, GN, followed by a unique accession number (Table 1). Multiple specimens can comprise one accession number, or lot, so alphabetical letters are used to denote individual specimens within a lot. Specimens that were not accessioned will still be referable to by an associated GN identifier.

The features of each animal were photographed in detail from multiple views (lateral, ventral, etc.) and the images edited in Photoshop Elements 12 to enhance and clarify the identifying features. 
Table 1

List of Specimens Used in Genetic Analysis

\begin{tabular}{|c|c|c|c|c|}
\hline Species & Field ID \# & GN \# & Institution \# & GenBank \# \\
\hline Chimaera notafricana & 5083 & 16922 & CAS 241485 & \\
\hline Chimaera notafricana & 5198 & 16918 & CAS 241486 & \\
\hline Chimaera notafricana & 5851 & 16919 & CAS 241487 & \\
\hline Chimaera notafricana & 5652 & 16921 & USNM 438925 & \\
\hline Chimaera notafricana & 5600 & 16917 & USNM 438926 & \\
\hline Chimaera notafricana & 3394 & 16916 & & \\
\hline Chimaera notafricana & 4670 & 16920 & & \\
\hline Hydrolagus affinis (SA) & Dark -2 & 16944 & LOST & \\
\hline Hydrolagus affinis (SA) & Pale -1 & 16943 & LOST & \\
\hline Hydrolagus affinis (SA) & & 14842 & & \\
\hline Hydrolagus africanus & 4576 & 16938 & CAS 241488 & \\
\hline Hydrolagus africanus & 5020 & 16937 & CAS 241488 & \\
\hline Hydrolagus africanus & 5226 & 16936 & CAS 241488 & \\
\hline Hydrolagus africanus & 5237 & 16925 & CAS 241488 & \\
\hline Hydrolagus africanus & 5308 & 16939 & CAS 241488 & \\
\hline Hydrolagus africanus & 5446 & 16928 & CAS 241488 & \\
\hline Hydrolagus africanus & 5415 & 16934 & CAS 241489 & \\
\hline Hydrolagus africanus & 3026 & 16927 & CAS 241490 & \\
\hline Hydrolagus africanus & 5206 & 16924 & CAS 241490 & \\
\hline Hydrolagus africanus & 4900 & 16926 & CAS 241491 & \\
\hline Hydrolagus africanus & 3932 & 16929 & CAS 241492 & \\
\hline Hydrolagus africanus & 5144 & 16935 & CAS 241492 & \\
\hline Hydrolagus africanus & 5368 & 16933 & CAS 241493 & \\
\hline Hydrolagus africanus & 5918 & 16932 & USNM 438927 & \\
\hline Hydrolagus africanus & 5907 & 16941 & USNM 438928 & \\
\hline Hydrolagus africanus & 5064 & 16931 & USNM 438929 & \\
\hline Hydrolagus africanus & 4898 & 16942 & USNM 438930 & \\
\hline Hydrolagus africanus & 4427 & 16923 & USNM 438931 & \\
\hline Hydrolagus africanus & 3554 & 16930 & USNM 438932 & \\
\hline Hydrolagus africanus & 3178 & 16940 & USNM 438933 & \\
\hline Hydrolagus erithacus sp. nov. * & & 10470 & SAIAB 200578 & 934298 \\
\hline Hydrolagus erithacus sp. nov. ** & & 10465 & SAIAB 200579 & 934297 \\
\hline
\end{tabular}

Note. GN refers to G. Naylor's personal collection *=holotype, **=paratype. 


\section{Morphological Measurements}

Morphometrics is the quantitative study of biological shape, shape variation and covariation of shape with biotic or abiotic factors that together with photographs, illustrations and the designation of type material constitute a new species description

(Webster \& Sheets, 2010). These measurements serve to quantify and standardize the size and shape of an individual so conspecifics can be compared to one another. Measurements are presented as percentages of body length (BDL) for comparison of specimens of differing sizes. External morphological measurements follow a modification of Didier and Serét (2002) and include, in part, total length (TL), dorsal fin height $(\mathrm{D} 1 \mathrm{H})$, and pectoral fin anterior margin (P1AM) (Appendix 3, Figure 1). Ninetysix measurements were taken per specimen. Due to wide variability, nearly a third of these measurements where eliminated from analysis. Measurements were taken as a horizontal distance using digital calipers and a measuring tape to the nearest 0.1 millimeter (mm) on fresh and preserved specimens. These measurements can be affected by a variety of factors including preservation, human error, and a lack of reproducibility. Despite these flaws, morphological analysis and comparisons remains an integral part of species descriptions.

The computer program ImageJ (Version 1.48) was utilized to calculate basic measurements like body length when standard morphological measurements were not possible, but photographs were taken of specimens. A measurement could be calculated via this method only when a ruler was present in the photograph to calibrate the 


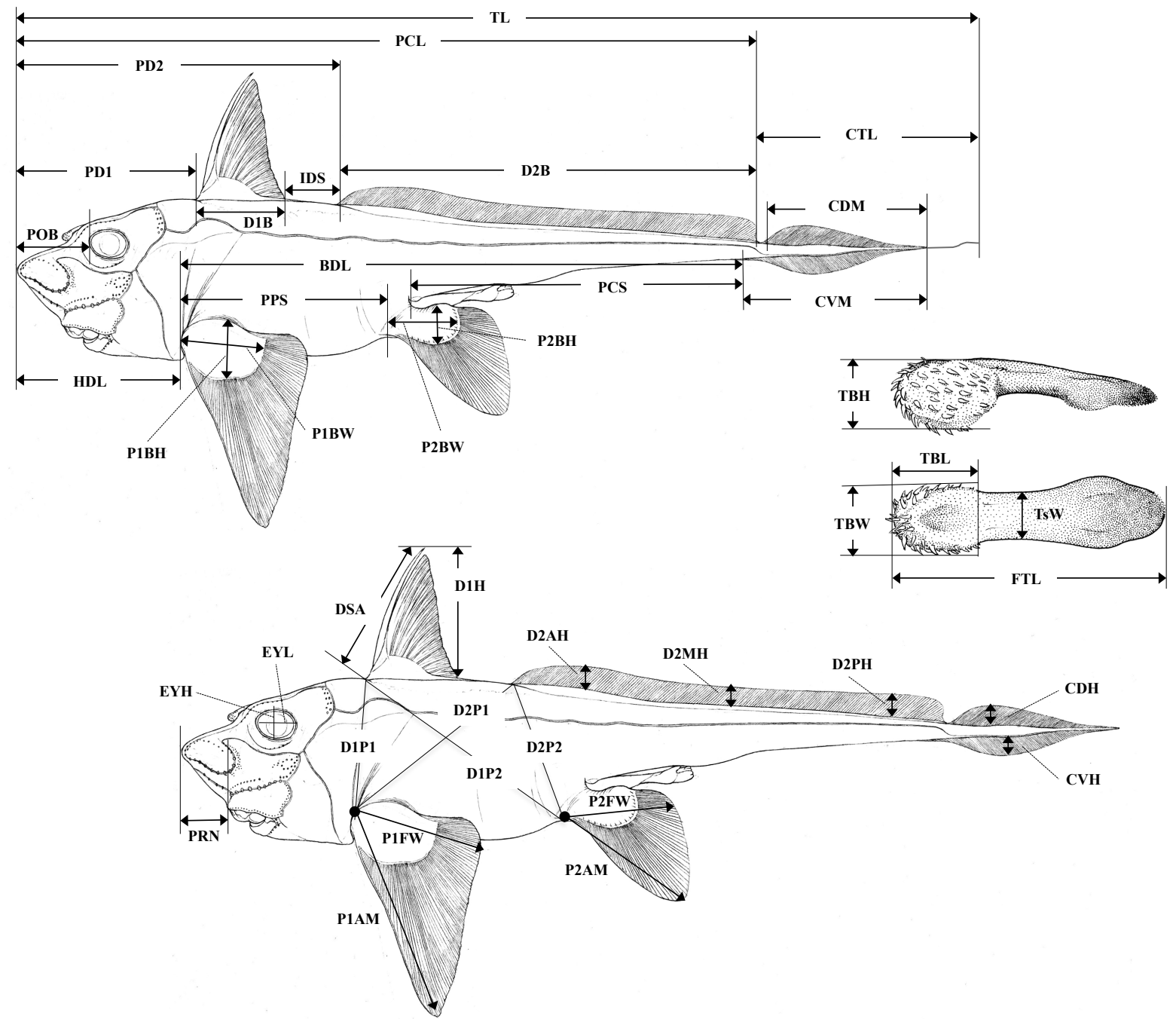

Figure 1. Diagram of morphological measurements for Chimaeridae species. Illustrations by Marc Dando (lateral view) and Mattias Lanas (frontal tenaculum).

measurement. Although the error associated with this interpolative method is small, in these limited circumstances the measurement are denoted with an asterisk $\left(^{*}\right)$.

Sexual maturity in females was determined by external examination of the oviducal openings; open and distended oviducal openings indicate maturity compared to closed openings found in juveniles. Male maturity was determined by the emergence and 
development of frontal tenaculum and prepelvic tenaculae, and degree of calcification of pelvic claspers and prepelvic tenaculae spines (Didier \& Séret, 2002). Length at 50\% maturity (L50) was estimated for male Hydrolagus africanus specimens using logistic regression (Neer \& Cailliet, 2001).

The diagnosis, description and comparisons sections are written in the telegraphic style of taxonomic description, in which adjectives and verbs are eliminated. This style of writing is used to save space and, when used with a standardized format and vocabulary, can be easier to translate into different languages (Winston, 1999). Telegraphic style conforms to current taxonomic standards when describing new species of Chimaeriformes (Winston, 1999).

\section{Genetic Analysis}

Traditional morphological studies have been increasingly combined with genetic analysis to identify cryptic species and species complexes of Chondrichthyans and other taxa (Bickford et al., 2006; Dudgeon et al., 2012; Naylor et al., 2012; Straube et al., 2015). Genetic analysis has proven useful to studies on the individual level (i.e. markrecapture analysis, multiple paternity), species level (i.e. defining distributions, identification of cryptic species and species complexes) and at the population level (i.e. stock structure assessment, philopatry) (Bickford et al., 2006; Dudgeon et al., 2012; White \& Last, 2012). Several genes have been utilized to achieve these goals including nuclear DNA, microsatellites and mitochondrial DNA (COI, NADP2, 12sRNA and 16s RNA) (Dudgeon et al., 2012). 
Mitochondrial DNA (mtDNA) has been widely used in the study of cartilaginous fishes because of its compact size compared to nuclear DNA. mtDNA is maternally inherited and mutates faster than nuclear DNA, therefore achieving about twice the level of differentiation compared to nuclear markers (Heist, 2012). As a result, mtDNA genes like the mitochondrial cytochrome $c$ oxidase I (COI) gene and the protein coding nicotinamide adenine dinucleotide dehydrogenase subunit 2 (NADH2) are useful to distinguish phylogenetic relationships and stock structure (Ward et al., 2009; Moore et al., 2003; Naylor et al., 2012). Although the COI gene has become the de facto standard for 'DNA barcoding' efforts including the Barcode of Life Initiative, the 650 base pair COI sequence is both shorter (650 vs. 1044bp) and evolves slower in chondrichthyans than the NADH2 gene fragment (Naylor et al., 2012). The NADH2 gene has been used to differentiate co-occurring chimaeroid species whose morphological characters overlap including Chimaera carophila from New Zealand (Kemper et al., 2015). The NADH2 gene was utilized in this study for its ability to distinguish cryptic or closely related species that may exist in the southern African region.

Muscle tissue was collected from 32 specimens including Hydrolagus africanus, Chimaera notafricana, Hydrolagus erithacus and Hydrolagus affinis. Muscle tissue was stored in $95 \%$ ethanol at $4{ }^{\circ} \mathrm{C}$ until further processing at the Hollings Marine Laboratory (Charleston, South Carolina). Total DNA was extracted using the E.Z.N.A. Tissue DNA Kit (Omega Bio-Tek) and stored at $-20^{\circ} \mathrm{C}$. Samples were PCR amplified with TaKaRa Ex Taq using primers designed to target the complete coding sequence for NADH dehydrogenase subunit 2 (Naylor et al., 2005). The PCR master mix was comprised of 1x 
TaKaRa buffer, 2 to $3.5 \mathrm{mM} \mathrm{MgCl}_{2}, 200 \mathrm{mM}$ of dNTPs, $0.32 \mathrm{mM}$ forward and reverse primers, 0.625 units of Taq, $2 \mathrm{~mL}$ of undiluted DNA template derived directly from the E.Z.N.A. kit, and PCR grade water. The reaction mix was denatured at $94{ }^{\circ} \mathrm{C}$ for 2 minutes, then subjected to 30 cycles at $94{ }^{\circ} \mathrm{C}$ for 30 seconds, 50 to $58^{\circ} \mathrm{C}$ for 30 seconds, and $72{ }^{\circ} \mathrm{C}$ for 1 minute, followed by $72{ }^{\circ} \mathrm{C}$ for 5 minutes, and a hold at $4{ }^{\circ} \mathrm{C}$. A sample of the PCR product was run on a $1 \%$ agarose gel and visualized under UV light to visually assess the efficacy of the PCR amplification. Samples successfully amplified were sent out for DNA sequencing (Retrogen, San Diego, CA).

The software program Geneious (version 8.1.7) was used to read sequences, assess quality, make nucleotide base calls, and align nucleotide and translated sequences. Phylogenetic analysis was preformed on the aligned sequences using the general-time reversible (GTR) + gamma nucleotide substitution model in RAxML v8.1.X (Stamatakis 2014), with 1,000 bootstrap replicates. To determine percent sequence divergence the software program PAUP* was used to calculate the distance matrix between sequences by dividing the number of base differences between sequences by the sequence length.

Samples utilized in publications were deposited in GenBank (see Table 1). Tissues were collected under the Institutional Animal Care and Use Committee (IACUC) NonLiving Tissue Protocol 2014D.

\section{Multivariate Statistical Analysis}

To test the potential differences between and among species in morphological characters, several multivariate methods were utilized. All data were normalized from percent body length (\%BDL) before multivariate analysis in order to account for varying 
body sized. No transformations were necessary before calculation of the resemblance matrix since morphological data is expressed as percentages. The Kolmogorov-Smirnov test indicated the data was not normally distributed; therefore non-parametric tests were used for data analysis. Non-metric Multidimensional scaling ordination (nMDS) was used for visualization of differences between purported species. Where necessary, cluster analysis was performed on nMDS plots to demonstrate similarity between groups. Analysis of similarities (ANOSIM) was calculated to test for differences between species, with a null hypothesis that no differences exist between species. The resulting statistic, expressed as R, compares the mean of ranked dissimilarities between groups to the mean of ranked dissimilarities among groups. An R-value near 1.0 implies a high degree of dissimilarity, while a value near 0 indicates little to no degree of dissimilarity. Because ANOSIM is based on ranks, it is less susceptible to outliers than other tests. The similarity percentage analysis (SIMPER) was calculated to determine the morphological trait contributing most to the differences between species. Multivariate statistics were preformed using the software program PRIMER-E (version 10).

One-way Analysis of variance (ANOVA) was used to compare the means of various morphological traits and the Tukey-Kramer HSD test was used to establish significance. ANOVA and Tukey-Kramer HSD analysis was conducted in the program JMP Pro 12 software.

To test for any changes in morphological measurements between random samples of preserved (P) and non-reserved (NP) Hydrolagus africanus a t-test was performed for each trait. Non-metric Multidimensional scaling ordination (nMDS) was used for 
visualization of the two groups. ANOSIM and SIMPER analyses where conducted to determine the degree of separation between groups and the contributing factors to those differences. 


\section{Chapter $\mathbf{1}^{1}$ \\ Re-Description Of Hydrolagus africanus (Gilchrist, 1922)}

\section{Introduction}

Hydrolagus africanus is a small-bodied chimaera ( $<500 \mathrm{~mm}$ body length BDL, $<900$ mm total length TL) originally described by Gilchrist (1922) based on specimens collected from the KwaZulu Natal coast, South Africa. The current known distribution of this species ranges from northern Namibia to Kenya (Compagno et al., 1989, 1991). Early records from the type locality are few and brief (Barnard, 1925; Compagno et al., 1989; Norman, 1935; Smith 1949, 1965). However, the majority of recent records are from the west coast of South Africa northward to Namibia (Compagno et al., 1991, Lleonart \& Rucabada, 1984, Macpherson \& Roel, 1987) where DAFF conducts annual demersal surveys.

The original description of $H$. africanus was based on several syntypes ${ }^{2}$, all of which appear to have been lost. There is no clear indication of where, if any, type specimens were catalogued by the original author J.D.F. Gilchrist or subsequent authors (Eschmeyer, 2015). Reference to the destruction of Gilchrist's type material following his death appears in the literature as early as 1926 and the current authors could not locate the type specimens (Brown, 1997; Eschmeyer, 2015). Several illustrations of $H$.

\footnotetext{
${ }^{1}$ Published as Walovich, K.A., Ebert, D.A., Long, D.J. \& Didier, D.A. (2015). Redescription of Hydrolagus africanus (Gilchrist, 1922) (Chimaeriformes: Chimaeridae), with a review of southern African chimaeroids and a key to their identification. African Journal of Marine Science, 37(2), 157-165.

${ }^{2}$ Syntypes are two or more specimens chosen from available material to serve as types (Winston, 1999).
} 
africanus have been published (Compagno et al., 1989; Gilchrist, 1922; Smith, 1965), but these lack sufficient detail to make reliable species identification, and other reference material is sparse.

The lack of descriptive information has made identification of $H$. africanus problematic, despite being the only formally described species of the genus from this region. These issues are due, in part, to the existence of other small, brown species in the region including Hydrolagus mirabilis (Collett, 1904) off Angola and possibly Namibia, and reports of an unidentified, sympatric species (Compagno et al., 1989; 1991; Walovich et al., 2015). Hydrolagus mirabilis and the alleged second species are small, brown colored species, further adding to the general confusion regarding this species. Given the uncertain status of the species and the absence of original type material, Walovich et al. (2015) re-described H. africanus based on new information from morphometric individual variation, ontogeny and sexual dimorphism, and designated a neotype ${ }^{3}$.

\section{Results}

The purpose of a re-description is the examination of historical and current information and materials in order to make a more complete description of a species (Winston, 1999). The information provided in the following sections expands on the original description by Gilchrist in 1922 to provide an accurate description of Hydrolagus africanus.

\footnotetext{
${ }^{3}$ A neotype is a specimen selected to serve as the type when the original material has been lost or destroyed (Winston, 1999).
} 


\section{Systematics.}

Synonymies are bibliographic lists of all names used in the literature referring to a specific species, serving as a historical record of the nomenclature of a species. This synonymy includes all references (to the best of the author's knowledge) to Hydrolagus africanus in the southern African region, including its original genus (Chimaera) and any misidentifications. The list includes the reference, as well as the pages and figures in which the species is referenced.

Hydrolagus africanus (Gilchrist 1922), African Chimaera Neotype: SAM 34420, mature male, 600+ mm TL, $388 \mathrm{~mm}$ BDL, SW Atlantic (30 4' $\left.59.88 \mathrm{~S}, 14^{\circ} 54^{\prime} 6.12 \mathrm{E}\right), 465 \mathrm{~m}, \mathrm{R} / \mathrm{V}$ "Africana"

Chimaera africana: Gilchrist, 1922: 51, pl. 8; Barnard, 1925: XXI, 95; Norman, 1935: 47; Fowler, 1941: 499-500; Smith, 1949: 79, fig. 94; Fowler, 1950; Bigelow \& Schroeder, 1953: 543; Smith, 1961: 573; Smith, 1961: 76-77, fig. 94; Smith, 1965: 76, fig. 94

Hydrolagus sp.: Compagno et al., 1991:113; Bianchi et al., 1999a: 101

Hydrolagus africanus: Smith, 1968: 3, plate 1a; Karrer, 1975: 201; Shcherbachev et al., 1982; Lloris, 1986: 148, fig. 56; Turon et al., 1986: 71, 137, 178, 236, 300; Compagno 1986: 145; Macpherson \& Roel, 1987: 591; Roel, 1987: 581; Compagno et al., 1989: 120; Didier, 1995: 15; Compagno, 1999; Bianchi et al., 1999b: 101; Novikov, 2002: 279; Compagno \& Dagit, 2006; Human, Owen, Compagno \& Harley, 2006: 387; Kyne \& Simpfendorfer, 2007: 19; Kemper et al., 2010: 55; Licht et al., 2012

Hydrolagus mirabilis?: Lleonart \& Rucabado, 1984: 43

\section{Diagnosis.}

A small species of Hydrolagus distinguished from its congeners by a lateral patch of one to three denticles on the male prepelvic tenaculae, a second dorsal fin slightly indented in the center and a long curved spine, equal to or sometimes exceeding the 
height of the first dorsal. Body color light brown, head often darker than trunk, pale grayish brown ventral surface and dark brown fins that lighten near the body margin.

\section{Description.}

Morphometric measurements, expressed as ratios of body length (BDL), of all specimens are presented in Table 2. Morphometric traits are presented in parentheses as neotype, range of all specimens and the abbreviation of that trait. A small-bodied species with slender head (21.6, 17.9-31.1\% BDL, HLD), blunt rounded snout that quickly tapers posteriorly to a long, thin caudal filament (Figure 2). Large eyes (22.4-41.9 \% HDL, EYL; $14.5-27.3 \% \mathrm{HDL}, \mathrm{EYH})$ and deciduous skin, flaking off in large patches $1-3 \mathrm{~cm}$ in diameter.

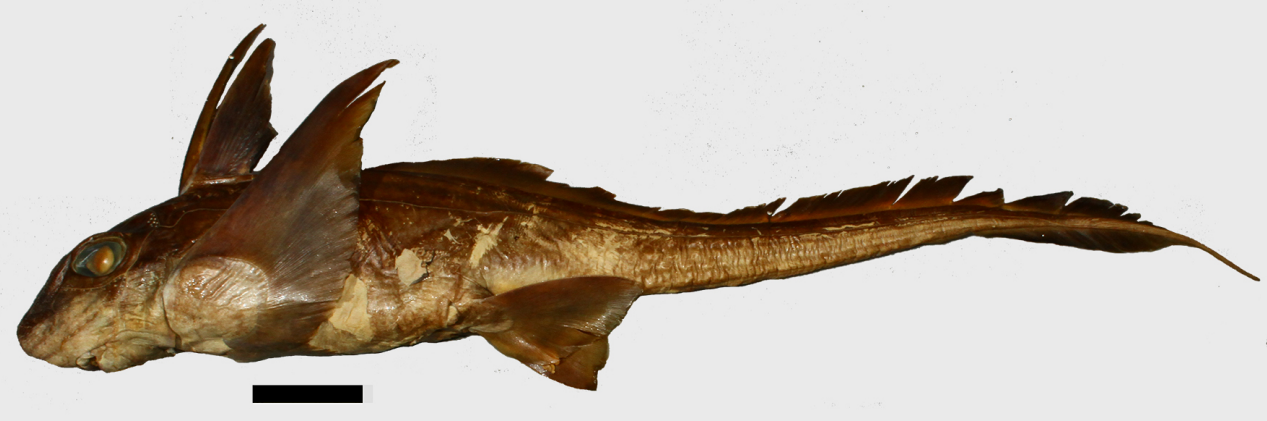

Figure 2. Hydrolagus africanus (Gilchrist, 1922) neotype, SAM 34420, mature male, $600+\mathrm{mm}$ TL, $388 \mathrm{~mm}$ BDL, collected from the west coast of South Africa. Scale bar $=5$ $\mathrm{cm}$. 
Table 2

Hydrolagus africanus Morphometric Data

\begin{tabular}{|c|c|c|c|c|}
\hline Measurement & $\begin{array}{l}\text { Neotype } \\
\text { (Male) }\end{array}$ & $\begin{array}{l}\text { Range All } \\
\qquad(\mathrm{n}=65)\end{array}$ & $\begin{array}{l}\text { Range Females } \\
\qquad(\mathrm{n}=31)\end{array}$ & $\begin{array}{l}\text { Range Males } \\
\qquad(n=34)\end{array}$ \\
\hline $\mathrm{TL}$ & 154.6 & $117.2-293.8$ & $119.9-293.8$ & $117.2-251.4$ \\
\hline PCL & 121.4 & $116.1-130.0$ & $116.1-130.0$ & $116.5-125.3$ \\
\hline BDL & $388(\mathrm{~mm})$ & $221-465(\mathrm{~mm})$ & $221-465(\mathrm{~mm})$ & $292-415(\mathrm{~mm})$ \\
\hline SVL & 53.9 & $51.9-77.9$ & $54.0-74.7$ & $51.9-77.9$ \\
\hline TRL & 35.6 & $30.9-46.8$ & $34.0-46.8$ & $30.9-45.1$ \\
\hline PD2 & 46.4 & $41.1-57.7$ & $41.1-57.7$ & $41.3-51.7$ \\
\hline PD1 & 25.5 & $20.3-33.9$ & $20.3-33.9$ & $20.6-29.8$ \\
\hline POB & 11.3 & $8.5-15.0$ & $8.8-15.0$ & $8.5-13.7$ \\
\hline D2B & 79.6 & $69.6-86.7$ & $70.5-78.3$ & $69.6-86.7$ \\
\hline D2AH & 4.9 & $4.3-7.5$ & $4.5-7.5$ & $4.3-6.9$ \\
\hline D2PH & 4.1 & $3.4-6.5$ & $3.4-5.9$ & $3.5-6.5$ \\
\hline D2MH & - & $2.8-5.0$ & $2.8-4.4$ & $2.8-5.0$ \\
\hline D1B & 9 & $9.0-18.9$ & $13.0-18.9$ & $9.0-17.5$ \\
\hline DSA & 25.8 & $18.6-28.3$ & $18.6-25.8$ & $21.2-28.3$ \\
\hline $\mathrm{D} 1 \mathrm{H}$ & 19.3 & $11.8-20.5$ & $11.8-19.7$ & $13.2-20.5$ \\
\hline CDM & 21.1 & $16.0-25.6$ & $16.1-23.7$ & $16.0-25.6$ \\
\hline $\mathrm{CDH}$ & 2.6 & $2.3-5.0$ & $2.4-5.0$ & $2.3-4.4$ \\
\hline CTL & 34.3 & $33.8-163.0$ & $34.4-163.0$ & $33.8-127.7$ \\
\hline CVM & 33.8 & $22.8-44.1$ & $25.8-43.0$ & $22.8-44.1$ \\
\hline $\mathrm{CVH}$ & 2.8 & $2.0-5.0$ & $2.4-5.0$ & $2.0-4.1$ \\
\hline $\mathrm{CPH}$ & 2.6 & $0.0-3.0$ & $0.0-3.0$ & $0.0-2.6$ \\
\hline HDL & 21.6 & $17.9-31.3$ & $17.9-31.3$ & $18.2-26.5$ \\
\hline P1AM & 37.1 & $29.3-41.4$ & $29.3-41.4$ & $31.52-39.7$ \\
\hline P2AM & 19.3 & $16.3-23.5$ & $16.3-23.5$ & $16.3-22.1$ \\
\hline IDS & 12.6 & $2.1-12.6$ & $3.9-11.9$ & $2.1-12.6$ \\
\hline DCS & 0 & $0.0-1.3$ & $0-1.0$ & $0.0-1.3$ \\
\hline PPS & 28.4 & $25.5-37.6$ & $27.8-37.6$ & $25.5-35.7$ \\
\hline D1P1 & 14.7 & $14.4-21.9$ & $15.7-21.9$ & $14.4-20.4$ \\
\hline D1P2 & 38.9 & $25.6-44.0$ & $37.6-44.0$ & $25.6-42.7$ \\
\hline D2P1 & 27.6 & $23.5-34.1$ & $25.3-32.8$ & $23.5-34.1$ \\
\hline D2P2 & 23.5 & $18.8-27.7$ & $20.0-27.7$ & $18.8-25.7$ \\
\hline EYL & 8.2 & $5.1-9.7$ & $5.8-9.7$ & $5.1-8.3$ \\
\hline EYH & 4.9 & $2.9-5.9$ & $2.9-5.7$ & $3.8-5.9$ \\
\hline CLT & 12.1 & $3.8-14.2$ & - & $3.8-14.2$ \\
\hline
\end{tabular}




\begin{tabular}{lllll} 
CLM & 4.9 & $4.5-7.7$ & - & $4.5-7.7$ \\
CLL & 4.9 & $4.3-7.2$ & - & $4.3-7.2$ \\
\hline
\end{tabular}

Note. Values are the minimum and maximum percent of body length (\%BDL), unless otherwise noted. Abbreviations and definitions can be found in Appendix 3.

First dorsal fin triangular with a short base $(9.0,10.3-18.9 \%$ BDL, DIB) and attaches to the basal third of the spine. First dorsal fin spine equal to or slightly longer than height of first dorsal fin. Spine curved with two rows of serrations along distal third of spine along posterior edge and keeled along anterior edge. Spine length $(25.8,18.6-28.3 \%$ BDL, DSA) nearly equal to or slightly longer head length (21.6, 17.9-31.1\%BDL, HDL). Spine tip when depressed reaches to origin or slightly past the origin of second dorsal fin. Interdorsal space usually small (12.6, 2.1-11.9\% BDL, IDS) and connected by a low membrane. Anterior portion of second dorsal fin (4.9, 4.3-7.5\% BDL, D2AH) slightly higher than posterior portion (4.1, 3.4-6.5 \% BDL, D2PH). Second dorsal fin long and slightly depressed in center (2.8-5.0\% BDL, D2MH); distance from second dorsal fin insertion to caudal lobe origin $(0,0-1.3 \% \mathrm{BDL}, \mathrm{DCS})$ with little to no separation; posterior portion of second dorsal rounded, extending to or beyond the insertion of caudal lobe. Caudal dorsal margin $(21.1,16.0-25.6 \% \mathrm{BDL}, \mathrm{CDM})$ shorter than ventral margin $(33.8,22.8-44.1 \%$ BDL, CVM); caudal dorsal height (2.6, 2.3-5.0\% BDL, CDH) nearly equal to ventral height $(2.8,2.0-5.0 \% \mathrm{BDL}, \mathrm{CVH})$ and extending as a fleshy ridge along the posterior body. Anal fin absent.

Pectoral fins large, triangular with anterior margin (37.1, 29.3-41.4\% BDL, P1AM) extending to, or just beyond insertion of pelvic fins when laid against the body; anterior margin approximately 1.2 to 2.2 times larger than pelvic anterior margin $(19.3,16.3-$ 
23.5\% BDL, P2AM). Pelvic fin pointed distally, broadly rounded along posterior edge where it joins fin base.

A volmerine and palatine tooth plate are present on each side of the upper jaw, with two mandibular plates on the lower; each volmerine tooth plate with five to six tritor ridges. Palatine tooth plates flat, triangular in shape, and lying posterior to volmerine plates on upper jaw. Tooth plate color varies from yellow to light brown in preserved specimens.

Lateral lines with open grooves and dilations around the snout. Preopercular and oral canals share a common branch from infraorbital canal in most specimens, however in some individuals the preopercular (POP) and oral (O) canals and infraorbital (IO) canals share a common origin (Figure 3). Trunk lateral line curves downward in sigmoid shape near its origin before extending in a straight line to its termination.
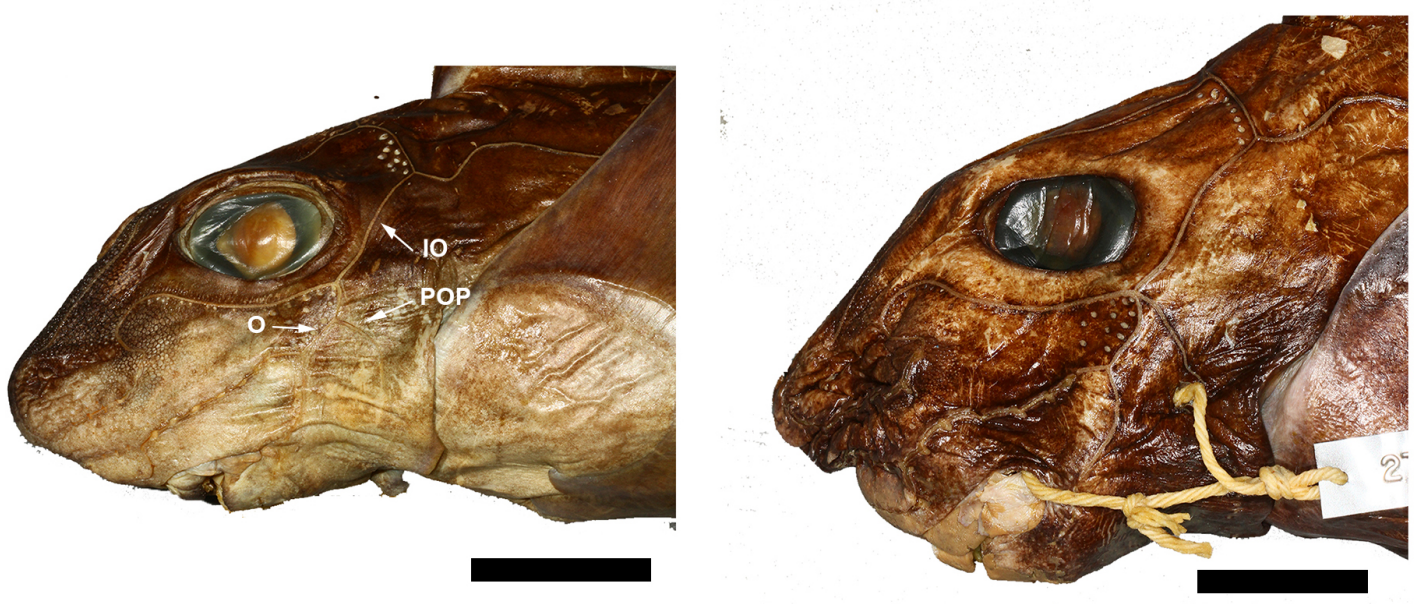

Figure 3. Intraspecific comparison of lateral line canals of (a) Hydrolagus africanus neotype and (b) adult male (SAM 27750); preopercular (POP), oral (O) and intraorbital (IO). Scale bar $=3 \mathrm{~cm}$. 
Male frontal tenaculum slender with a bulbous tip that curves slightly upward with several overlapping rows of fine denticles on ventral surface (Figure 4A).

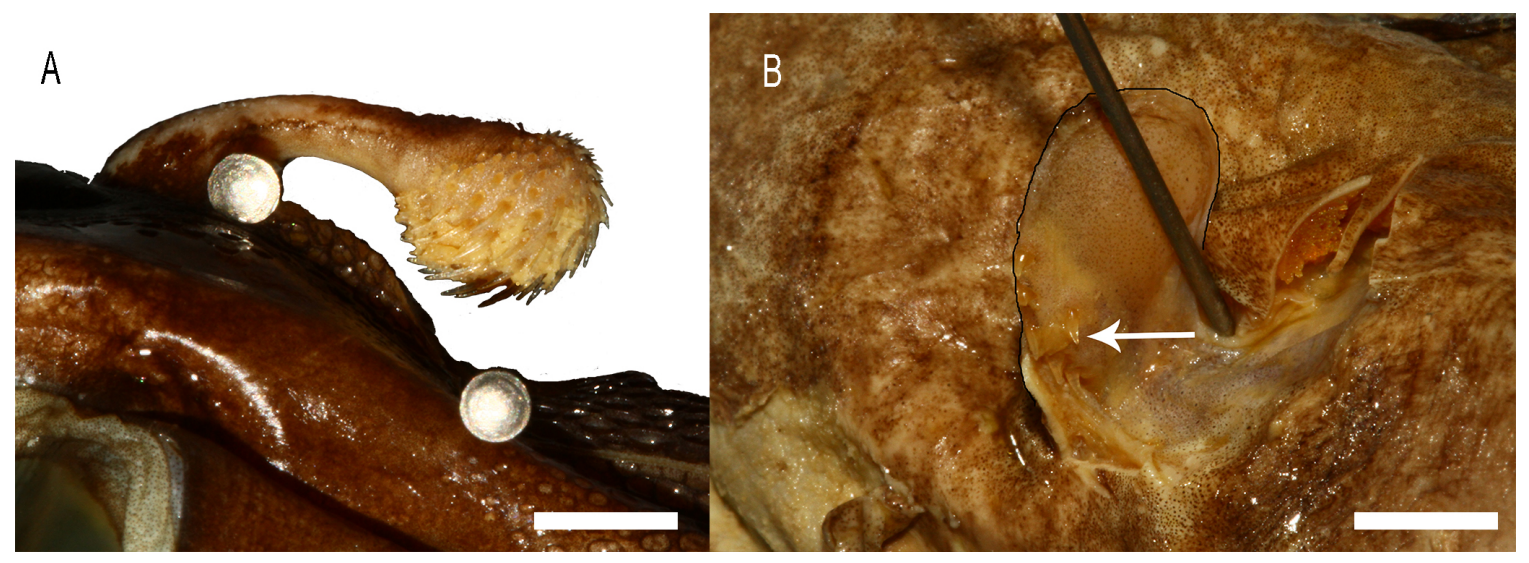

Figure 4. Sexual characters in adult male neotype SAM 34420, (a) lateral view of frontal tenaculum and (b) prepelvic tenaculum with five medial denticles and one lateral denticle (arrow). Scale bar $=3 \mathrm{~cm}$.

Prepelvic tenacula with five strong denticles along medial edge and one to three lateral denticles next to the medial row (Figure 4B). Pelvic claspers small, trifurcate, pale in color, and do not extend beyond distal edge of pelvic fins. Claspers divided along distal one-third of length, and distal tips with small fleshy bulbs bearing extremely fine shagreen of denticles (Figure 5). Females with small anal pads on base of tail posterior to cloaca.

\section{Coloration.}

Body coloration a light brown dorsally, with no distinctive markings or patterns; head often darker than trunk; ventral surface pale grey to brown. Fins dark brown to blackish, lightening in color near the body margin. 


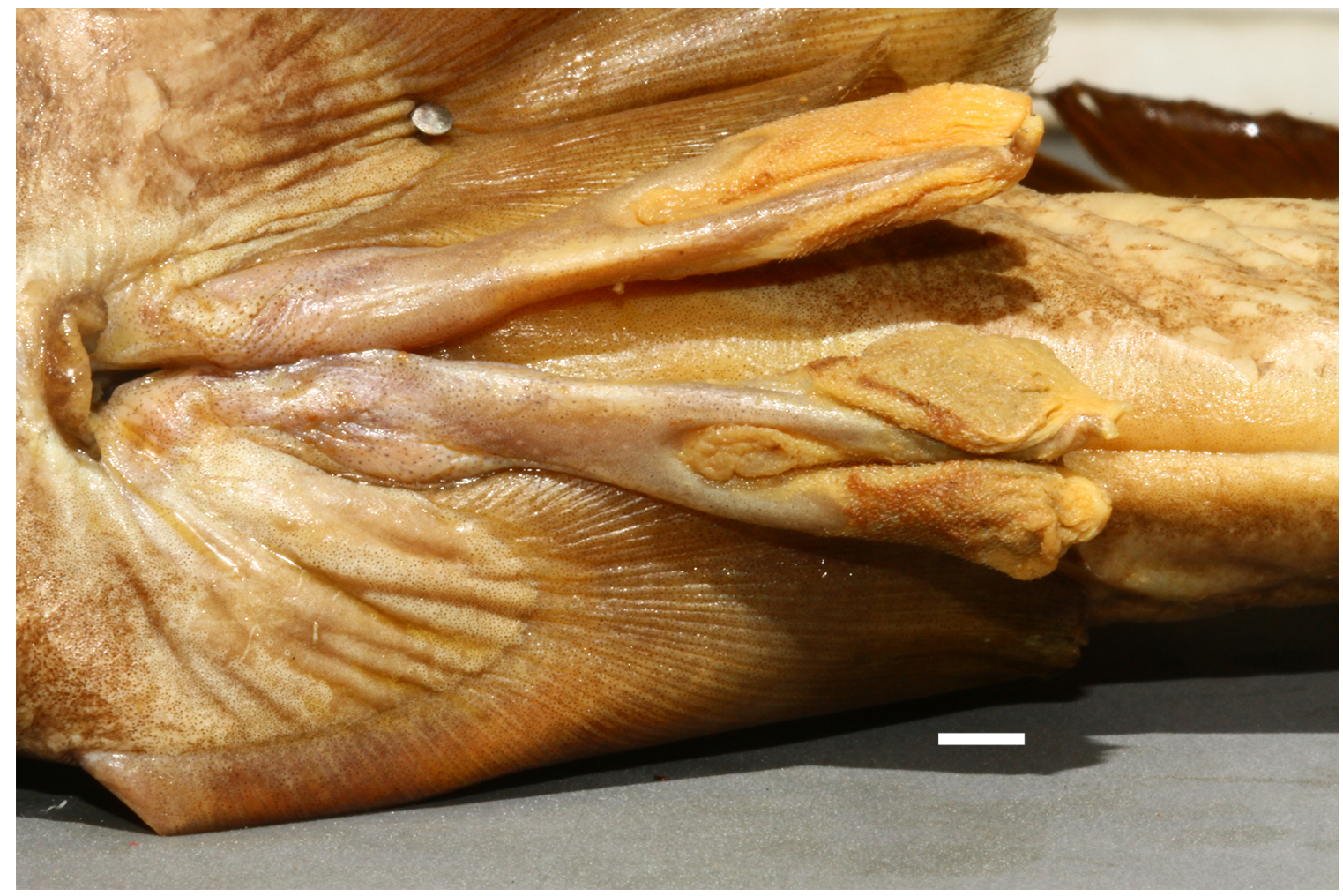

Figure 5. Ventral view of neotype SAM 34420 claspers. Scale bar $=3 \mathrm{~cm}$.

\section{Distribution.}

This species occurs in the western Indian Ocean from Kenya, Mozambique to the Western Cape Province, South Africa, and along the west coast of South Africa north to Angola in the Southeastern Atlantic. The occurrence of this species in Angolan waters is confirmed here for the first time. Records of this species from Southwestern Indian Ocean ridges and seamounts (Novikov, 2002; Parin et al., 2008) require confirmation as recent surveys have found other Hydrolagus species to occur here, but no confirmed specimens of $H$. africanus have been observed (P. Clerkin, personal communication, July $23,2014)$. The species has been recorded from depths of 300-1,030 meters, but most 
commonly occurs at depths of 300-500 meters, on soft or muddy substrates on the continental slope (Compagno et al., 1991). This species has been reported to occur at depths of 1,570 meters; however, the identification of these specimens remains uncertain (Novikov, 2002; Parin et al., 2008; Scherbachev et al., 1982).

\section{Biological Notes.}

Virtually nothing is known about the biology of this species, although Macpherson and Roel (1987) speculated that it likely feeds on infaunal invertebrates and small fishes. Reproductive mode is oviparous, however reproductive information for this species remains limited. Males and females appear to mature at body lengths greater than 350 $\mathrm{mm}$ based on observational estimates. Using a logistic regression of the proportion of clasper total length (CTL) to body length (BDL), the length at $50 \%$ maturity in males is $345.3 \mathrm{~mm}(\mathrm{n}=53 ; 95 \%$ CI; 321.6-364.0 mm; Neer \& Cailliet, 2001). The original species description details eggs cases recovered on the same trawl as adults: poorly developed lateral web-like expansions, pointed anterior, narrow posterior ( $54 \% \mathrm{TL})$, a median keen along the egg length, and numerous respiratory openings at the posterior (Gilchrist, 1922). However, egg cases were not taken directly from the female oviduct therefore it cannot be confirmed the egg cases belong to H. africanus. Both Smith (1961) and Compagno (1986) provide illustrations of egg capsules of $H$. africanus, but neither identifies the figure origins and a search of the literature failed to reveal additional egg capsules for this species. 


\section{Comparisons.}

Hydrolagus africanus bears some resemblance to several other small bodied Hydrolagus species including H. alberti Bigelow \& Schroeder, 1951 from the Gulf of Mexico and Caribbean, H. mitsukurii (Jordan \& Snyder, 1904) from Japan, Taiwan, the Philippines and Indonesia and H. mirabilis (Collett, 1904) from the Northern Atlantic Ocean. Subtle characters differentiate these species from H. africanus. Hydrolagus mirabilis, or the Large-eyed Ratfish, is most commonly known from the Northeast Atlantic, but records from Namibia indicate the $H$. mirabilis range may overlap $H$. africanus (Krefft, 1990). Hydrolagus mirabilis has a pronounced concave dorsal margin, nearly separating fin into anterior and posterior portions, and a larger eye, $35 \% \mathrm{HDL}$ compared to $31 \%$ HDL in $H$. africanus. Hydrolagus mitsukurii has a longer spine than $H$. africanus and darker colored snout. Hydrolagus alberti can be separated from $H$. africanus by a short common lateral line canal branch compared to a long shared branch in $H$. africanus, however H. alberti is very difficult to distinguish from other similar species because of overlapping morphometrics. Preliminary mitochondrial genetic data suggests that $H$. africanus, $H$. alberti, $H$. mitsukurii and $H$. mirabilis are closely related and may, with additional investigation, prove to be a species complex (J. Kemper, College of Charleston, pers. comm.).

Norman (1935) speculated that H. africanus would prove identical to Hydrolagus affinis; however both Bigelow and Schroeder (1953) and Smith (1968) disagreed based on a longer dorsal spine, higher dorsal fin and considerable larger pectoral fins in $H$. africanus compared to $H$. affinis. 
Hydrolagus affinis, formally referred to as Hydrolagus cf. trolli, is the only Hydrolagus species to geographically overlap in range with $H$. africanus and can be easily distinguished based on its large size, a second dorsal of uniform height and long pointed snout. The juveniles of this species may be confused with $H$. africanus based on similar brown coloration of some specimens, a fact that contributed to the speculation of a third Hydrolagus species in the region.

\section{State of Preservation.}

Ichthyological specimens are preserved in a 50\% formalin solution for at least two weeks before being transferred to a $50 \%$ ethanol storage solution, after which specimens may experience shrinkage and degradation that is exacerbated over time. To determine if significant changes occur to morphological measurements after preservation, a t-test was performed between the two groups of specimens, before (NP) and after preservation (P).

Eleven traits exhibited significant changes post-preservation including: caudal ventral height $(\mathrm{CVH})$, first dorsal height $(\mathrm{D} 1 \mathrm{H})$, distance from origin of first dorsal fin to origin of pelvic fin (D1P2), distance from origin of second dorsal fin to origin of pelvic fin (D2P2), dorsal spine length (DSA), inter-dorsal space (IDS), pectoral fin base height (P1BH), Pelvic-caudal space (PCS), pre-pelvic fin length (PP2), distance from posterior base of pectoral fin to anterior base of pelvic fin (PPS), pre-orbital length (POB), and snout length (SNL)(Table 3). Multidimensional scaling and ANOSIM analyses indicate little separation between the two groups (Figure 6; $\mathrm{R}=0.233 ; \mathrm{p}=0.003$ ). SIMPER results 
indicate total caudal length (CTL) is the overwhelming contributor $(62.62 \%)$ for the differences between preserved and non-preserved samples.

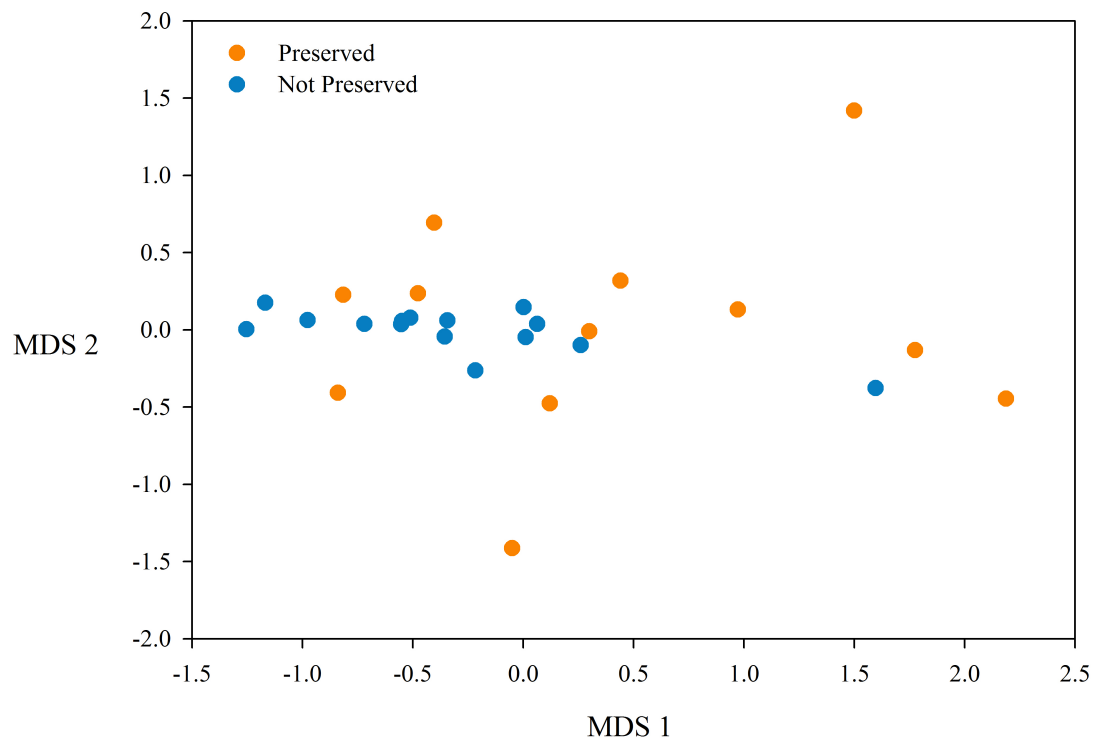

Figure 6. Two-dimensional non-Metric Multidimensional Scaling (n-MDS) plots comparing the preserved (orange) and non-preserved (blue) specimens of Hydrolagus africanus.

\section{Discussion}

The redescription of $H$. africanus presented here is crucial to clarifying its status and improving the identification of this species relative to other Hydrolagus species in the region. In general, these findings agree with the original description of $H$. africanus by Gilchrist (1922), but the additional material available allows for further clarification of the morphological distinctiveness of this species. These traits include the second dorsal fin shape, and prepelvic tenaculae and clasper morphology. 
Table 3

Summary Table of One-Sample T-test for Differences in Hydrolagus africanus Morphological Traits Before (NP) and After (P) Preservation

\begin{tabular}{lccccc}
\hline Trait & Mean (NP) & Mean (P) & $\mathrm{t}$ & $\mathrm{p}$ & $\begin{array}{c}\% \\
\text { change }\end{array}$ \\
\hline CVH & 3.27 & 2.84 & 2.68 & 0.011 & 13.16 \\
D1H & 20.25 & 18.51 & 2.80 & 0.0078 & 8.59 \\
D2P2 & 24.43 & 21.95 & 3.47 & 0.0013 & 10.16 \\
DSA & 23.07 & 24.79 & 2.30 & 0.0273 & 7.45 \\
IDS & 6.54 & 4.57 & 3.24 & 0.0024 & 30.03 \\
P1BH & 9.47 & 10.37 & 2.43 & 0.0199 & 9.58 \\
PCS & 59.90 & 51.99 & 5.18 & $<.0001$ & 13.21 \\
PP2 & 62.84 & 58.94 & 3.29 & 0.0023 & 6.21 \\
PPS & 32.05 & 28.02 & 2.86 & 0.0088 & 12.57 \\
POB & 12.73 & 11.25 & 2.48 & 0.0174 & 11.66 \\
SNL & 11.65 & 7.95 & 4.64 & $<0.0001$ & 31.74 \\
\hline
\end{tabular}

Note. Trait abbreviations found in Appendix 3.

Examination of additional specimens revealed a lateral line branching pattern not previously reported for this species. The POP and $\mathrm{O}$ canals in the majority of $H$. africanus examined share a common branch from the IO canal, however the POP, O and IO canals of several specimens share a common origin (see Figure 3). In the past, lateral line morphology has been utilized to separate some Hydrolagus species, however numerous species are known to have intraspecific branching patterns (Angulo et al., 
2014; Didier \& Séret 2002; James et al., 2009; Kemper et al., 2010; Walovich, Ebert \& Kemper, 2017). Therefore, these branching patterns are most useful when considered in combination with other morphological characters (Didier et al., 2012).

Hydrolagus africanus is the only known species to posses a lateral patch of denticles on the pre-pelvic tenaculae in addition to the denticles present along the medial edge. All chimaeroid species exhibit a row of five to seven denticles on the paired pre-pelvic tenaculae, which articulate anteriorly with the pelvic girdle to anchor male to female during copulation (Didier et al., 2012). This patch of denticles was not included in the original description, but can serve as a key diagnostic characteristic in separating it from other Hydrolagus species. Gilchrist (1922) detailed six short, recurved spines on the outer margin of the pre-pelvic tenaculae, however the lateral patch observed likely accounts for this discrepancy.

Sexual dimorphism occurs in many species of Chondrichthyes (excluding male sexual organs), but this phenomenon has not yet been recorded in chimaeroid fishes (Stevenson et al., 2007). Statistical analysis of this species reveals only one morphological trait with differences between adult male and female specimens. The taller caudal ventral height in females, although statistically significant, does not necessarily constitute sexual dimorphism in this species, since sample size could have an effect on the means. More pronounced sexual dimorphic traits or sexual segregation would be relevant to managements and conservation, however a slight difference in caudal dorsal height is negligible in the wider context of chimaera identification. 
Statistically significant changes to morphological measurements occur after preservation. These changes are the result of many factors, including, but not limited to physical damage, shrinkage of specimen post preservation and human error. Damage before or after preservation leads to skewed measurements or the inability to even record certain measurements. These traits, including broken spines or damaged fins, are mainly due to specimen contortion to fit inside jars, bins and containers of convenience rather than one that best fits the specimen. In addition, time severely degrades traits: frayed fins, lost caudal filaments, and damaged caudal regions are often torn or cut off in the field. For larger specimens like H. erithacus, pectoral fins are ripped off due to the large weight of the specimens because fins are often the most convenient way to lift specimens from barrels. The damage and degradation of specimens highlights the need to constantly maintain museum collections with new specimens.

The percent of change pre- and post-preservation vary depending on the measurements, but interdorsal space (IDS) and snout length (SNL), show significant changes, decreasing by $30 \%$ and $32 \%$ respectively. Nine of the eleven traits that changed significantly after preservation showed a decrease in mean trait value, consistent with the 'shrinkage' explanation, however the mean dorsal spine height (DSA) and pectoral fin base height (P1BH) increased following preservation. Since the dorsal spine is a hard structure and pectoral fin pads are fairly rigid, robust structures, sample size could have influenced the two means. Because the aforementioned traits, especially interdorsal space and snout length, appear to be influenced by preservation, care should be taken when examining these traits between species. 
Very few methodological studies exist to analyze the current procedure and its propensity for human error when collecting morphological traits (Francis, 2006). Other biological techniques, like otolith band analysis for age estimates, require multiple 'readers', who conduct the same analysis multiple times to reduce bias and increase accuracy and precision (Campana, 2001). Because these chimaeroid species are morphologically similar and preservation can influence morphological values, it is necessary to reform our methods for collection of morphological data. Increased reliability could be achieved by recording measurements multiples times by multiple researchers, however this can be difficult when measuring large quantities of specimens.

The differences between fresh and preserved specimens have contributed to assertions of multiple species of small, brown Hydrolagus species in the southern African region (Compagno et al., 1989, 1991). Hydrolagus mirabilis has been reported from Namibia (Krefft, 1990), but the identification of this species is difficult because the defining trait of $H$. mirabilis (i.e. indentation of the second dorsal fin) can be widely interpreted. Hydrolagus africanus belongs to a group of small brown species including $H$. alberti (Bigelow \& Schroeder, 1951) from the Gulf of Mexico and the Caribbean, H. mirabilis (Collett, 1904) from the North Atlantic, and H. mitsukurii (Dean, 1904) from Japan to the Philippines, that have very similar traits and may prove to be a species complex following genetic analysis (Walovich et al., 2015). Despite the consequences of preservation, the re-description of Hydrolagus africanus is an important first step to identifying and describing all Hydrolagus species from the region. 


\section{Chapter $2^{4}$}

\section{Description Of Hydrolagus erithacus sp. nov. Walovich, Ebert \& Kemper, 2017}

\section{Introduction}

The deep-sea remains a largely unexplored environment and the creatures that inhabit it are virtually unknown; however recent scientific research has begun to explore this region in more depth. While the majority of seamounts remain isolated, some are increasingly exposed to fishing pressure as shallow water fish stocks become depleted (Dulvy et al., 2014). Within the southern African region, the Prince Edwards Islands have undergone an increase deep-sea long lining for the Patagonian toothfish (Dissostichus eleginoides) (Lombard et al., 2007). The Prince Edward Island Archipelago (PEI) is an isolated sub-Antarctic archipelago, comprised of Marion and Prince Edward Islands, situated approximately 2,000 km southeast from the South African coastline (Pakhomov et al., 2006). Many of these seamounts, especially those far from continental landmasses, have faunas that are unique and potentially endemic to these marine geological features. As an example, in 2012 several very large chimaera specimens were obtained as bycatch from a commercial long lining ventures in PEI region. Subsequent investigation of these specimens plus additional specimens found in fish collections at iSAM and SAIAB led to the finding of a new species of chimaera. Examination of these

\footnotetext{
${ }^{4}$ Published as Walovich, K.A., Ebert, D.A. \& Kemper, J.M. (2017). Hydrolagus erithacus sp. nov. (Chimaeriformes: Chimaeridae), a new species of chimaerid from southeastern Atlantic and southwestern Indian oceans. Zootaxa. 4226 (4): 509-520.
} 
specimens and comparisons led to the formal description of the new species, Hydrolagus erithacus sp. nov by Walovich et al. (2017).

\section{Results}

\section{Systematics.}

Synonymies are not usually included in new species descriptions, but since one publication referenced this species it has been included. The metadata for the holotype, or the specimen chosen to represent the whole species in the description, and for the eight paratypes (the specimens designated in the type series and usually distributed to various locations for easier access by researchers) is included.

Hydrolagus erithacus sp. nov: Walovich, Ebert \& Kemper, 2017, Robin's Ghostshark Hydrolagus sp. nov (Big black chimaera): Compagno, 1999:120

Holotype: SAIAB 200578, adult male, $1290 \mathrm{~mm}$ TL, $790 \mathrm{~mm}$ BDL, Discovery Seamount, SE Atlantic Ocean, $43^{\circ} 46 \mathrm{~S}, 01^{\circ} 21 \mathrm{~W}$

Paratypes: (n=8) SAIAB 200579, adult female, $1357 \mathrm{~mm}$ TL, $869 \mathrm{~mm}$ BDL, Discovery Seamount, SE Atlantic Ocean, $43^{\circ} 43 \mathrm{~S}, 01^{\circ} 23 \mathrm{~W}$; SAM 34432, adult female, $1220 \mathrm{~mm}$ TL, 765 mm BDL, R.S.A Seamount, SE Atlantic Ocean, 39 40' S, $6^{\circ}$ 40' W, 470-972 m; SAM 34434, adult male, 1185+ mm TL, $863 \mathrm{~mm}$ BDL, SW Indian Ocean, 44 46'S, $36^{\circ}$ 18'E, 1097 m, 31 Jan 1997; SAM 34723, immature male, 1169 mm TL, 775 mm BDL, Marion Island, SW Indian Ocean, 46 49' 0.11"S, 37 43' 59.87" E, 1000 m; SAM 35442, adult male, $1324 \mathrm{~mm}$ TL, $842 \mathrm{~mm}$ BDL, Marion Island, SW Indian Ocean, $46^{\circ} 49^{\prime}$ $0.11^{\prime \prime S}, 37^{\circ} 45^{\prime} \mathrm{E}, 20 \mathrm{Feb} 2000$; SAM 34724, adult female, $1442 \mathrm{~mm}$ TL, $915 \mathrm{~mm}$ BDL, Marion Island, SW Indian Ocean, 44 46' 0.12"S, 36 17' 59.99"E, 600 m; SAM 35446, adult female, 1399+ mm TL, 945 mm BDL, Schmidt-Ott Seamount, SE Atlantic Ocean; SAM 35447, adult female, 1405 mm TL, 915 mm BDL, Schmidt-Ott Seamount, SE Atlantic Ocean. 


\section{Diagnosis.}

Hydrolagus erithacus is a large species (765-945 mm BDL) distinguished from all other congeners based on the following combination of characters: head large and bulky followed by stocky body, height similar from about pectoral fin origins to pelvic fin origins, remaining consistent in height until the insertion of the pelvic fins, and tall dorsal spine greater in height than first dorsal fin. Second dorsal fin up to $81 \%$ of total body length, uniform in height, and equal to dorsal caudal fin height. Paired claspers trifurcate, forked for approximately $20 \%$ of total length with fleshy, bulbous tips. Prepelvic tenaculae with five to seven medial spines and thick frontal tenaculum, nearly uniform in width. Coloration after preservation uniform black with no distinct markings. Comparison of mitochondrial NADH2 gene sequences with other related species suggests a distinct lineage.

\section{Description.}

Morphometric measurements of the holotype are given followed by a range of eight paratypes, and the trait abbreviation (Table 4). Large bodied species (1169-1442 mm TL, 765-945 mm BDL) with bulky head (28, 27-31\% BDL, HDL) and pointed snout (15, 15 $18 \%$ BDL, POB) (Figure 7). Body depth uniform from insertion of pectoral fins to insertion of pelvic fins. Pectoral-pelvic space (35, 29-36\% BDL, PPS), approximately two-thirds (54-71\% BDL) the pelvic-caudal space (51, 46-61\% BDL, PCS). Snout-tovent length $(70,62-69 \%$ BDL, SVL), longer than pelvic-caudal space (51, 46-61\% BDL, 


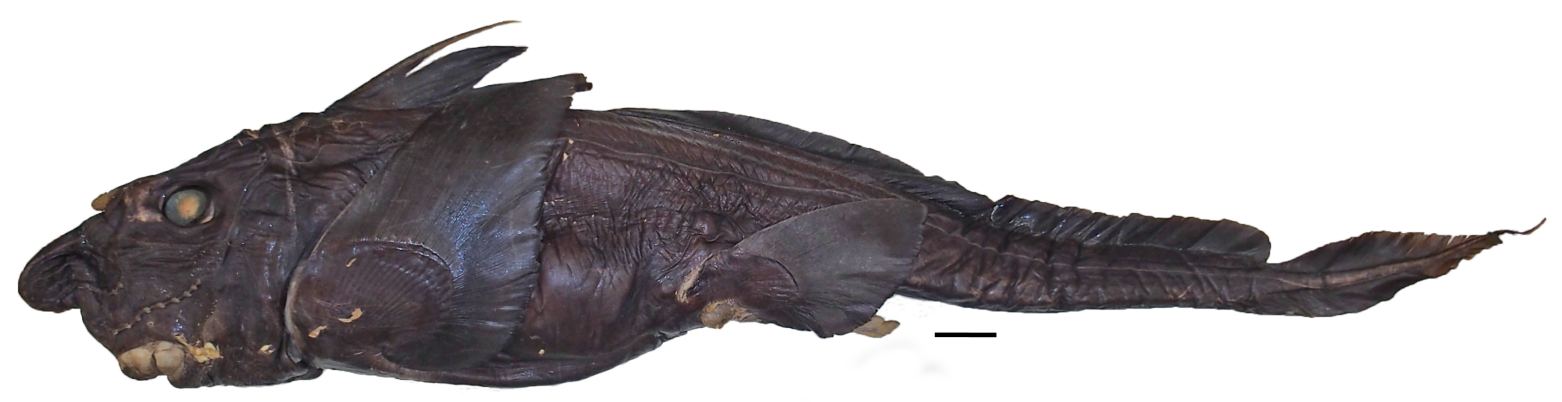

Figure 7. Hydrolagus erithacus sp. nov. holotype, SAIAB 200578, mature male, 1290 $\mathrm{mm}$ TL, $790 \mathrm{~mm}$ BDL, collected from Discovery Seamount, southeastern Atlantic Ocean Scale bar $=5 \mathrm{~cm}$.

Table 4

Measurements of Hydrolagus erithacus sp. nov. Holotype (SAIAB 200578) and Paratypes $(\mathrm{n}=8)$

\begin{tabular}{lcccc}
\hline & \multicolumn{2}{c}{ Holotype } & \multicolumn{2}{c}{ Paratypes $(\mathrm{n}=8)$} \\
\cline { 2 - 5 } Measurement & $\mathrm{mm}$ & $\% \mathrm{BDL}$ & $\mathrm{mm}$ & $\%$ BDL \\
\hline TL & 1290 & 163 & $1169-1442$ & $151-159$ \\
PCL & 1025 & 130 & $935-1210$ & $121-132$ \\
SVL & 550 & 70 & $483-635$ & $62-69$ \\
BDL & 790 & - & $765-945$ & - \\
TRL & 320 & 41 & $275-383$ & $35-44$ \\
HDL & 225 & 28 & $219.9-282$ & $27-31$ \\
PD1 & 225 & 28 & $225-295$ & $28-35$ \\
PD2 & 419 & 53 & $419-515$ & $53-57$ \\
PP1 & 245 & 31 & $231-380$ & $29-42$ \\
PP2 & 575 & 73 & $531-655$ & $69-75$ \\
POB & 120 & 15 & $113.5-163.4$ & $15-18$ \\
PRN & 85 & 11 & $32.5-105$ & $4-12$ \\
POR & 109 & 14 & $46.5-130$ & $5-15$ \\
SNL & 107 & 14 & $97.8-137.8$ & $12-15$ \\
EYL & 46.4 & 6 & $44-58$ & $5-7$ \\
EYH & 35.1 & 4 & $26.5-44.5$ & $3-5$ \\
D1P1 & 150 & 19 & $150-260$ & $19-28$ \\
D1P2 & 384 & 49 & $357-450$ & $43-49$ \\
& & & &
\end{tabular}




\begin{tabular}{lcccc}
\hline D2P1 & 270 & 34 & $220-285$ & $25-34$ \\
\hline D2P2 & 190 & 24 & $157.3-285$ & $20-31$ \\
\hline IDS & 90 & 11 & $65.1-106.9$ & $8-12$ \\
\hline DCS & 13.6 & 2 & $4.5-22.9$ & $1-3$ \\
\hline PPS & 276 & 35 & $233.6-310$ & $29-36$ \\
\hline PCS & 400 & 51 & $361-555$ & $46-61$ \\
\hline PRS & 250 & 32 & $161-250$ & $21-27$ \\
\hline P1AM & 279 & 35 & $263.4-300$ & $31-38$ \\
\hline P1FW & 163 & 21 & $155.8-171.2$ & $18-22$ \\
\hline P1BW & 93 & 12 & $80.8-99$ & $9-13$ \\
\hline P1BH & 75 & 9 & $75-108.1$ & $9-12$ \\
\hline P2AM & 164 & 21 & $159.1-183.6$ & $18-22$ \\
\hline P2FW & 62 & 8 & $62-115.3$ & $10-14$ \\
\hline P2BW & 44 & 6 & $36.8-91.7$ & $4-12$ \\
\hline P2BH & 127 & 16 & $35.5-127$ & $4-7$ \\
\hline DSA & 200 & 25 & $174.8-200$ & $21-25$ \\
\hline D1B & 128 & 16 & $107.7-128$ & $12-16$ \\
\hline D1H & 92.8 & 12 & $92.8-129.6$ & $11-15$ \\
\hline D2B & 600 & 76 & $557-745$ & $71-81$ \\
\hline D2AH & 29.7 & 4 & $27.1-37.2$ & $3-5$ \\
\hline D2PH & 36.8 & 5 & $28.5-38.7$ & $3-5$ \\
\hline D2MH & 30.2 & 4 & $29.3-40$ & $3-5$ \\
\hline CDM & 185 & 23 & $176.1-196.8$ & $21-25$ \\
\hline CDH & 32.2 & 4 & $25.7-38.1$ & $3-5$ \\
\hline CVM & 305 & 39 & $242.3-305$ & $30-36$ \\
\hline CVH & 29.26 & 4 & $21.7-31.2$ & $3-4$ \\
\hline CTL & 260 & 33 & $209.7-267.3$ & $25-32$ \\
\hline CLT & 151.5 & 19 & $151.5-164.2$ & $19-20$ \\
\hline CLM & 25.3 & 3 & $25.3-36$ & $3-4$ \\
\hline CLL & 37.7 & 5 & $28.6-37.7$ & $3-4$ \\
\hline CLO & 46.8 & 6 & $46.8-121.1$ & 14 \\
\hline CLI & 113.1 & 14 & $113.1-152.1$ & $17-20$ \\
\hline CLB & 111 & 14 & $20.5-111$ & $2-3$ \\
\hline FTL & 41.8 & 5 & $36.6-42.4$ & $4-5$ \\
\hline TBH & 11.6 & 1 & $6.9-12.7$ & 1 \\
\hline TBL & 17.5 & 2 & $11.2-20.7$ & $1-2$ \\
\hline TBW & 11.1 & 1 & $8.3-12.1$ & 1 \\
\hline TSW & 7.5 & 1 & $4.6-7.5$ & 1 \\
\hline ONC & 25.3 & 3 & $19.5-32$ & $3-4$ \\
\hline LRC & 2 & $11.1-25$ & $1-3$ \\
\hline & & & & \\
\hline
\end{tabular}




\begin{tabular}{lcccc} 
LNC & 54.4 & 7 & $26.2-64.3$ & $3-7$ \\
IOA & 26.1 & 3 & $5.3-38.6$ & $1-4$ \\
OTM & 77.2 & 10 & $73.1-88.8$ & $8-11$ \\
OCL & 26 & 3 & $26-55.5$ & $4-6$ \\
STL & 50.6 & 6 & $39.1-74$ & $5-8$ \\
SPS & 21.7 & 3 & $21.7-57$ & $4-6$ \\
\hline
\end{tabular}

Note. Measurements in mm and percentage of body length (\% BDL). Abbreviations and definitions found in Appendix 3.

PCS). Eyes oval along horizontal axis, length (6, 5-7\% BDL; 17, 18-22\% HDL; EYL) and height (4, 3-5\% BDL; 15, 12-17\% HDL; EYH). Skin firm, not deciduous.

Pectoral fins large and triangular; pectoral fin length $(35,31-38 \%$ BDL, P1AM), 1.71.9 times pectoral fin width $(21,18-22 \% \mathrm{BDL}, \mathrm{P} 1 \mathrm{FW})$, with a strait anterior margin tapering distally to a rounded apex. Pelvic fin length (21, 18-22\% BDL, P2AM) equal to pectoral fin width $(21,18-22 \% \mathrm{BDL}, \mathrm{P} 2 \mathrm{FW})$ and nearly half the pectoral fin length. Pectoral and pelvic anterior margins weakly convex, overall oval in shape. Fins remain intact and do not fray after preservation.

First dorsal fin triangular with straight medial edge, base (16, 12-16\% BDL D1B) terminating to a low membrane connecting to second dorsal fin in a gentle slope. Dorsal spine $(25,21 \%$ BDL, DSA) robust, curving anteriorly and taller than the first dorsal fin height $(12,11-15 \% \mathrm{BDL}, \mathrm{D} 1 \mathrm{H})$; dorsal spine when depressed is slightly shorter than or just reaches origin of second dorsal fin. Second dorsal fin base long $(76,71-81 \%$ BDL, D2B) and uniform in height along entire length. Second dorsal fin curves downward toward caudal insertion, but does not meet dorsal body margin before dorsal caudal margin begins. 
Caudal ventral margin $(39,30-36 \%$ BDL, CVM) generally longer than caudal dorsal margin (23, 21-25\% BDL, CDM). Caudal dorsal height 4\% (3-5\%) BDL nearly equal to average second dorsal height (4, 3-5\% BDL), slightly taller than caudal ventral height (4, 3-4\% BDL, CVH). No caudal filament observed in available specimens.

Paired claspers trifurcate, forked for $\sim 20 \%$ total length of clasper (17-22\% BDL). Medial branch slender with small tip, lateral branches with bulbous tips, extending onethird the length of the clasper, covered in small denticles (8A). Frontal tenaculum stalk thick and nearly uniform in width. Bulb round with slender, sporadically arranged spines (Figure 8B-C). Prepelvic tenaculae rectangular in shape with 5 to 7 robust medial spines (Figure 8D).

Intraspecific variation of oral (O), preopercular (POP) and infraorbital (IO) canals was observed. In half of the specimens the $\mathrm{O}$ and $\mathrm{POP}$ canals share a common branch from the IO, in the remaining the $\mathrm{O}$ and POP canals connect separately to the IO canal.

Body coloration and fins a uniform black with no distinctive patterns or markings based on preserved specimens. Claspers variable in color from black to pale tan, tips light yellow. Frontal tenaculum dark on dorsal surface, light on ventral. Prepelvic tenaculae tan in color along medial edge near spines, darkening to black along on distal and medial edge posterior to spines. 

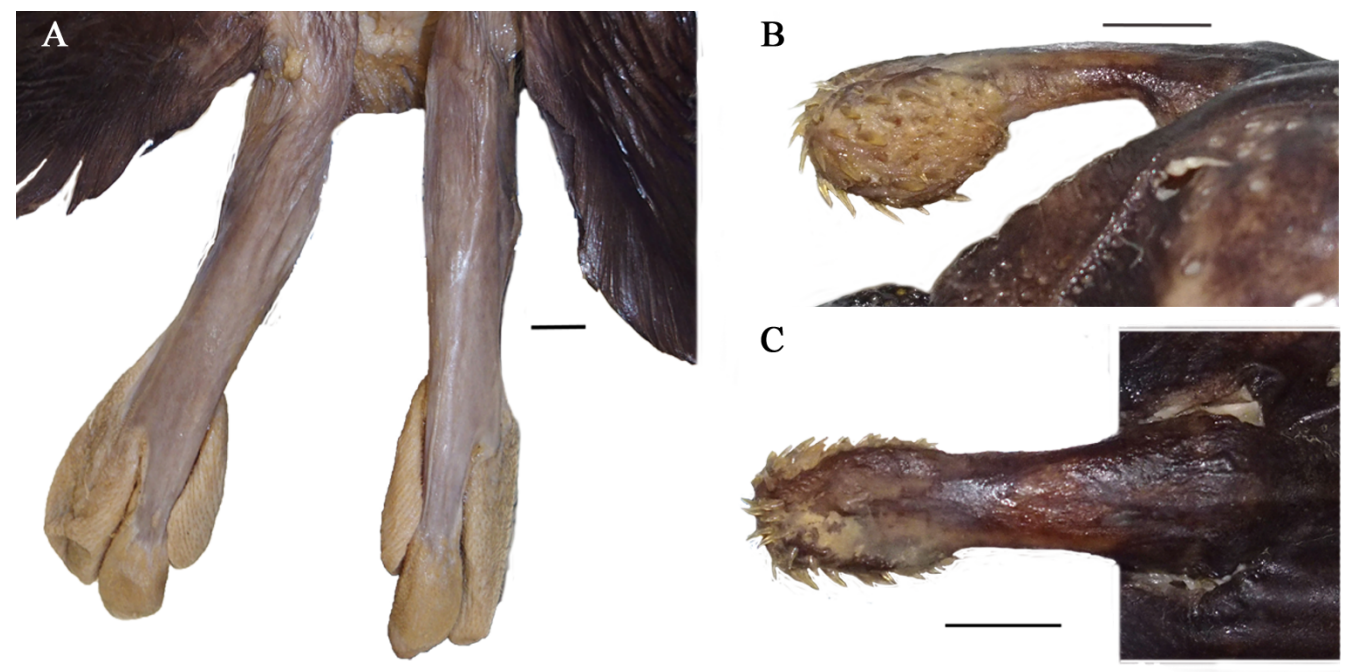

$\mathrm{D}$

$\mathrm{E}$
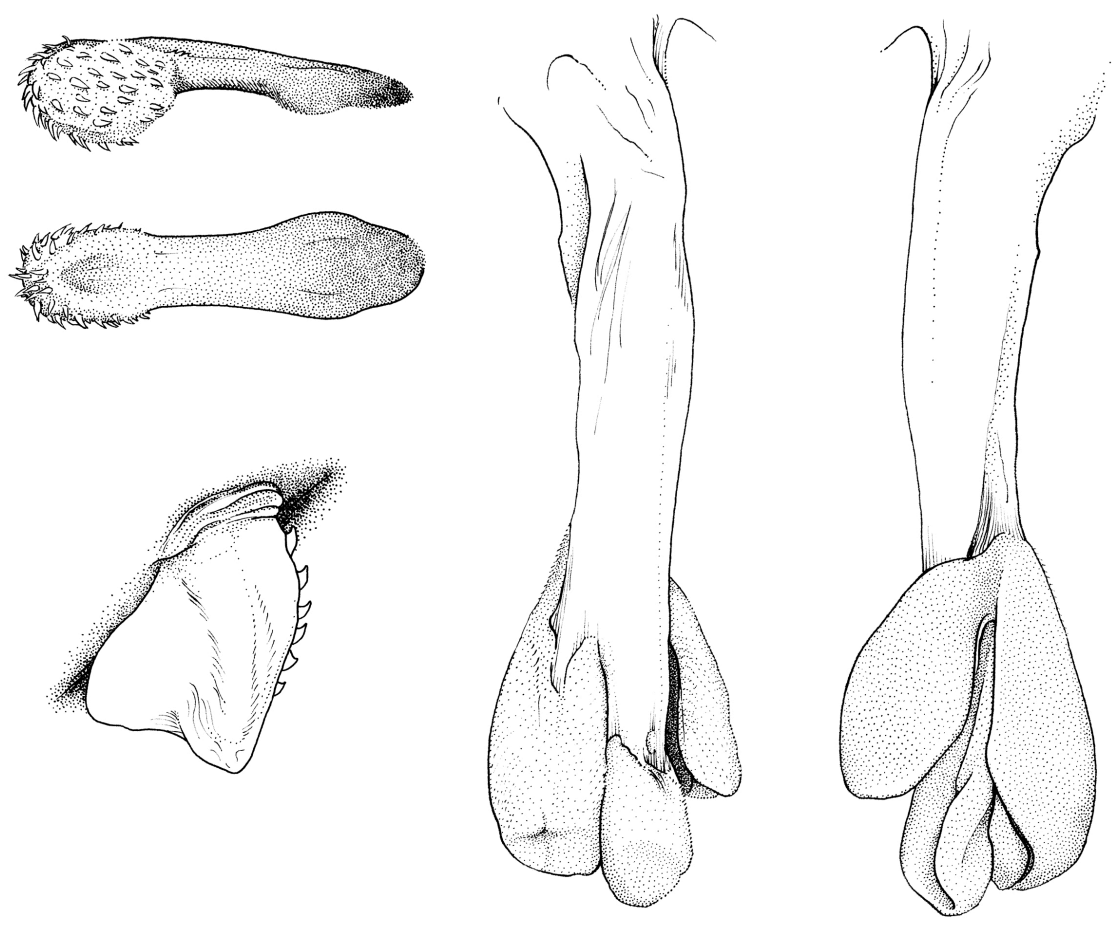

Figure 8. Sexual characters of adult $H$. erithacus holotype including the (A) claspers (B) frontal tenaculum in lateral view (C) frontal tenaculum in dorsal view and (D) pre-pelvic tenaculum in ventral view. Illustration of male reproductive organs by Mattias Lanas $(\mathrm{E})$ Scale bars $=5 \mathrm{~mm}(\mathrm{~A})$, and $1 \mathrm{~mm}(\mathrm{~B})-(\mathrm{D})$. 


\section{Etymology.}

The species name erithacus derives from the avian genus of the robin (Aves: Passeriformes: Muscicapidae: Erithacus Cuvier, 1800). Named after Robin Leslie (DAFF), a fanatic birder, in recognition of his help and support on this project, and his overall contribution to Chondrichthyan research in southern Africa.

\section{Distribution.}

Hydrolagus erithacus is currently known from other remote seamounts throughout the southern Atlantic, southern Indian and southern Oceans including the RSA and Discovery Seamounts between latitudes $39^{\circ}$ to $47^{\circ} \mathrm{S}$, from depths of $470-1,000$ meters 9). Based on the depth distribution of similarly sized species and accounts from the Patagonian toothfish (Dissostichus eleginoides) fishery operating within its range, this species likely occurs to depths in excess of 2,000 meters (R. Leslie, personal communication, Sept. 15, 2015).

\section{Biological Notes.}

A large bodied species growing to at least $945 \mathrm{~mm}$ BDL, $1405 \mathrm{~mm}$ TL. Smallest observed mature individuals were $842 \mathrm{~mm}$ and $765 \mathrm{~mm}$ BDL for males and females, respectively. Largest immature male individual was $775 \mathrm{~mm}$ BDL, no immature females were observed. Sample size was too small to estimate the size at $50 \%$ maturity for males and destructive examination of female specimens was not allowed, therefore this metric 


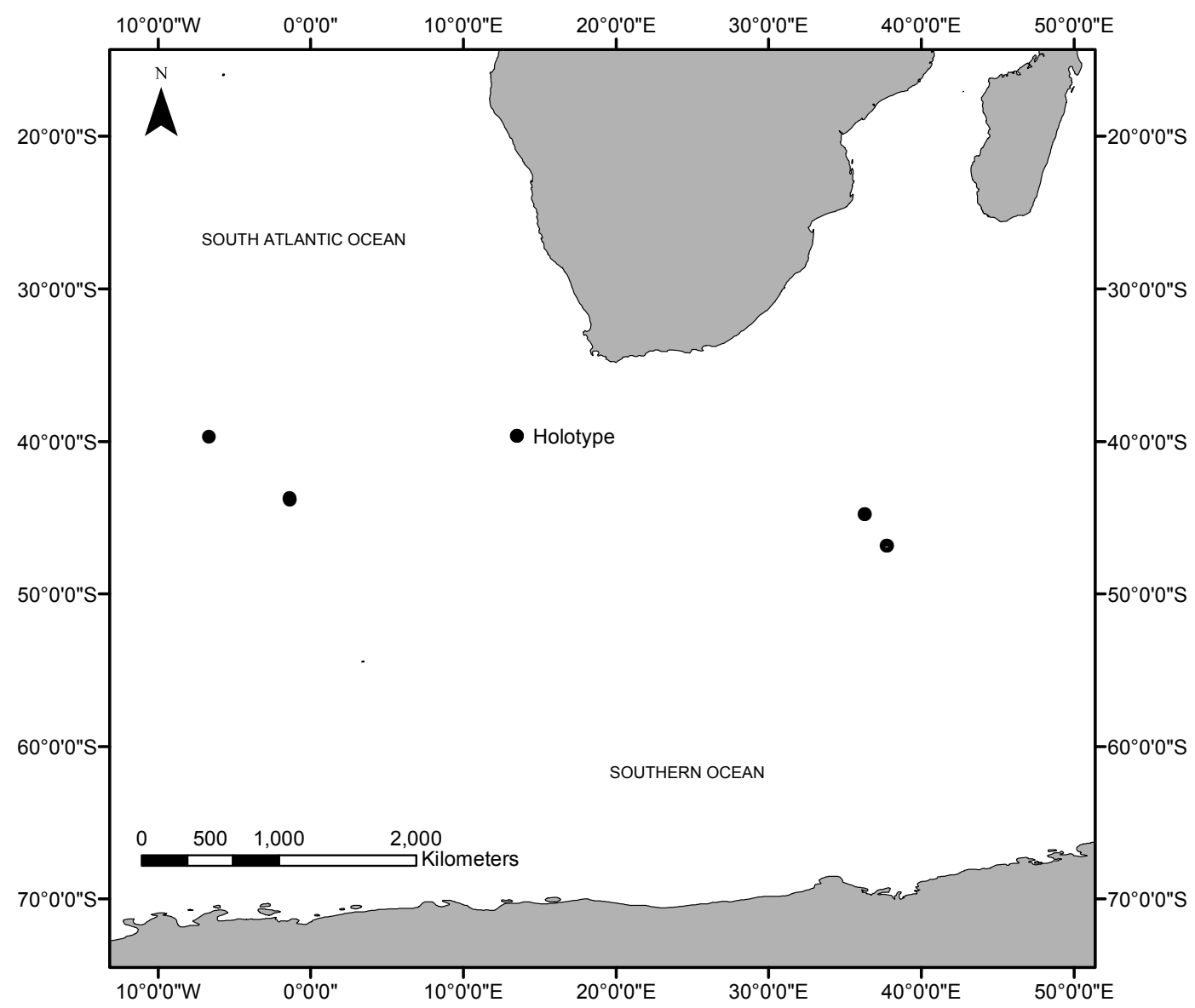

Figure 9. Distribution of H. erithacus in the southeast Atlantic and southwest Indian Oceans.

could not be calculated for males or females. Internal examination of a mature female specimen (SAM 34724) measuring 915 mm BDL revealed a fully developed uterus and oviducal glands with several oocytes measuring approximately $30 \mathrm{~mm}$ in diameter. Fragments of possible crab appendages were recovered from the digestive tract of the holotype specimen, indicating a diet of crustaceans and other benthic fauna. 


\section{Comparisons.}

Hydrolagus erithacus is the second largest Hydrolagus species described to date, and can clearly be differentiated from the small-bodied chimaerids in the genus (e.g. $H$. africanus, $H$. alberti, H. alphus, H. barbouri, H. colliei, H. macrophthalmus, $H$. mirabilis, and H. mitsukurii). Hydrolagus africanus occurs nearest in geographic proximity to $H$. erithacus, but does not overlap in distribution, and is a much smaller species ( $<500 \mathrm{~mm} \mathrm{BDL},<900 \mathrm{~mm} \mathrm{TL}$ and size at maturity $>300 \mathrm{~mm}$ ) (Walovich et al. 2015). The anterior second dorsal fin height of $H$. africanus is taller (4-8\% vs. $3-5 \%$ $\mathrm{BDL}, \mathrm{D} 2 \mathrm{AH})$ and the second dorsal height taller across its entire length (2-7\% vs. 3-5\% BDL, D2PH, 1-6\% vs. 3-5\% BDL, D2MH). The coloration of fresh $H$. africanus is silver and brown and when preserved turns a uniform light brown. Additionally, the uniform black color of H. erithacus separates it from the patterned species such as H. alphus, $H$. colliei, H. marmoratus, H. mccoskeri, and H. novaezealandiae.

The seven species most similar to H. erithacus in color and body size are compared. Three species of these large bodied Hydrolagus are known only to occur in the North Atlantic, H. affinis, H. pallidus and H. lusitanicus (Ebert \& Stehmann 2013). Hydrolagus affinis relative to $H$. erithacus differs proportionally by having a smaller snout to second dorsal fin distance (47-55\% vs. $53-57 \%$ BDL, PD2), head length (23-31\% vs. $27-32 \%$ BDL), pre-pectoral fin length (28-34\% vs. $29-42 \%$ BDL), pre-orbital length (12-14\% vs. $15-18 \%$ BDL), dorsal caudal margin (16-21\% vs. $21-25 \%$ BDL) and dorsal caudal height (2-4\% vs. 3-5\% BDL). Hydrolagus affinis has been described as having 4-6 medial spines on the prepelvic tenaculae (Hardy \& Stehmann 1990), however investigation of 
additional specimens reveals a slightly wider spine count range (4-8 spines, average 6). Hydrolagus pallidus is distinct from H. erithacus based on a shorter head length (23-30\% vs. $27-31 \%$ BDL), pre-pectoral fin length (26-34\% vs. $29-42 \%$ BDL) and pectoral fin length-to-width ratio (1.3-1.7 vs. 1.7-1.9). Previously reported pectoral fin length-towidth ratios are less than 1.5 for H. pallidus (Hardy \& Stehmann 1990, Ebert \& Stehmann 2013), however an additional specimen measured by the authors was outside this range (1.7). Hydrolagus pallidus turns white to creamy grey colored in fixative, whereas H. erithacus turns a uniform black. Hydrolagus lusitanicus appears to reach similar body lengths as $H$. erithacus, however the species was poorly described, did not use standard measurement methods for comparison to other Hydrolagus species, and did not provide any maximum size or size at maturity information (Moura et al., 2005). However, H. lusitanicus has a larger pectoral fin length-to-width ratio (1.9-2.3 vs. 1.71.9), longer first dorsal fin base length (19-20\% vs. $13-16 \%$ BDL), and a distinct coloration from H. erithacus, being a uniform rose to light brown with irregular spots and violet-blue fins.

Hydrolagus purpurescens from the central and western North Pacific is poorly known, but can be separated from H. erithacus by a longer snout-to-vent length (68-72\% vs. $62-69 \%$ BDL), shorter distance from first dorsal fin origin to pectoral fin origin (20$21 \%$ vs. $19-28 \%$ BDL), and greater eye length (6-8\% vs. $5-7 \%$ BDL) and eye height (4$6 \%$ vs. $3-5 \%$ BDL). Second dorsal fin height is taller and with a slight dip at the center (4-5\% BDL), while remaining a consistent height in H. erithacus. 
The eastern Pacific H. melanophasma has a shorter snout-to-vent length (57-60\% vs. $62-70 \%$ BDL), larger eyes (22-26\% vs. 17-22\% HDL), longer pectoral fin anterior margin (39-41\% vs. 31-38\% BDL), and fewer prepelvic tenaculae spines (3-4 vs. 5-7 spines) (James et al., 2009).

Hydrolagus trolli, found in the waters off New Zealand and New Caledonia, is a slightly smaller species, reaching sexual maturity at 550-650 mm BDL (Didier \& Séret 2002). Hydrolagus trolli has a greater range of snout-to-vent lengths (63-75\% vs. $62-69 \%$ BDL), longer pre-orbital length (14-19\% vs. 15-18\% BDL), smaller head (22-26\% vs. $23-39 \%$ BDL), shorter caudal dorsal height (3-4\% vs. 3-5\% BDL), shorter caudal ventral margin (30-36\% vs. $28-40 \%$ BDL) and fewer medial spines on the prepelvic tenaculae (4-5 vs. 5-7 spines). Hydrolagus trolli is a uniform pale, blue-grey when fresh, becoming brown to purple when fixed, compared to the uniform black coloration of H. erithacus.

Hydrolagus homoncyteris is a medium bodied (667 mm maximum BDL) species from southeast Australia and New Zealand, whose diagnostic short, round pelvic fins (13$18 \%$ BDL) make it distinguishable from the larger, oval shaped pectoral fins of $H$. erithacus (18-22\% BDL) despite its similar uniform, black coloration (Didier, 2008).

\section{Genetics.}

The tissue from seven species of Chimaeriformes was analyzed for molecular comparison, including $H$. africanus $(\mathrm{n}=25), H$. affinis from the North Atlantic (NA; $=3)$, H. pallidus $(\mathrm{n}=3), H$. trolli $(\mathrm{n}=3), H$. erithacus $(\mathrm{n}=2)$, and $R$. atlantica $(\mathrm{n}=1)$ and $H$. 
raleighana $(\mathrm{n}=1)$. Neighbor joining, parsimony and maximum likelihood analyses yield similar tree topologies (Figure 10). The tree topology of sequence data at the NADH2

gene locus suggests five distinct clades, corresponding to H. africanus, H. affinis (NA), H. pallidus, H. trolli and H. erithacus. Rhinochimaera atlantica and Harriotta raleighana were used to root the tree. The sequence data suggests $H$. erithacus is a new species distinct from similar Hydrolagus species. However, we caution that this inference is the tree topology for only a single mitochondrial gene and may not correspond to the species tree based on multiple markers. It may be necessary to analyze a suite of independent molecular markers to infer a more robust species tree.

\section{Statistical Analysis.}

Non-metric multidimensional scaling (nMDS) ordination was performed in order to visualize the relatedness of the specimens studied due to the numerous morphological traits collected for each specimen. Lateral line and sexual characteristics were omitted from the dataset to prevent bias in the data, leaving a subset of the morphological traits. The n-MDS plot shows low levels of dissimilarities between species, visualized as one tightly clustered group (Figure 11). Hydrolagus africanus specimens exhibit some separation from other species, driven mostly by differences in first dorsal height (D1H), dorsal spine length (DSA), second dorsal fin anterior height (D2AH), eye length (EYL), and eye height (EYH). ANOSIM results showed modest separation among species groupings (Global $\mathrm{R}=0.307, \mathrm{p}=0.01$ ). Pairwise tests between species indicate significant separation of species, with the exception of $H$. affinis $(\mathrm{SA})$ and $H$. erithacus $(\mathrm{R}=0.086$, 


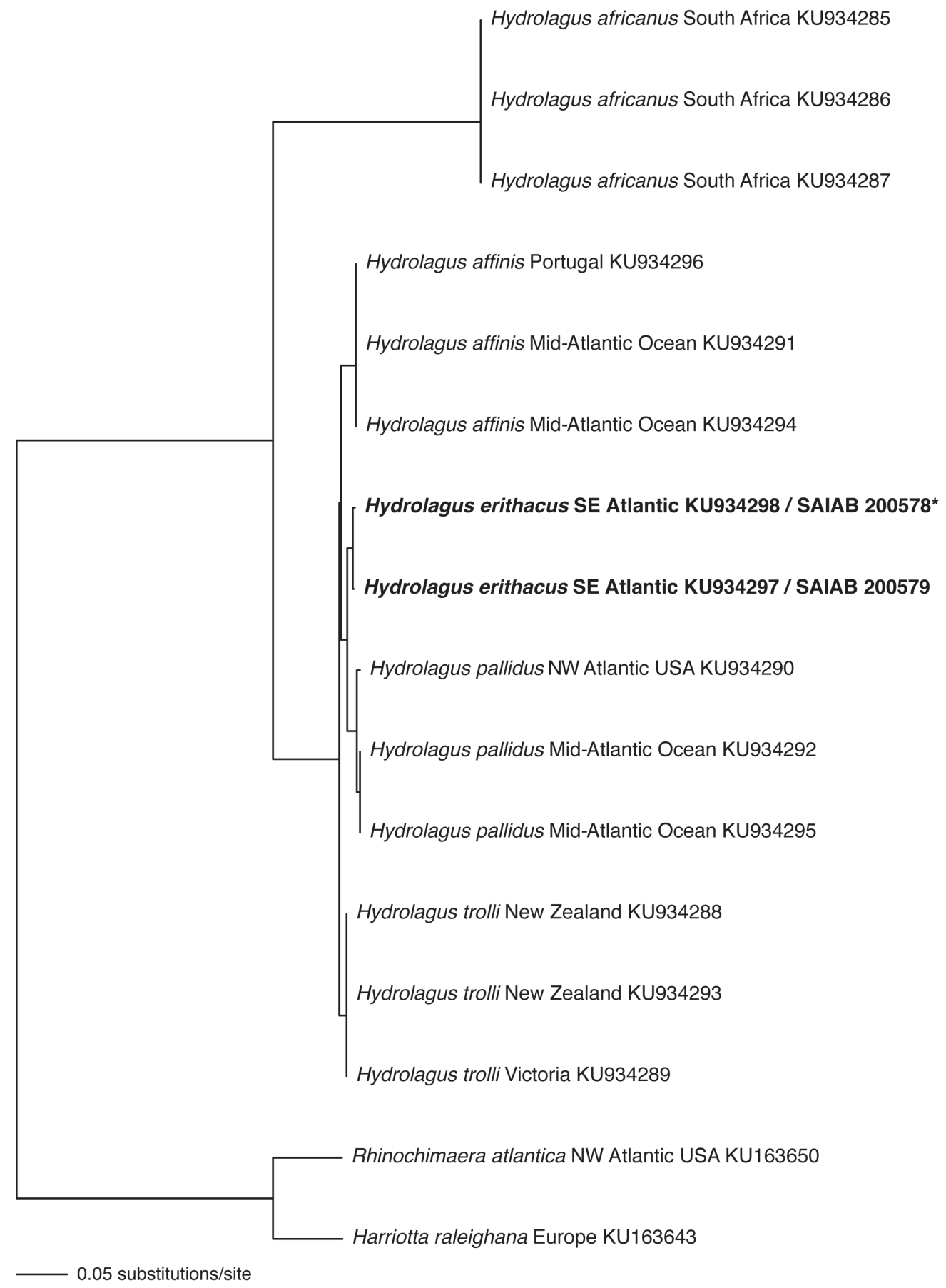

Figure 10. Maximum likelihood tree estimate using general-time reversible (GTR) + gamma model based on NADH2 sequence data of Hydrolagus erithacus and comparative species. GenBank accession numbers follow species names. Hydrolagus erithacus position indicated in bold; collection number follows GenBank accession number. * ${ }^{*}$ holotype. 
$\mathrm{p}=0.082)$ and $H$. erithacus and $H$. trolli $(\mathrm{R}=-0.13, \mathrm{p}=0.869)$ (Table 5). Percent contributions of traits that differentiate species were determined using SIMPER analysis (Table 5). The top three contributing traits contributed to between $4-8 \%$ each, with head height $(\mathrm{HDH})$ and pelvic fin base width (P2BW) reoccurring as differentiating characters in multiple species group comparisons.

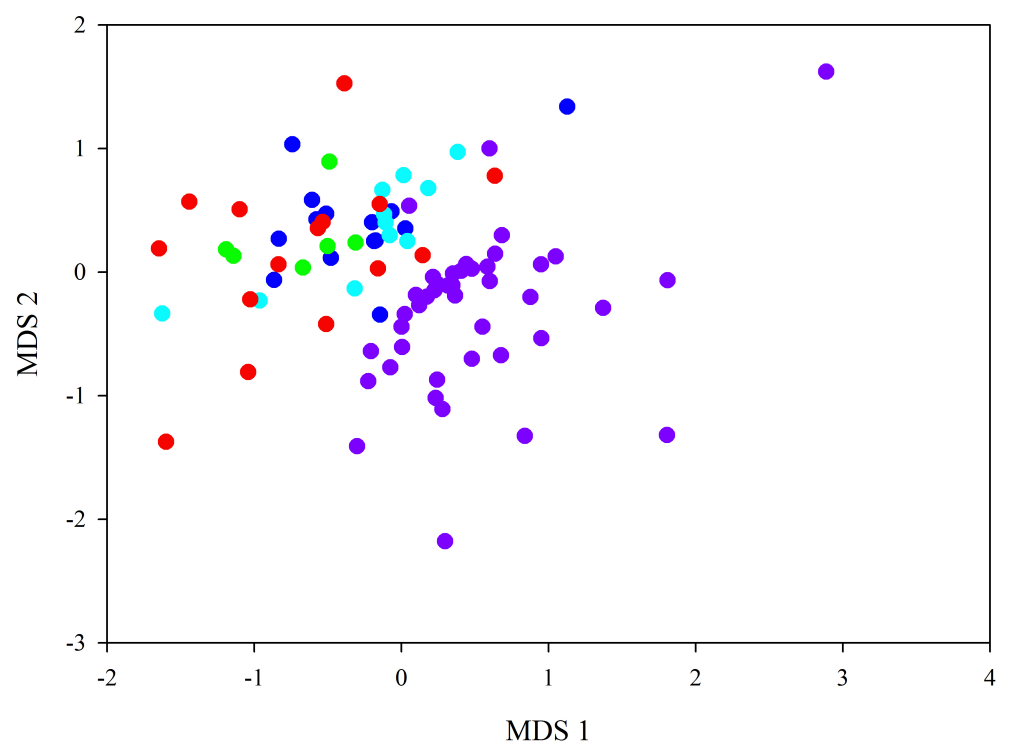

Figure 11. Two-dimensional non-Metric Multidimensional Scaling (n-MDS) plot comparing the morphological traits of four Hydrolagus species including Hydrolagus affinis (NA) (dark blue), Hydrolagus affinis (SA)(light blue), Hydrolagus africanus (purple), Hydrolagus erithacus (red) and Hydrolagus trolli (green). 
Table 5

Analysis of Similarity (ANOSIM) and Similarity Percentage Analysis (SIMPER) Results for Differences Between Species

\begin{tabular}{|c|c|c|c|c|}
\hline \multirow[b]{2}{*}{ Species Groups } & \multicolumn{2}{|c|}{ ANOSIM Analysis } & \multicolumn{2}{|c|}{ SIMPER Analysis } \\
\hline & $\begin{array}{c}\mathrm{R} \\
\text { Statistic }\end{array}$ & $\begin{array}{l}\text { Significance } \\
\text { Level }(\%)\end{array}$ & Traits & $\begin{array}{c}\text { Contribution } \\
\%\end{array}$ \\
\hline \multirow[t]{3}{*}{$\begin{array}{l}\text { H. affinis (NA) \& H. africanus } \\
*\end{array}$} & 0.395 & 0.1 & $\mathrm{HDH}$ & 5.85 \\
\hline & & & $\mathrm{D} 1 \mathrm{P} 1$ & 5.02 \\
\hline & & & $\mathrm{D} 2 \mathrm{P} 2$ & 4.51 \\
\hline \multirow[t]{3}{*}{$\begin{array}{l}\text { H. affinis (NA) \& H. affinis } \\
\text { (SA)* }\end{array}$} & 0.259 & 0.1 & $\mathrm{HDH}$ & 7.93 \\
\hline & & & $\mathrm{D} 2 \mathrm{P} 2$ & 7.38 \\
\hline & & & D1P1 & 6.13 \\
\hline \multirow[t]{3}{*}{$\begin{array}{l}\text { H. africanus \& H. affinis (SA) } \\
*\end{array}$} & 0.261 & 1.0 & $\mathrm{D} 1 \mathrm{~B}$ & 4.70 \\
\hline & & & D2AH & 4.31 \\
\hline & & & EYH & 4.13 \\
\hline \multirow[t]{3}{*}{$\begin{array}{l}\text { H. affinis (NA) \& H. erithacus } \\
*\end{array}$} & 0.133 & 0.5 & $\mathrm{D} 2 \mathrm{P} 2$ & 5.51 \\
\hline & & & PPS & 5.00 \\
\hline & & & $\mathrm{HDH}$ & 4.96 \\
\hline \multirow[t]{3}{*}{ H. africanus \& H. erithacus * } & 0.482 & 0.1 & HDL & 4.28 \\
\hline & & & P2BW & 4.09 \\
\hline & & & PPS & 3.49 \\
\hline \multirow[t]{3}{*}{ H. affinis (SA) \& H. erithacus } & 0.086 & 8.2 & PPS & 5.09 \\
\hline & & & P2BW & 4.84 \\
\hline & & & HDL & 4.39 \\
\hline
\end{tabular}




\begin{tabular}{lcccc} 
H. affinis (NA) \& H. trolli * & 0.291 & 0.5 & D2P2 & 7.29 \\
& & & HDH & 7.17 \\
& & D1P1 & 6.57 \\
& & & \\
H. africanus \& H. trolli * & 0.45 & 0.3 & POB & 4.94 \\
& & & DSA & 4.86 \\
& & PD1 & 4.04 \\
H. affinis (SA) \& H. trolli * & 0.27 & 1.3 & POB & 5.82 \\
& & & PD1 & 5.29 \\
& & & DSA & 5.14 \\
H. erithacus \& H. trolli & -0.13 & 86.9 & PPS & 5.61 \\
& & & P2BW & 5.40 \\
& & & P2BH & 5.25 \\
\hline
\end{tabular}

Note. An asterisk $(*)$ denotes significant differences. Similarity percentage (SIMPER) analysis results to determine the relative contributions of morphological traits to the differences between species.

\section{Discussion}

The lack of prominent differentiation between species in the n-MDS and post-hoc analysis indicates highly overlapping morphological traits. Some traits do not vary between species, including trunk length (TRL), second dorsal to pelvic fin distance (D2P2), dorsal caudal space (DCS), posterior base of pectoral fin to anterior base of pelvic fin length (PPS), pelvic caudal space (PCS), pectoral fin anterior margin (P1AM), and pelvic fin base height $(\mathrm{P} 2 \mathrm{BH})$. Other traits like pre-second dorsal length (PD2), prepelvic fin length (PP2), pre-narial length (PRN), snout length (SNL), dorsal spine height (DSA), second dorsal fin base length (D2B) are highly variable between species, making 
them potentially ideal traits to differentiate species. Since traits D2P2 and PCS are not particularly variable between species and are influenced by preservation, these traits can be omitted based on their lack of diagnostic strength and reliability. Traits like PD2 and D2B are variable between species and not strongly influenced by preservation, therefore should be considered preferentially among traits. Since spine height (DSA) is a hard structure, it should not be affected by preservation. Although DSA showed statistically significant changes before and after preservation, this is likely an artifact of sampling. While spines are a valuable diagnostic trait, a large percentage of preserved species do not have intact spines, therefore pooled measurements of this feature may be influenced by small samples size.

Eliminating traits heavily influenced by preservation will result in a smaller subset of morphological traits to reduce unimportant traits and spend more time improving the accuracy of important ones. If a smaller set of traits can be measured, it may be possible to measure specimens multiple times over a comparable time frame in order to reduce the variability of these measurements. With a more succinct set of traits to measure and less variability, the distinguishing characteristics of these species will be easier to define.

The morphological and genetic data largely agree on the putative species identification. The NADH2 data shows Hydrolagus africanus is a distinct, yet closely related clade from the larger species of Hydrolagus included in the analysis. This separation concurs with the nMDS of the morphological data. Although H. erithacus and $H$. trolli are geographically closer, genetically $H$. erithacus is most closely related to $H$. pallidus from the North Atlantic. This data contrasts with the morphological data that 
indicates no morphological differences between H. erithacus and H. trolli, however these results are not statistically significant (ANOSIM; $\mathrm{R}=0.13 ; \mathrm{p}=0.869$ ). Although the two methods disagree slightly, the totality of the results are robust enough to be confident in the overall species determinations.

The inclusion of genetic analysis, in addition to morphometric analysis has improved our ability to identify and differentiate species of this genus. While morphometric descriptive information is important for field identification, genetic analysis can provide differentiation where morphometric data may be lacking due to small sample size or overlapping traits. Less is known about the ecological role, behavior and diets and the degree to which each species is specialized of many chimaera species, so small differences in genetics may have little influence on species identifications. The small degree of genetic variation among species in the Chimaeridae family indicates the family has only begun to diverge (Kemper et al., 2015; Moura et al., 2015).

As genetic analysis becomes more efficient and cheaper to perform, its prevalence in taxonomic studies will continues to grow. Currently and moving forward the combination of morphometric and genetic analysis is necessary to describe and identify new species. 


\section{Chapter 3 \\ Identification Of The Southern African Ghost Shark Formerly Known As Hydrolagus ef. trolli}

\section{Introduction}

The identity of a large Hydrolagus species sympatric with the smaller bodied $H$. africanus has remained a mystery since the 1980's due to a lack of adequate descriptive external morphological characteristics for $H$. africanus. Without this basic descriptive information, distinguishing this larger species from $H$. africanus was impossible. Based on morphological characteristics including a long, pointed snout and light blue coloration, this species was tentatively identified in the southern African literature as Hydrolagus cf. trolli, a species known from Australian and New Zealand waters (Compagno, 1999; Ebert and van Hees, 2015). Until now, little to no efforts were made to re-describe $H$. africanus or to confirm the identity of $H$. cf. trolli. Following the redescription of $H$. africanus in 2015 (Walovich et al., 2015), an examination of Hydrolagus specimens in the Iziko-South African Museum (iSAM) and South African Institute for Aquatic Biodiversity (SAIAB) fish collections and additional specimens collected during the annual DAFF survey was performed in order to ascertain the identity of this species. A review of literature, field notes and collected specimens resulted in the discovery of a Hydrolagus species different from H. africanus (Compagno, 1999). Upon analysis of morphological and genetic information, this species has been identified as Hydrolagus affinis (de Brito Capello, 1868) from the North Atlantic.

The North Atlantic population of Hydrolagus affinis is sympatric with two other large bodied species, H. pallidus Hardy \& Stehmann 1990 and H. lusitanicus Moura et 
al., 2005, throughout its range, but this species had not been reported in the literature south of the Canary Islands (off the coast of Morocco) until recently (Ebert \& Stehmann, 2013). The range of $H$. affinis was extended even more recently to the waters of Namibia, but without explanation or detailed information on the basis of this new record (Didier, 2016). Therefore, to clarify the identity of this large bodied species, the species formerly referred to as $H$. cf. trolli from southern African deep-waters is described, and confirmed its identity as H. affinis. Furthermore, this species was compared to the North Atlantic population (NA) of $H$. affinis and to the southern hemisphere $H$. trolli. The identification of $H$. affinis in southern Africa significantly expands its known range, changing it from a regional endemic species, restricted to the eastern North Atlantic, to a wide-ranging one, necessitating a review of management and conservation strategies.

\section{Results}

The results section details the information necessary to give a clear description of this species and explain how it differs from others in the genus. This section includes: systematics (a list of references concerning this species), a diagnosis (the characters that distinguish this species from others), the description (a detailed account of the species' features), comparisons to similar species and other important information like distribution and biological notes.

\section{Systematics.}

This synonymy includes all references (to the best of the author's knowledge) to Hydrolagus affinis in the southern African region, including misidentifications. The list 
includes the reference and the page (s) the species is referenced. This list does not include the references of $H$. affinis from the North Atlantic.

Hydrolagus affinis (de Brito Capello, 1868), Atlantic Chimaera, Smalleyed Rabbitfish Hydrolagus affinis: Didier, 2016: 1455

Hydrolagus cf. trolli: Ebert \& van Hees, 2015: 148; Ebert, 2014: 95; Ebert, 2015: 195197; Walovich, Ebert, Long \& Didier, 2015: 162,165; Walovich, Ebert \& Kemper, 2017: 509; Weigmann, 2016: 168

Hydrolagus sp. (?): Smith, 1964: 145; Compagno et al., 1991: 113-114

Hydrolagus sp. nov. (Pointynose Blue Chimaera): Compagno, 1999: 120

\section{Diagnosis.}

A large bodied species, with a large, stocky head and torso, with a short snout-topelvic fin length (PP2). Second dorsal fin becoming slightly taller toward the posterior and caudal ventral margin longer than caudal dorsal margin. Pelvic fins small, round with round fin pads. Claspers trifid with tan fleshy pads, and rectangular shaped pre-pelvic tenacula with three to five medial spines.

\section{Description.}

Description based on twelve adult individuals, ten male and two females. Traits presented as mean, followed by range of percent body length (BDL) and trait abbreviation. A complete table of traits and values for $H$. affinis and comparable species can be found in Table 6. A large bodied species (536-719 mm BDL, 841-1069 mm TL) whose body tapers from a large, stocky head $(26.2,20.0-32.2 \%$ BDL) to short $(2-3 \mathrm{~cm})$ 
Table 6

Hydrolagus affinis (NA), H. affinis (SA), and H. trolli Morphometric Data

\begin{tabular}{|c|c|c|c|c|c|c|}
\hline \multirow[b]{2}{*}{ Measurement } & \multicolumn{2}{|c|}{$\begin{array}{l}\text { Hydrolagus affinis } \\
\text { (NA) }\end{array}$} & \multicolumn{2}{|c|}{$\begin{array}{l}\text { Hydrolagus affinis } \\
\text { (SA) }\end{array}$} & \multicolumn{2}{|c|}{ Hydrolagus trolli } \\
\hline & Min & Max & Min & Max & Min & Max \\
\hline $\mathrm{TL}$ & 144.9 & 162.0 & 142.9 & 159.0 & 151.2 & 171.1 \\
\hline PCL & 121.1 & 129.4 & 115.4 & 131.8 & 125.4 & 132.1 \\
\hline SVL & 57.1 & 71.1 & 57.5 & 68.5 & 63.1 & 74.8 \\
\hline BDL & $568(\mathrm{~mm})$ & $853(\mathrm{~mm})$ & $536(\mathrm{~mm})$ & $719(\mathrm{~mm})$ & $418(\mathrm{~mm})$ & $685(\mathrm{~mm})$ \\
\hline TRL & 32.9 & 43.9 & 33.6 & 42.9 & 38.4 & 42.6 \\
\hline HDL & 22.9 & 30.8 & 20.0 & 32.2 & 26.0 & 34.2 \\
\hline PD1 & 25.0 & 31.1 & 24.9 & 34.5 & 28.3 & 35.5 \\
\hline PD2 & 46.5 & 55.4 & 44.5 & 53.2 & 49.2 & 57.4 \\
\hline PP1 & 27.7 & 34.3 & 23.5 & 34.2 & 28.5 & 35.1 \\
\hline PP2 & 63.2 & 71.7 & 56.0 & 73.3 & 64.4 & 74.8 \\
\hline POB & 11.5 & 14.1 & 11.1 & 18.9 & 13.8 & 19.3 \\
\hline PRN & 4.1 & 9.1 & 5.1 & 12.7 & 6.5 & 11.1 \\
\hline POR & 4.9 & 11.0 & 7.4 & 14.3 & 7.5 & 15.6 \\
\hline SNL & 5.6 & 14.0 & 6.8 & 14.6 & 8.4 & 14.2 \\
\hline EYL & 5.5 & 6.6 & 5.6 & 6.9 & 5.2 & 6.8 \\
\hline EYH & 4.2 & 5.7 & 3.8 & 5.1 & 3.9 & 4.8 \\
\hline D1P1 & 16.4 & 23.6 & 14.8 & 20.9 & 16.6 & 24.1 \\
\hline D1P2 & 36.8 & 48.1 & 39.0 & 45.5 & 40.1 & 46.6 \\
\hline $\mathrm{D} 2 \mathrm{P} 1$ & 21.1 & 34.5 & 23.2 & 32.5 & 27.4 & 33.3 \\
\hline $\mathrm{D} 2 \mathrm{P} 2$ & 21.2 & 31.9 & 19.2 & 27.8 & 20.9 & 28.5 \\
\hline IDS & 6.1 & 11.4 & 2.4 & 11.5 & 7.0 & 12.0 \\
\hline DCS & 0.0 & 1.8 & 0.0 & 1.8 & 0.0 & 3.0 \\
\hline PPS & 30.8 & 38.1 & 28.7 & 35.7 & 31.2 & 34.4 \\
\hline PCS & 41.6 & 59.3 & 46.1 & 58.3 & 46.7 & 56.2 \\
\hline PRS & 19.5 & 37.0 & 16.4 & 28.2 & 13.2 & 26.4 \\
\hline P1AM & 30.8 & 38.2 & 31.9 & 37.9 & 33.6 & 38.8 \\
\hline P1FW & 17.9 & 22.9 & 17.6 & 21.7 & 18.2 & 21.5 \\
\hline P1BW & 9.6 & 13.1 & 8.9 & 12.3 & 9.1 & 10.4 \\
\hline P1BH & 9.2 & 14.6 & 8.1 & 11.9 & 8.1 & 11.7 \\
\hline P2AM & 17.9 & 22.8 & 16.4 & 19.8 & 16.3 & 20.6 \\
\hline P2FW & 11.6 & 15.3 & 9.7 & 12.0 & 12.0 & 13.8 \\
\hline
\end{tabular}




\begin{tabular}{lcccccc} 
P2BW & 5.1 & 7.2 & 4.3 & 6.9 & 4.9 & 6.6 \\
\hline P2BH & 5.1 & 7.6 & 4.9 & 7.3 & 4.6 & 6.1 \\
\hline DSA & 17.1 & 22.5 & 18.1 & 25.6 & 12.5 & 21.7 \\
\hline D1B & 12.9 & 15.4 & 7.1 & 15.7 & 13.2 & 15.1 \\
\hline D1H & 10.2 & 14.8 & 12.4 & 15.2 & 11.4 & 18.1 \\
\hline D2B & 72.8 & 81.3 & 70.4 & 81.2 & 70.6 & 81.0 \\
\hline D2AH & 2.9 & 4.6 & 2.6 & 4.7 & 2.8 & 4.1 \\
D2PH & 3.2 & 4.8 & 3.0 & 4.9 & 3.1 & 4.8 \\
\hline CDH & 2.1 & 3.7 & 2.6 & 4.1 & 2.6 & 3.8 \\
\hline CVM & 27.7 & 37.4 & 22.3 & 34.5 & 27.7 & 39.9 \\
RCI & 0.0 & 37.7 & 32.8 & 66.8 & 29.3 & 36.9 \\
\hline CVH & 2.4 & 3.5 & 2.3 & 4.1 & 2.4 & 4.0 \\
\hline CTL & 18.5 & 30.8 & 23.5 & 33.2 & 23.4 & 45.1 \\
\hline CLT & 3.5 & 16.0 & 16.9 & 23.0 & 3.3 & 14.1 \\
\hline CLM & 1.1 & 5.0 & 2.1 & 6.3 & 1.0 & 4.0 \\
\hline CLL & 1.3 & 5.9 & 3.5 & 5.4 & 1.3 & 5.8 \\
\hline CLO & 2.5 & 15.5 & 4.8 & 14.9 & 3.3 & 13.3 \\
CLI & 3.9 & 17.4 & 12.9 & 18.3 & 5.4 & 14.5 \\
\hline CLB & 1.2 & 2.9 & 2.3 & 2.8 & 1.6 & 2.3 \\
\hline FTL & 3.8 & 5.6 & 3.6 & 4.9 & 2.9 & 4.3 \\
\hline TBH & 1.3 & 1.4 & 1.0 & 1.5 & 1.2 & 1.3 \\
\hline TBL & 1.5 & 2.2 & 1.8 & 2.0 & 1.6 & 1.8 \\
\hline TBW & 1.1 & 1.5 & 1.2 & 1.5 & 1.1 & 1.2 \\
\hline TsW & 0.8 & 1.0 & 0.5 & 0.9 & 0.8 & 0.8 \\
\hline ONC & 2.5 & 4.6 & 2.0 & 3.8 & 3.0 & 5.4 \\
\hline LRC & 0.8 & 1.8 & 0.9 & 2.0 & 1.1 & 2.2 \\
\hline LNC & 6.1 & 8.6 & 5.0 & 7.0 & 5.8 & 7.4 \\
\hline IOA & 3.2 & 4.9 & 2.1 & 4.6 & 3.6 & 5.3 \\
\hline OTM & 8.0 & 9.6 & 7.5 & 9.6 & 7.0 & 8.6 \\
\hline OCL & 2.5 & 5.0 & 2.8 & 4.8 & 3.0 & 4.5 \\
\hline STL & 4.5 & 6.6 & 4.5 & 6.6 & 4.1 & 6.0 \\
\hline SPS & 3.3 & 6.1 & 2.9 & 5.0 & 5.2 & 6.8 \\
\hline
\end{tabular}

Note. Values are the minimum and maximum percent of body length (\%BDL), unless otherwise noted. Abbreviations and definitions can be found in Appendix 2. 
caudal filament (Figure 12). Pointed snout (13.3,11.1-18.9\% BDL, POB) and oval eyes, eye length (6.4, 5.6-6.9\% BDL, EYL) longer than eye height (4.9, 3.8-5.1\% BDL, EYH). Stocky torso section $(43.1,39.0-45.5 \%$ BDL, D1P2) $(27.9,23.2-32.5 \%$ BDL, D2P1) with

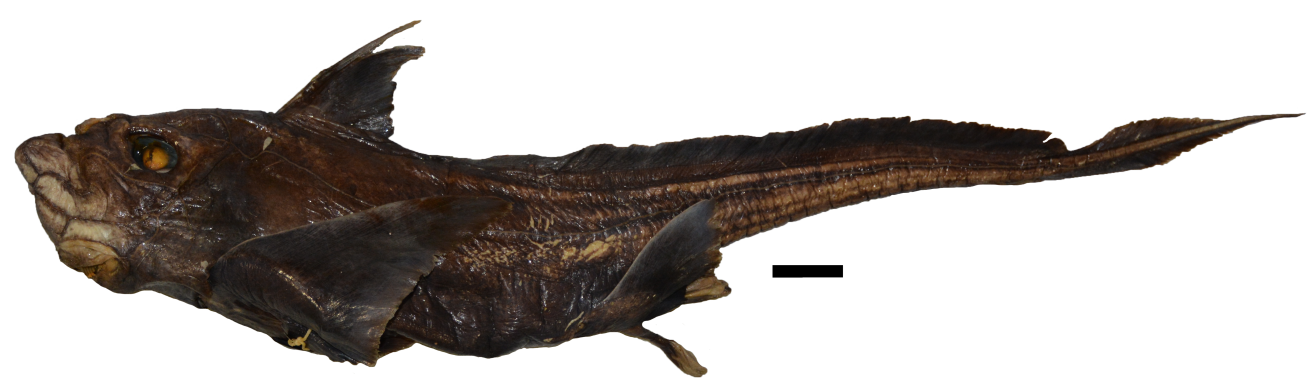

Figure 12. Hydrolagus affinis (SA) SAM 33297A, mature male, $935 \mathrm{~mm}$ TL, $613 \mathrm{~mm}$ BDL. Scale bar $=5 \mathrm{~cm}$.

a first dorsal-to-pectoral fin length (18.1, 14.8-20.9\% BDL, D1P1) shorter than the second dorsal-to-pelvic fin length (24.0, 19.2-27.8\% BDL, D2P2).

First dorsal fin height similar to, or slightly greater than base (13.7, 12.4-15.7\% BDL, D1H vs 13.5, 7.1-15.7\% BDL, D1B). Dorsal spine relatively straight (21.6, 18.1-25.6\% BDL, DSA) and mostly overlaps second dorsal fin origin when depressed. Wide range of interdorsal space (8.1, 2.4-11.5\% BDL, IDS) between first and second dorsal fins. Second dorsal fin long $(76.3,70.4-81.2 \%$ BDL, D2B), becoming slightly higher towards the posterior section $(3.6,2.6-4.7 \% \mathrm{D} 2 \mathrm{AH})(3.8,3.0-4.9 \% \mathrm{BDL}, \mathrm{D} 2 \mathrm{MH})(3.9,3.1-5.7 \% \mathrm{BDL}$, D2PH). Distance between origin of second dorsal fin (49.0, 44.5-53.2\% BDL, PD2) to insertion of pelvic fins $(63.8,56.0-73.3 \%$ BDL, PP2) averages $14.8 \%$ of body length. 
Dorsal caudal space very small (0.9, 0.0-1.8\% BDL, DCS). Caudal ventral margin (29.3, 22.3-34.5\% BDL, CVM) longer than caudal dorsal margin (20.2, 16.7-23.9\% BDL, $\mathrm{CDM})$, with a slightly taller caudal dorsal height (3.31, 2.6-4.1\% BDL, CDH) than ventral height $(2.9,2.3-4.1 \% \mathrm{BDL}, \mathrm{CVH})$.

Pectoral fins relatively narrow $(34.9,31.9-37.9 \%$ BDL, P1AM) $(19.5,17.6-21.7 \%$ BDL, P1FW) with rounded fin pads (10.6, 8.9-12.3\% BDL, P1BW)(10.1, 8.1-11.9\% BDL, P1BH). Pelvic fins oval and small (17.8, 16.4-19.8\% BDL, P2AM) (10.9, 9.712.0\% BDL, P2FW) with round fin pads (5.9, 4.3-6.9\% BDL, P2BW) (5.9, 4.9-7.3\% BDL, P2BH). Paired and unpaired fins remain intact upon preservation. Skin not deciduous, or flaking off in large patches. Skin damaged in some specimens as a result of preservation, but generally remains intact.

Claspers trifid, distal section of the dorsal and lateral branches fleshy pads with a fine covering of denticles extending approximately $30 \%$ of total clasper length. Medial (ventral) branch a slender stalk with a small, distal cap of flesh. Pre-pelvic tenaculae rectangular in shape with three to five spines. Frontal tenaculum robust, bulb oval in shape (lateral view) with length (1.9, 1.8-2.0 \% BDL, TBL) 1.5 times the bulb height $(1.3,1.0-1.5 \% \mathrm{BDL}, \mathrm{TBH})$ with small, tightly packed, curved spines. Bulb width (1.3, $1.2-1.5 \%$ BDL, TBW) twice the width of bulb stalk (0.66, 0.5-0.9\% BDL, TSW).

The branching pattern of the lateral line canals (oral (O), preopercular (POP) and infraorbital (IO)) is highly variable, exhibiting three branching patterns including ' $\mathrm{Y}$ ', ' $V$ ' and ' $\pi$ '. Only half of the specimens exhibit matching patterns on both sides of the face. 


\section{Color.}

Hydrolagus affinis specimens from southern Africa exhibit two distinctly different body color morphs: a tan and lilac form and a dark form (Figure 13). The

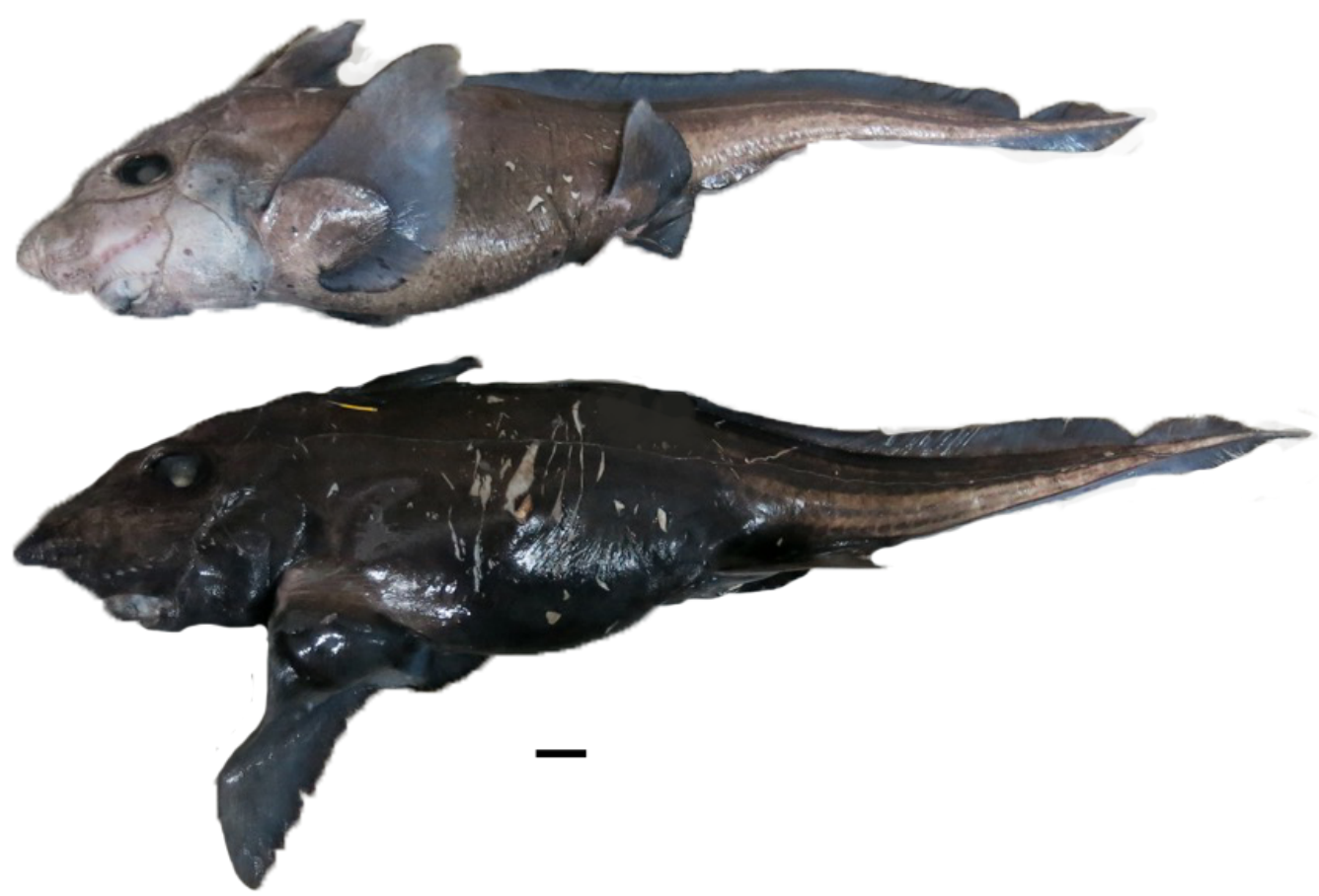

Figure 13. Two color variants of Hydrolagus affinis found in South Africa including a lighter morph (top; GN 16943) and a darker form (bottom; GN 16944). Scale bar $=5 \mathrm{~cm}$.

lighter bodied color morph is tan on its dorsal surface, becoming lighter ventrally with slight blue tones and a white to cream color face. Paired and unpaired fins a light blue to lilac color fading to whitish-tan along the distal margin of the pelvic fins. Blue-lilac coloration is most prominent along the second dorsal and caudal fins. Clasper stalks are dark brown to purple with tan fleshy pads. When preserved, specimens of the lighter 
color morph become light purple to pale brown in hue with distinctly lilac colored paired and dorsal fins and ventral surface.

The darker color morph is dark brown with purple tones over most of the body, except for a lighter brown color on ventral surface from insertion of pelvic fins rearward toward caudal fin and occasionally below the mouth. Some specimens have purple coloration of paired and dorsal fins and on the ventral surface of the snout. Claspers color dark brown and/or purple with tan fleshy pads. Frontal tenaculum dark brown on dorsal surface, usually matching the body coloration, and tan on the ventral surface. After preservation, specimens largely maintain their chocolate brown with dark purple prepreservation coloration. The tan color on ventral surface from insertion of the pelvic fins rearward toward the caudal fin and near the mouth remains after preservation. Fins become dark grey with a slight blue coloration.

\section{Distribution.}

Specimens collected from just south of the Orange River, in the Western Cape Province, near the Namibian border, south to Cape Town and eastwards to Port Elizabeth, Eastern Cape Province, South Africa along the continental shelf from depths ranging from $915-1,500 \mathrm{~m}$. One specimen was also collected from the Discovery Seamount in the Southeast Atlantic Ocean. A recent account identifies a H. affinis specimen from Namibia, but this record remains unconfirmed (Didier, 2016). 


\section{Biological Notes.}

The smallest mature male (SAM 34933) measured was $851 \mathrm{~mm}$ TL, $536 \mathrm{~mm}$ BDL indicating this species matures at by at least $536 \mathrm{~mm}$ BDL. This appears to be a much smaller size at maturity than similar species including the NA population of Hydrolagus affinis that reaches maturity at body lengths 660-685 mm (Ebert \& Stehmann, 2013). Maximum length observed is 1,069 mm TL, $719 \mathrm{~mm}$ BDL and 1,000 mm TL, $700 \mathrm{~mm}$ BDL for females and males, respectively. Egg cases have not been reported for this species. Nothing is known about the diet of this species, yet similar species are known to feed on benthic invertebrates (Didier et al. 2012).

\section{Comparisons.}

Hydrolagus affinis from southern Africa (SA) is compared to Hydrolagus trolli due to its tentative identification as $H$. cf. trolli in the literature and to the North Atlantic population of Hydrolagus affinis (Table 6). Percentages listed in parentheses are means of percent body length, calculated using the Tukey-Kramer HSD test followed by the measurement acronym for clarity.

Hydrolagus affinis from southern Africa has been tentatively identified as the Western Pacific species Hydrolagus trolli Didier \& Séret, 2002 based on a similar long snout and coloration. Overall, H. affinis (SA) is a more compact species than H. trolli with shorter pre-caudal length (122.9 vs. $128.2 \%$ BDL, PCL) and snout-to-vent length (62.3 vs. $68.3 \%$ BDL, SVL), as well as shorter pre-first dorsal length (27.3. vs. $32.2 \%$ 
BDL, PD1), pre-second dorsal length (49.0 vs. 53.0\% BDL, PD2) and pre-pelvic fin length (63.8 vs. $69.3 \%$ BDL, PP2).

Hydrolagus affinis (SA) was referred to in literature as 'pointy-nose blue' (Compagno, 1999), but it has a smaller snout length or pre-orbital length than true $H$. trolli specimens (13.3 vs. $16.9 \%$ BDL, POB). In addition, $H$. affinis (SA) has narrower pelvic fin widths (10.9 vs. $12.8 \%$ BDL, P2FW) and a larger spine (21.6 vs. $17.3 \%$ BDL, DSA) than H. trolli. Based on these morphological differences, we conclude that Hydrolagus affinis (SA) is not Hydrolagus trolli.

The morphometrics of $H$. affinis (SA) differ in several regards from North Atlantic (NA) Hydrolagus affinis including a shorter pre-second dorsal length (63.8 vs. $67.7 \%$ BDL, PP2), and smaller pelvic fins including the anterior margin (17.8 vs. 19.4\% BDL, P2AM) and width (10.9\% BDL, P2FW) than H. affinis (NA; 13.3\% BDL).

The prepelvic tenaculae spine count varies slightly, $H$. affinis (SA) has three to five spines, while the re-description of $H$. affinis (NA) describes four to six spines, but with higher samples size this discrepancy may not be present (Hardy \& Stehmann, 1990). The re-description of H. affinis (NA) by Hardy \& Stehmann (1990) describes the prepelvic tenaculae as deeply and broadly indented along the distal margin, compared to a relatively straight distal margin exhibited by $H$. affinis (SA) specimens. However, the degree of indentation of the distal margin may be affected by preservation; an examination of the underlying cartilage is necessary to determine if this is a truly variable trait of an effect of preservation. 
Based on the available samples, H. affinis (SA) appears to mature at lengths less than $536 \mathrm{~mm}$ BDL. This appears to be a much smaller size at maturity than $H$. affinis (NA) that reaches maturity at body lengths $660-685 \mathrm{~mm}$ BDL (Ebert \& Stehmann, 2013).

The darker H. affinis (SA) color morph is very similar, if not identical, to the coloration of the H. affinis (NA) population. Hydrolagus affinis (NA) is a uniform dark, purplish-brown color, with a slightly paler ventral portion of the tail and around mouth (Ebert \& Stehmann 2013; Hardy \& Stehmann, 1990). Hydrolagus affinis (SA) exhibits the same brown-to-purple coloration with a lighter ventral surface.

The majority of the morphological measurements of H. affinis (SA) fall within the reported ranges of the North Atlantic Hydrolagus affinis (de Brito Capello, 1868). These include snout-to-vent length (62.3 vs. $65.4 \%$ BDL, SVL), trunk length (38.6 vs. $39.4 \%$ BDL, TRL) and head length (26.2 vs. $27.1 \%$ HDL). Pectoral fin length (34.9 vs. $35.2 \%$ BDL, P1AM) and width (19.5 vs. 30.1\% BDL, P1FW) are similar, as well as first dorsal fin height (13.7 vs. $12.6 \% \mathrm{BDL}, \mathrm{D} 1 \mathrm{H})$ and spine height (21.6 vs. $19.4 \% \mathrm{BDL}, \mathrm{DSA})$. The known depth range of $H$. affinis (SA; 915-1,500 meters) is consistent with the depth profile of $H$. affinis (NA) found between 300 and 2,410 meters, but most common below 1,000 meters (Ebert \& Stehmann, 2013; Didier, 2016).

\section{Genetics.}

Tissues from three specimens were available for genetic analysis of the mitochondrial NADH2 marker. Genetic tissue samples were taken from a single Hydrolagus affinis 
specimen (GN 14842) by D. Ebert in May 2014, and from two additional specimens (GN 16943 \& 16844) collected in 2015 by Robin Leslie, DAFF.

Neighbor joining, parsimony and maximum likelihood analysis of the 1,004 bp NADH2 mitochondrial marker of three specimens yield similar tree topologies (Figure 14). Analysis indicates Hydrolagus affinis (SA) is a distinct species from $H$. trolli, $H$. pallidus and H. erithacus. However, based on this single mitochondrial marker, the southern African H. affinis cannot be distinguished from the North Atlantic Hydrolagus 


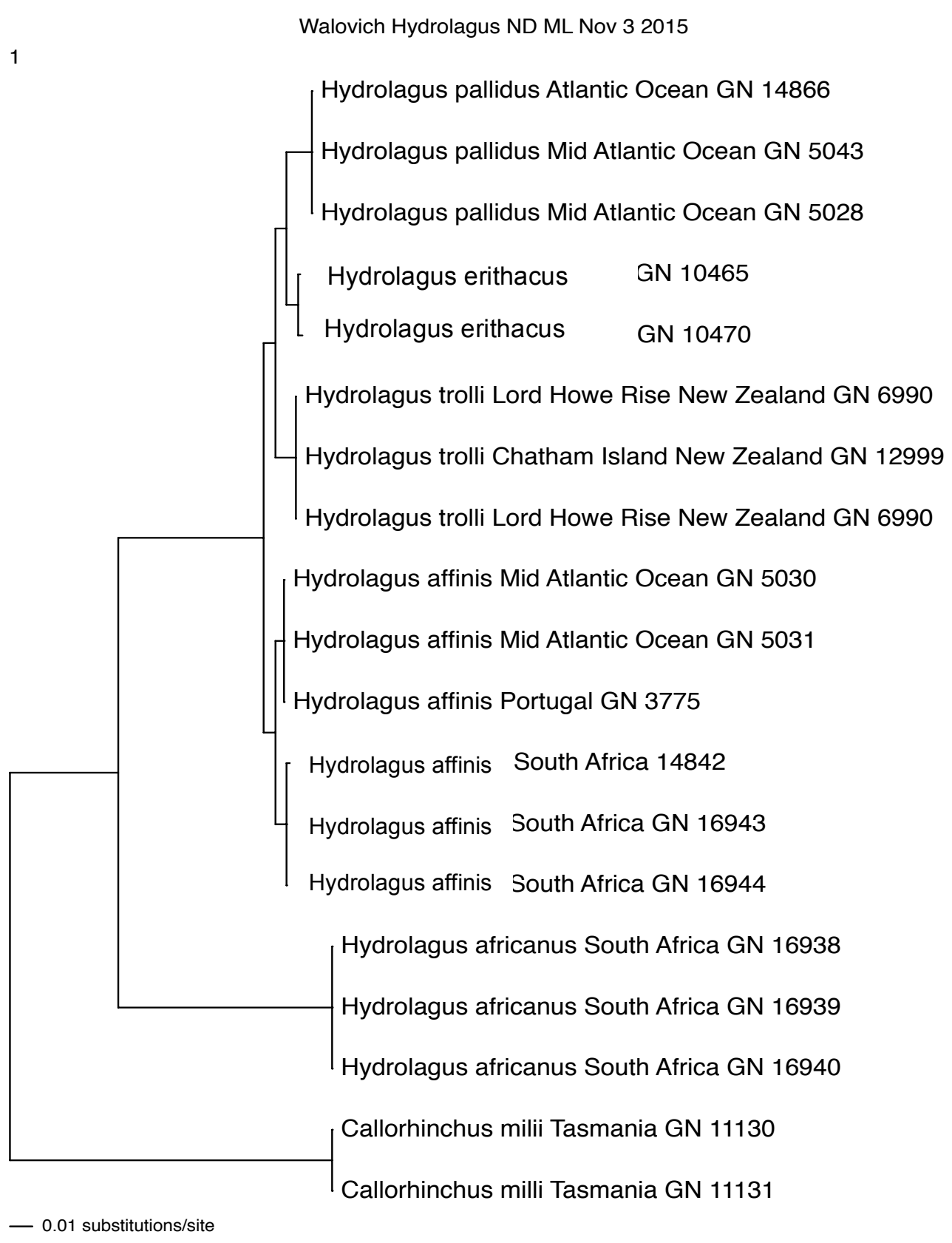

Figure 14. Maximum likelihood tree estimate using general-time reversible (GTR) + gamma model based on NADH2 sequence data of Hydrolagus affinis (SA and NA) and comparative species. 
affinis. For both the uncorrected p-distances and the GTR model the percent sequence divergence was very low: $0.13 \%$ among $H$. affinis (SA) specimens, $0.10 \%$ among $H$. affinis (NA) and 1.01\% sequence difference between $H$. affinis (SA) and H. affinis (NA) The genetic divergence observed between the two populations of $H$. affinis samples are comparable to the intraspecific variation seen among other chimaera species (Jenny Kemper, personal communication, June 15, 2015).

Members of the genus Hydrolagus are genetically very closely related, presenting challenges when delimiting new species (Kemper et al., 2015). Hydrolagus affinis (SA) may prove to be a new species given a larger sample size and analysis of additional genetic markers, but based on the current data it cannot be deemed a distinct species from H. affinis (NA).

\section{Statistical Analysis.}

Results of the n-MDS analysis of $H$. affinis (SA), H. affinis (NA) and H. trolli reveal little to no levels of dissimilarity visualized by a seemly random placement of representative points (Figure 15). ANOSIM analysis corroborates this assertion, suggesting limited separation among species groupings (Global $\mathrm{R}=0.262, \mathrm{p}=0.001$ ). Pairwise comparisons show similar low, yet statistically significant differences between species (Table 7). SIMPER analysis indicates pelvic fin width (P2FW) is the largest contributor, approximately $4 \%$, to the dissimilarity between the two $H$. affinis populations, which is consistent with morphological findings. In addition, the long snout 


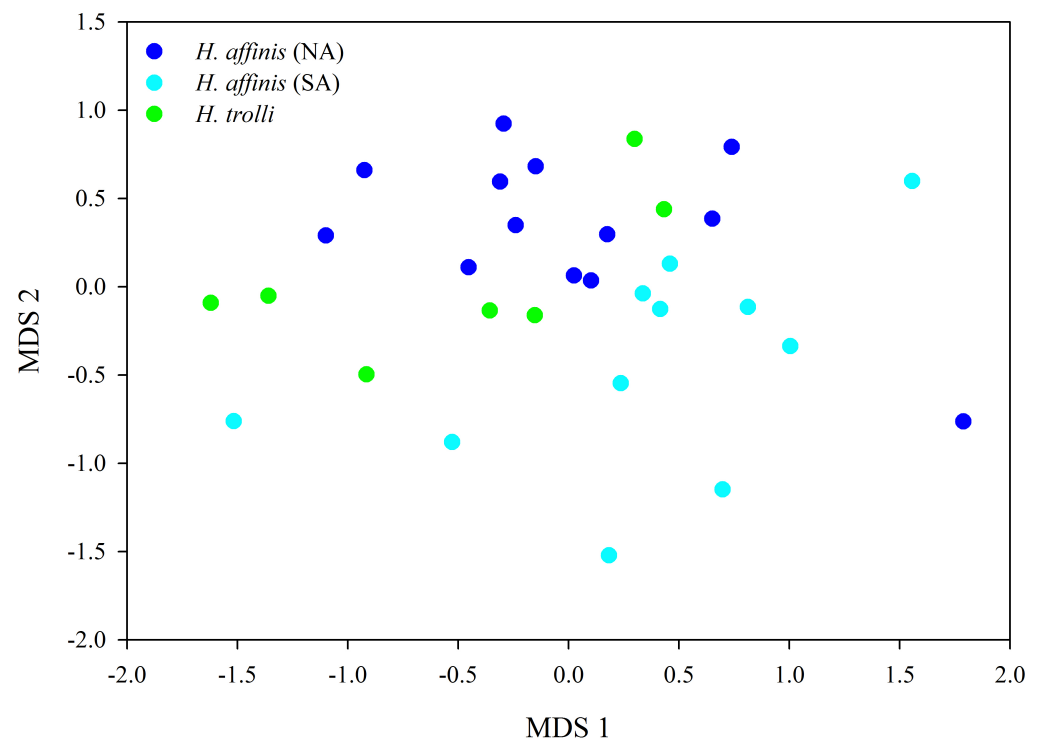

Figure 15. Two-dimensional non-Metric Multidimensional Scaling (n-MDS) plot comparing the morphological traits of the north Atlantic (dark blue) and southern African (light blue) H. affinis populations and H. trolli (green).

length (POB and POR) of H. trolli, considered a diagnostic to this species, is a top contributor to differences between this species and H. affinis.

\section{Discussion}

The initial identification of the species formerly known as $H$. cf. trolli has been disproven based on the combination of morphometric and genetic data. Few morphological characters separate H. trolli, H. affinis (NA), and H. affinis (SA), however genetic analysis reveals that the two populations of $H$. affinis from the North Atlantic and southern African regions are so genetically similar they cannot be deemed separate species. Currently the two Hydrolagus affinis populations appear to be allopatric 
Table 7

Analysis of Similarity (ANOSIM) and Similarity Percentage Analysis (SIMPER) Results for Differences Between H. affinis Populations and H. trolli

\begin{tabular}{|c|c|c|c|c|}
\hline \multirow[b]{2}{*}{ Species Groups } & \multicolumn{2}{|c|}{ ANOSIM Analysis } & \multicolumn{2}{|c|}{ SIMPER Analysis } \\
\hline & $\begin{array}{c}\mathrm{R} \\
\text { Statistic }\end{array}$ & $\begin{array}{c}\text { Significance } \\
\text { Level }(\%)\end{array}$ & Traits & $\begin{array}{c}\text { Contribution } \\
\%\end{array}$ \\
\hline \multirow[t]{3}{*}{ H. affinis (NA) \& H. affinis (SA) * } & 0.265 & 0.1 & $\mathrm{P} 2 \mathrm{FW}$ & 4.03 \\
\hline & & & TL & 2.99 \\
\hline & & & D1B & 2.90 \\
\hline \multirow[t]{3}{*}{ H. affinis (SA) \& H. trolli * } & 0.295 & 0.7 & PD1 & 4.14 \\
\hline & & & POB & 4.10 \\
\hline & & & PP2 & 3.64 \\
\hline \multirow[t]{3}{*}{ H. affinis (NA) \& H. trolli * } & 0.220 & 2.3 & $\mathrm{D} 1 \mathrm{H}$ & 4.49 \\
\hline & & & POB & 4.41 \\
\hline & & & POR & 3.96 \\
\hline
\end{tabular}

Note. An asterisk (*) denotes significant differences. Relative contributions of morphological traits to the differences between $H$. affinis (SA), $H$. affinis (NA) and $H$. trolli. Similarity percentage (SIMPER) analysis listed for each species comparision contributing most to dissimilarity.

(occupying different geographic areas), however the apparent lack of known populations in the regions between the North Atlantic and southern Africa is likely due to large information gaps along the west coast of Africa, east coast of South America and the deep ocean between. The only known species to occur in the vast southern Atlantic region is Hydrolagus matallanasi Soto \& Vooren, 2004 off the coast of Brazil (Soto \& Vooren, 2004). It is likely that a population of undiscovered H. affinis in the tropical and/or southern Atlantic exist in the region between the two populations exhibiting a gradient of morphological characters exhibiting continued gene flow. Based on the 
genetic and morphological findings of this and other recent work (Reichert, Lundsten \& Ebert, 2016) it appears this genus contains much wider ranging species than previously thought. New records and range extensions continue to expand our knowledge of chimaera distributions, indicating that some species once thought to be endemic or range restricted are much more widespread (Didier et al., 2012).

The amount of color variation across the entire $H$. affinis population combined with small morphological differences may appear to contradict the genetic information, however the use of color as a defining character has led to taxonomic confusion in many cases of Chondrichthyan identification (Last, White \& Séret, 2016). However, a recent surge in next-generation gene sequencing has resolved some of these issues by determining when color variants are in fact new species (Donnellan et al., 2015; Ball et al., 2016) and when species display a wide range of color variation (Last, White \& Séret, 2016). While color variation as a form of albinism or leucism (partial albinism) has been observed in more than thirty Chondrichthyan genera (Bigman, Knuckey \& Ebert, 2015), true non-albino color variation is rare and poorly documented (Reum et al., 2008).

The degree of intraspecific color variation exhibited within the southern African population of Hydrolagus affinis is notable. Intraspecific color variation in the genus Hydrolagus has not been reported in the literature and the reason for variable coloration within a species is currently unknown. The light and dark color morphs collected in 2015 (see Figure 13) were female, giving no evidence for sexual dimorphism. The three specimens were similar sizes, providing no evidence for ontogenetic changes in color (BDL: GN 14842=710mm, GN 16944=636mm* and GN 16843=553mm*). Two 
specimens were recovered on the same trawl; therefore depth doesn't appear to have influence on color. Based on such a small sample size these conclusions are tentative, a larger sample size is required to determine the true patterns in this trait. Despite the low samples size, the genetic analysis of the three specimens provides corroboration of a single species exhibiting distinct color variations.

The color variation exhibited by the southern African population of $H$. affinis further complicates the uncertainty regarding the use of color as a valid distinguishing trait in the genus. The North Atlantic species, H. affinis, H. pallidus and H. lusitanicus, exhibit a very similar set of morphological traits, but are distinguishable based on color to a fair degree of accuracy (C. Cotton, personal communication, September 20, 2016). According to current, yet limited genetic data $H$. affinis and $H$. pallidus are separate species (J. Kemper, personal communication, October 13, 2015). The identification of $H$. lusitanicus is questionable since the original description of $H$. lusitanicus did not use standard measurement methods for comparison to other Hydrolagus species, and did not provide any maximum size or size at maturity information, making comparisons with other Hydrolagus species nearly impossible (Moura et al., 2005). A genetic study conducted by the same authors found a $\sim 1.6 \%$ divergence in the COI mitochondrial maker between $H$. affinis and H. lusitanicus, providing weak evidence for species distinction (Moura, Silva \& Figueiredo, 2015). Hydrolagus lusitanicus may be a color variant of H. pallidus (Walovich et al., 2017; Weigmann, 2016). The darker southern African H. affinis color morph is consistent with the North Atlantic population, however the lighter color morph appears unique to the southern African region. A comprehensive, 
global genetic study of these three species will likely determine if this complex is three individual species or a wide ranging, single species with variable coloration.

The patterns of genetic structure of chimaeras, in fact most deep-sea Chondrichthyans, are largely unknown (Cunha et al., 2012). A comprehensive genetic analysis of the two $H$. affinis populations and other large bodied Hydrolagus including $H$. pallidus, H. lusitanicus, H. erithacus and $H$. trolli is necessary to determine the status of these species and their population structure. The outcome of such studies will greatly influence the trajectory of chimaeroid studies as well as conservation and management policies. 


\section{Discussion}

Chimaeroid species are very similar morphologically, making it difficult to identify distinguishing traits to characterize new species. Often the characters to differentiate species are few and subtle. For example, the three species of Callorhinchidae are nearly identical in morphology and coloration, yet are distinguished based on egg capsule morphology and geographical range (Didier et al., 2012). Rhinochimaera pacifica (Mitsukuri, 1895) and R. atlantica Holt \& Byrne, 1909 are differentiated by the counts of caudal tubercles along the dorsal caudal margin (Compagno et al., 1990). Within the Hydrolagus genus, almost all of the large bodied species have overlapping morphometrics, as demonstrated in Chapter 2. These minute physical differences, compounded by vague original descriptions and ranges, complicate the delineation of chimaera species further rendering them vulnerable to mis-identification and ultimately, exploitation or mis-management.

Circumstances independent of true morphological overlap can result in the misinterpretation of data, including small sample size or the effects of preservation. Small sample sizes can greatly alter the interpretation of data, leading to misrepresentative results. For example, dorsal spine length is a key trait to differentiate Chimaera obscura Didier, Last, \& White, 2008 and Chimaera macrospina Didier, Last, \& White, 2008, however when Kemper et al. (2015) increased specimen sample size, this characteristic overlapped between the two species. Perseveration of specimens can have significant impacts on some morphological measurements, which become more pronounced as specimen's age as demonstrated in Chapter 1. The continued acquisition of museum 
material helps mitigate these problems, and provided material for genetic analysis. As demonstrated in Chapter 3, the acquisition of genetic material cemented the identification of Hydrolagus affinis as an existing species rather than a new one when morphometrics were ambiguous.

The confusion caused by similar and overlapping morphological traits is compounded by the fact that many of the species are very close genetic relatives. Traditional morphological studies have been increasingly combined with genetic analysis to identify cryptic species and species complexes of Chondrichthyans and other taxa (Bickford et al., 2006; Dudgeon et al., 2012; Naylor et al., 2012; Straube et al., 2014). Several genes have been utilized to achieve these goals including nuclear DNA, microsatellites and mitochondrial DNA (COI, NADP2, 12s RNA and 16s RNA) (Dudgeon et al., 2012). Mitochondrial DNA (mtDNA) has been widely used in the study of cartilaginous fishes because of its compact size compared to nuclear DNA. mtDNA is maternally inherited and mutates faster than nuclear DNA, therefore achieving about twice the level of differentiation compared to nuclear markers (Heist, 2012). As a result, mtDNA genes like the mitochondrial cytochrome $c$ oxidase I (COI) gene and the protein coding nicotinamide adenine dinucleotide dehydrogenase subunit 2 (NADH2) are useful to distinguish phylogenetic relationships and stock structure (Moore et al., 2011; Naylor et al., 2012; Ward et al., 2009). Although the COI gene has become the de facto standard for 'DNA barcoding' efforts including the Barcode of Life Initiative, the 650 base pair COI sequence is both shorter (650 vs. 1044 bp) and evolves more slowly in Chondrichthyans than the NADH2 gene fragment (Naylor et al., 2012). Comprehensive 
genetic studies of chimaeroid fishes are limited (Human, Owen, Compagno \& Harley 2006; Inoue et al., 2010; Moura, Silva \& Figueiredo, 2015), but several studies have used the COI or NADH2 genes to identify new species (De La Cruz-Agüero et al., 2012; Kemper et al. 2015; Luchetti, Iglésias \& Sellos, 2011). Based on the sequence length and rate of evolution, the NADH2 gene was chosen to genetically differentiate the species in this study.

The tree topology of the maximum likelihood analysis of sequence data at the NADH2 gene locus suggests five distinct clades, corresponding to $H$. africanus, $H$. affinis. H. pallidus, H. trolli and H. erithacus (see Figure 14). Hydrolagus africanus is clearly distinguishable from the other four species based on sequence data. However, the remaining four species show limited sequence divergence at this locus, indicating two potential scenarios: (1) these are valid species, or (2) that they represent populations of a single species. The inference suggests separate species, since they fall out into their respective species lineages and show geographic structure. However, this topological pattern is also typical of little movement between populations of the same species, limiting gene flow due to isolation by distance. Interestingly, H. affinis and H. pallidus are known to overlap in distribution, and here, are recovered as their respective species, indicating two unique species. Based on the molecular data, H. erithacus appears to be a new species distinct from similar Hydrolagus species. We caution that this inference is the tree topology for only a single mitochondrial gene and may not correspond to the species tree based on multiple markers. To fully ascertain the relationships between these 
similar species, it may be necessary to analyze a suite of independent molecular markers and increased sample sizes to infer a robust species tree.

The question remains, if Hydrolagus species are so morphologically and genetically similar, how can we call them different species? The answer to "What is a species?" remains a contentious and vexing debate in systematics. Over twenty different species concepts have been developed to group species, based on criteria as diverse as morphological or molecular similarity, interbreeding and genealogical relationships (Richards, 2010). The biological species concept (BSC) developed by Ernst Mayr is the dominant definition, characterizing species as reproductively isolated, separate evolutionary lineages (Agapow et al., 2004; Mayr, 1942). However, the BSC has become controversial when considering allopatric populations, organisms that are difficult to observe or culture in the laboratory, extinct or rare species only available as preserved specimens or asexual organisms (Agapow et al., 2004). The development and application of molecular methods lead to the evolution of the phylogenetic species concept (PSC), commonly defined as a group of organisms that share at least one uniquely derived character with a shared pattern of ancestry and descent or monophyly ${ }^{5}$ (Nixon \& Wheeler, 1992; Wheeler \& Meier, 2000). Although most scientists agree that species represent biologically distinct entities, yet occasionally difficult to identify, the positives and negatives of each theory have spurned never-ending debate (Shaffer \& Thomson, 2007).

\footnotetext{
${ }^{5}$ A monophyletic taxon is defined as one that includes the most recent common ancestor of a group of organisms, and all of its descendants (Padial et al., 2010).
} 
Researchers do not always agree on a single species definition, leading to differing strategies and conclusions for delimiting species (Marshall et al., 2006). When species are 'old' and have had time to develop well-differentiated characters, most methods will lead researchers to the same conclusions. However, when species are newly derived and have not achieved monophyly, species delimitation can be difficult. Disparities in strategy or definition, the tendency to lump or split species and a phenomenon called 'count creep ${ }^{6}$, has contributed to alarming discrepancy in species counts (Hey, 2001). For example, Agapow et al. (2004) found the application of the BSC compared to the PSC resulted in a $300 \%$ increase in fungus species, a $259 \%$ increase in lichen species, a $137 \%$ increase among reptile species and an $87 \%$ increase among mammals. An integrated approach, combining the theoretical and operational components of various species definitions, is important to strengthen the validity of a new species description (Florio et al., 2012; Padial et al., 2010).

A multiple method approach, in this case morphometric and genetic analyses, is vital for accurate and practical species determinations. Analysis of morphology in order to provide a detailed physical characterization will always remain a vital component of delineation. When genetic analysis reveals distinct species, morphological analysis is still necessary data to identify the species in the future. As demonstrated in Chapter 3, when distinguishing morphological characters are minute, genetic analysis can provide the necessary additional information to define species. Neither technique is necessarily more reliable than the other, each presenting a different set of challenges. Morphometric

\footnotetext{
${ }^{6}$ The more specimens one looks at, the more differences observed and more species are postulated (Hey, 2001)
} 
analysis can be influenced by preservation and specimen damage, genetic analysis influenced by tissue degradation, and the choice and number of genetic markers selected. Both techniques are influenced by sample size. These potential shortcomings must be acknowledged, but when the two techniques are combined, these issues can be mitigated.

While the threshold criterion to delineate species is interpretable, the strongest case can be made using a multi-method approach. The process of identifying and formally naming new species is not always an exact science, but is a necessary first step.

\section{Conservation and Management of Chimaeroid Fishes}

Once species from this genus can be properly characterized and distinguished, the information will be used to provide data to fishery bycatch monitoring. Chimaeroids are caught throughout South African waters primarily as bycatch in the deep-water trawl fisheries for the deep-sea hake Merluccius paradoxus, one of the largest components of the marine fishery in South Africa (DAFF, 2013). In the last decade, the Patagonian toothfish (Dissostichus eleginoides) fishery within the South African EEZ around the Prince Edward Archipelago has developed into a mostly unmonitored deep-water fishery expansion that may threaten chimaeroid populations (Lombard et al., 2007). Operating at depths between 70 and 1,600 meters, chimaeroid bycatch has been reported, albeit in small numbers (R. Leslie, personal communication, 25 April 2016). It is not known if this is under-reporting or if the species is rarely encountered in this region. The landings of both the offshore hake trawling and Patagonian toothfish fisheries are problematic since they are not monitored during discharge to ensure catch information is verified and generic reporting of species is common (DAFF, 2013). In addition, intense international 
pressures against such catch may preclude accurate reporting. Although management strategies for trawl fisheries bycatch exist in South Africa (Walmsley et al., 2006), fisheries statistics for chimaeras are sparse to non-existent.

Accurate and reliable fishery statistics inform conservation and management information, both of which are largely lacking for chimaeras. Several international organizations including the Food and Agriculture Organization (FAO) have made significant efforts to protect Chondrichthyan species. The FAO introduced the International Plan of Action (IPOA, 1999) for Sharks, an initiation calling upon all states to develop and implement National Plans of Action (NPOA) to identify research, monitoring and management needs for Chondrichthyan fisheries (Fowler \& Cavanagh, 2005). The South African National Plan of Action for the Conservation and Management of Sharks was released in 2013, however its coverage of the Chimaeriformes species in the region is minimal (DAFF, 2013). The plan does not assess to the species level and even omits $C$. notafricana, despite its formal description three years earlier (Kemper et al., 2010). The IUCN is another organization dedicated to providing the information necessary to preserve Chondrichthyan species. The IUCN Red List of Threatened Species is a comprehensive, global approach to evaluate the conservation status of plants and animals by providing the assessments necessary to set priorities and guidelines for governments, non-government organizations and scientific institutions (IUCN, 2012). The IUCN classifies $49 \%$ of chimaeroid fishes as Data Deficient due to a lack of adequate information to make an assessment of extinction risk based on its distribution and/or population status (IUCN, 2012). Thirty-three percent (33\%) of southern African 
chimaeroids are currently classified as Data Deficient (N. pinnata, R. africana, and $H$. africanus). However, H. raleighana and $R$. atlantica could be considered regionally Data Deficient despite their global status as of Least Concern and when H. erithacus is evaluated it will likely receive Data Deficient status. These additional species increase the total of Data Deficient species in this region to a concerning sixty-seven percent (67\%). Based on the deep distribution of the Chimaeridae and Rhinochimaeridae families, most of the Data Deficient species may be classified as Least Concern when regionally assessed, but the lack of information still remains an issue. Many of these issues stem form a lack of taxonomic clarity, the resolution of which has become a priority for the FAO and IUCN (Dulvy et al., 2014; Ebert \& van Hees, 2015).

The international community has taken positive strides to manage and conserve Chondrichthyan populations, however chimaeroid fishes remain largely ignored or marginalized for a variety of reasons. Most apparent is the paucity of information regarding chimaeroid fishes. This fact is due to the inherent difficulty of obtaining specimens and the challenging task of identifying them based on poor or no formal descriptions and incomplete geographic distributions. Taxonomic resolution is the first step to discovering this missing chimaera information. The identification and description of all chimaeroid species in the southern African region will facilitate the development and dissemination of simple identification keys, reliable range maps and accurate illustrations or photographs to resource managers and fisheries observers. The resulting improvements in fisheries statistics and reporting facilitate accurate baseline catch data required to understand the impact of expanding deep-sea fisheries and to develop 
appropriate management and conservation strategies in the future. And finally, the formal description of southern African chimaera species forms the foundation for future studies to determine basic life history characteristics (age and growth, age at maturity, etc.), habitat associations, and other ecological and behavioral questions. 


\section{References}

Agapow, P., Bininda-Edmonds, O.R.P., Crandall, K.A., Gittleman, J.L., Mace, G.M., Marshall, J.C., \& Purvis, A. (2004). The impact of species concept on biodiversity studies. The Quarterly Review of Biology, 79 (2), 161-179.

Anderson, W.D., \& Pietsch, T.W. (1997). Collection Building: an Overview. In: T.W. Pietsch \& W.D. Anderson (Eds.), Collection Building in Ichthyology and Herpetology. (pp 3-10). Kansas: The American Society of Ichthyologists and Herpetologists.

Angulo, A., Lopez, M.I., Bussing, W.A. \& Murase, A. (2014). Records of chimaeroid fishes (Holocephali: Chimaeriformes) from the Pacific coast of Costa Rica, with the description of a new species of Chimaera (Chimaeridae) from the eastern Pacific Ocean. Zootaxa, 3861(6), 554-574.

Apuan, D.A., Torres, M.A.J., \& Demayo, C.G. (2010). Describing variations and taxonomic status of earthworms collected from selected areas in Misamis Oriental, Philippines using principal component and parsimony analysis. Egyptian Academic Journal of Biological Sciences, B Zoology, 2(1), 27-36.

Ball, R.E., Serra-Pereira, B., Ellis, J., Genner, M.J., Iglésias, S., Johnson, A.F., Jones, C.S., Leslie, R., Lewis, J.,Mariana, S.,Menezes, G., Neat, F.,Noble, L.R.,Sims, D.W., \& Griffiths, A.M. (2016). Resolving taxonomic uncertainty in vulnerable elasmobranchs: are the Madiera skate (Raja maderensis) and the thornback ray (Raja clavata) distinct species? Conservation Genetics. doi/10.1007/s10592-0150806-1

Barnard, K.H. (1925). A monograph of the marine fishes of South Africa. Part 1(Amphioxus, Cyclostomata, Elasmobranchii, and Teleostei-Isopondyli to Hetersomata). Annals of the South African Museum, 21(1), 1-418.

Barnett, L.A.K., Didier, D.A., Long D.L. \& Ebert, D.A. (2006). Hydrolagus mccokseri sp. nov., a new species of chimaeroid fish from the Galápagos Islands (Holocephali: Chimaeriformes: Chimaeridae). Zootaxa, 1328, 27-38.

Bickford, D., Lohman, D.J., Sodhi, N.S., Ng, P.K.L., Meier, R., Winker, K., Ingram, K.K., \& Das, I. (2006). Cryptic species and a window on diversity and conservation. Trends in Ecology and Evolution, 22 (3), 148-155. 
Blackwelder, R.I., (1967). Taxonomy: A text and Reference Book. New York, NY: Wiley.

Bigelow, H.B., \& Schroeder, W.C. (1953). Fishes of the Western North Atlantic. Memoirs of the Sears Foundation for Marine Research. 1 (2), 1-588.

Bigman, J.S., Knuckey J.D.S., \& Ebert, D.A. (2015). Color aberrations in Chondrichthyan fishes: first records in the genus Bathyraja (Chondrichthyes: Rajiformes: Arhynchobatidae). Marine Biodiversity Records. doi/10.1007/s12526-015-0403-z

Briggs, J.C. (1995). Global Biogeography. Amsterdam: Elsevier.

Brown, A.C. (1997). John DF Gilchrist and the early years of marine science in South Africa. Transactions of the Royal Society of South Africa, 52 (1), 2-16.

Campana, S.E. (2001) Accuracy, precision and quality control in age determination, including a review of the use and abuse of age validation methods. Journal of Fish Biology, 59(2), 197-242.

Compagno, L.J.V. (1986). Families Pristidae, Torpinidae, Narkidae, Rhinobatidae, Myliobatidae, Mobulidae, Dasyatidae, Callorhinichidae, Chimaeridae, Rhinochimaeridae. (pp.144-148). In M.M. Smith \& P.C. Heemstra (Eds.). Smith's Sea Fishes, Johannesburg: Macmillian.

Compagno, L.V.J. (1999). An overview of Chondrichthyan systematic and biodiversity in southern Africa. Transactions of the Royal Society of South Africa, 45(1), 75-120.

Compagno, L.J.V., Ebert, D.A., \& Smale M.J. (1989). Guide to the Sharks and Rays of southern Africa. London: New Holland.

Compagno, L.V.J., Stehmann M., \& Ebert D.A. (1990). Rhinochimaera africana, a new longnose chimaera from southern Africa, with comments on the systematics and distribution of the genus Rhinochimaera Garman, 1901 (Chondrichthyes, Chimaeriformes, Rhinochimaeridae). South African Journal of Marine Science, 9, 201-222.

Compagno, L.V.J., Ebert, D.A., \& Cowley, P.D. (1991). Distribution of offshore demersal cartilaginous fish (Class Chondrichthyes) off the west coast of southern Africa, with notes on their systematics. South African Journal of Marine Science, 11,43-139. 
Compagno LJV, Musick JA (2005) Deepwater Species. In S.L. Fowler, R.D. Cavanagh, M. Camhi, G.H. Burgess, G.M. Cailliet, S.J. Fordham, C.A. Simpfendorfer \& J.A. Musick(Eds.), Sharks, Rays and Chimaeras: the status of the Chondrichthyan Fishes. Status Survey (pp 216-217). Gland \& Cambridge: IUCN/SSC Shark Specialist Group.

Cunha, R.L., Cosia, I., Madiera, C., Mariana, S., Stefanni, S., \& Castilho, R. (2012). Ancient Divergence in the Trans-Oceanic Deep Sea Shark Centroscymnus crepidater. PLOS One, 7(11), 1-13.

DAFF (Department of Agriculture, Forestry and Fisheries) (2013). National Plan of Action for the Conservation and Management of Sharks (NPOA-Sharks): 1-34.

DAFF (Department of Agriculture, Forestry and Fisheries) (2012). Status of the South African Marine Fishery Resources 2012: 1-44.

De La Cruz-Agüero, J., García-Rodríguez, F.J., Cota-Gómez, V.M., Melo-Barrera, N., \& González-Armas, R. (2012). Morphometric and molecular data on two mitochondrial genes of a newly discovered Chimaeran fish (Hydrolagus melanophasma, Chondrichthyes). Ocean Science Journal, 47(2), 147-153.

de Queiroz, K. (1998). The general lineage concept of species, species criteria, and the process of speciation: A conceptual unification and terminological recommendations. In D. J. Howard \& S. H. Berlocher (Eds.). Endless Forms: Species and speciation. (pp. 57-75). New York: Oxford University Press.

Didier, D.A. (1995). Phylogenetic systematic of extant chimeroid fishes (Holocephali, Chimaeroidei). American Museum Novitates, 3119, 1-86.

Didier, D.A., \& Nakaya, K. (1999). Redescription of Rhinochimaera pacifica (Mitsukurii) and first record $R$. africana Compagno, Stehmann \& Ebert from Japan (Chimaeriformes: Rhinochimaeridae). Ichthyological Research, 46(2), 139152.

Didier, D.A. (2008). Two new species of the genus Hydrolagus Gill (Holocephalii: Chimaeridae) from Australia. In Last P.R., White W.T., \& Pogonoski J.J. (Eds.), Descriptions of New Australian Chondrichthyans (pp. 349-356). CSIRO Marine and Atmospheric Research Paper Number 022.

Didier, D.A. (2016). Chimaeras. In K.E. Carpenter, \& N. De Angelis. (Eds). The living marine resources of the Western Central Atlantic. Volume 2: Bivalves, gastropods, hagfishes, sharks, batoid fishes, and chimaeras (pp. 1441-1456). FAO Species Identification Guide for Fisheries Purposes. Rome: FAO. 
Didier, D.A. \& Séret, B. (2002). Chimeroid fishes of New Caledonia with description of a new species of Hydrolagus (Chondrichthyes, Holocephali). Cymbium, 26(3), 225-233.

Didier, D.A., Kemper, J.M. \& Ebert, D.A. (2012). Phylogeny, Biology and Classification of Extant Holocephalans. In J.C. Carrier, J.A. Musick \& M.R. Heithaus (Eds.) The Biology of Sharks and Their Relatives $2^{\text {nd }}$ Edition. (pp. 97-122). Boca Raton: CRC Press.

Donnellan S.C., Foster R., Junge C., Huveneers C., Rogers P., Kilian A., \& Bertozzi T. (2015). Fiddling with the proof: the Magpie Fiddle Ray is a colour pattern variant of the common southern Fiddler Ray (Rhinobatidae: Trygonorrhina). Zootaxa, 3981(3), 367-384.

Dudgeon, C.L., Blower, D.C., Broderick, D., Giles, J.L., Holmes, B.J., Kasiwagi, T., Krück, N.C., Morgan, J.A.T., Tillett, B.J., \& Ovenden, J.R. (2012). A review of the application of molecular genetics for fisheries management and conservation of sharks and rays. Journal of Fish Biology, 80, 1789-1843.

Dulvy, N.K., Fowler, S.L., Musick, J.A., Cavanagh, R.D., Kyne, P.M., Harrison, L.R., Carlson, J.K., Davisson, L.N.K., Fordham, S.V., Francis, M.P., Pollock, C.M., Simpfendorfer, C.A., Burgess, G.H., Carpenter, K.E., Compagno, L.J.V., Ebert, D.A., Gibson, C., Heupel, M.R., Livingstone, S.P., Sanciangco, J.C., Stevens, J.D., Valenti, S., \& White, W.T. (2014). Extinction risk and conservations of the world's sharks and rays. eLife: e00590. doi 10.7554/eLife.00590

Duméril, A. (1865). Histoire naturelle des poissons ou ichtyologie générale. Tome premier. Elasmobranches, plagiostomes et holocephales, ou chimères. Première partie. Librairie encyclopédique de Roret, Paris.France.

Eschmeyer, W.N., \& Frinckle, R. (eds) (2014). Catalog of Fishes electronic version. (updated 19 May 2014) Available http://research.calacademy.org/ichthyology/catalog/fishecatsearch. [accessed 12 March 2014]

Ebert, D.A. (2014). Deep-sea Cartilaginous Fishes of the Indian Ocean. Volume 2: Batoids and Chimaeras. FAO Species Catalogue for Fishery Purposes. 8(2), Rome: FAO.

Ebert, D.A. (2015). Deep-sea cartilaginous fishes of the Southeastern Atlantic Ocean. FAO Species Catalogue for Fishery Purposes. 9. Rome: FAO. 
Ebert, D.A., Ho, H., White, W.T., \& de Carvalho, M.R. (2013). Introduction to the systematics and biodiversity of sharks, rays and chimaeras (Chondrichthyes) of Taiwan. Zootaxa, 3752(1), 005-019.

Ebert, D.A. \&. Stehmann. M.F.W (2013), Sharks, batoids, and chimaeras of the North Atlantic. FAO Species Catalogue for Fishery Purposes. No. 7. Rome, Italy: FAO.

Ebert, D.A. \& van Hees, K.E. (2015) Beyond Jaws: rediscovering the 'lost' sharks of southern Africa. African Journal of Marine Science, 37 (2), 141-156.

FAO (1999) International Plan of Action for the Conservation and Management of Sharks. Food and Agriculture Organization of the United Nations. Rome.

FAO (2011) Report of the workshop on the deep-sea species identification. Food and Agriculture Organization of the United Nations Fisheries and Aquaculture Report No 947. Rome.

FAO (2013). International Plan of Action for the Conservation and Management of Sharks In: FAO Fisheries and Aquaculture Department [online]. Rome. Updated. Available at .http://www.fao.org/fishery/ipoa-sharks/en

Felsenstein, J. (1985). Confidence limits on phylogenies: An approach using the bootstrap. Evolution, 39, 783-791.

Florio, A.M., Ingram, C.M., Rakotondravony, H.A., Louis, E.E., \& Raxworthy, C.L. (2012), Detecting cryptic speciation in the widespread and morphologically conservative carpet chameleon (Furcifer lateralis) of Madagascar. Journal of Evolutionary Biology, 25, 1339-1414.

Fowler, H.W. (1941). The fishes of the groups Elasmobranchii, Holocephali, Isopondyli, and Ostariophysi obtained by the United States Bureau of Fisheries Steamer Albatross in 1907 and 1910, chiefly in the Philippine Islands and adjacent seas. Bulletin of the United States National Museum, 100(13), 1-879.

Fowler, S.L. \& Cavanagh, R.D. (2005). Chapter 6: International Conservation and Management Initiatives for Chondrichthyan Fish. In S.L. Fowler, R.D. Cavanagh, M. Camhi, G.H. Burgess, G.M. Cailliet, S.J. Fordham, C.A. Simpfendorfer \& J.A. Musick(Eds.), Sharks, Rays and Chimaeras: the status of the Chondrichthyan Fishes. Status Survey (pp. 58-69). Gland \& Cambridge: IUCN/SSC Shark Specialist Group. 
Francis, M.P. (2006) Morphometric minefields-towards a measurement standard for Chondrichthyan fishes. Environmental Biology of Fishes, 77, 407-421.

Gilchrist, J.D.F. (1922). Deep-sea fishes procured by the S.S 'Pickle' (Part 1). Special Report (3), Report of the Fisheries and Marine Biological Survey, Union of South Africa, (2): 41-79.

Gotelli, N.J., \& Ellison, M. (2013). A primer of Ecological Statistics (2 ${ }^{\text {nd }}$ ed). Massachusetts: Sinauer Assocociates.

Hardy, G.S. \& Stehmann, M. (1990). A new deep-water ghost shark, Hydrolagus pallidus n.sp. (Holocephali, Chimaeridae), from the Eastern North Atlantic, and redescription of Hydrolagus affinis (Brito Capello, 1867). Archiv für Fischereiwissenschaft, 40, 229-248.

Hey, J. (2001). Genes, Categories and Species: the Evolutionary and Cognitive Causes of the Species Problem. Oxford University Press: Oxford.

Heist, E.J. (2012). Genetics of Sharks, Skates, and Rays. In J.C. Carrier, J.A. Musick \& M.R. Heithaus (Eds.), The Biology of Sharks and Their Relatives $\left(2^{\text {nd }}\right.$ ed., pp 487504). Boca Raton: CRC Press.

Hoenig, J.M., \& Gruber, S.H. (1990). Life-history patterns in Elasmobranchs: Implications for fisheries management. In H.L.J Pratt, S.H. Gruber, \& T.Taniuchi (Eds.). Elasmobranchs as living resources: advances in the biology, ecology, systematics and the status of the fisheries. NOAA Technical Report 90.

Human, B.A., Owen, E.P., Compagno, L.J.V., \& Harley, E.H. (2006). Testing morphologically based phylogenetic theories within cartilaginous fishes with molecular data, with species references to the catshark family (Chondrichthyes; Scyliorhinidae) and the interrelationships between them. Molecular Phylogenetics and Evolution, 39(2), 384-391.

ICZN (2008). International Code of Zoological Nomenclature ( $4^{\text {th }}$ ed.). London: The International Trust for Zoological Nomenclature.

Iglésias, S.P., Toulhoat, L., \& Sellos, D.Y. (2010). Taxonomic confusion and market mislabeling of threatened skates: important consequences for their conservation status. Aquatic Conservation: Marine and Freshwater Ecosystems, 20, 319-333. 
Inoue, J.G., Miya, M., Lam, K., Boon-Hui, T.,Danks, J.A., Bell, B., Walker, T.I., \& Venkatesh, B. (2010). Evolutionary origin and phylogeny of the modern Holocephalans (Chondrichthyes: Chimaeriformes): A mitogenomic perspective. Molecular Biology and Evolution, 27(11), 2576-2586.

IUCN. (2012). IUCN Red List Categories and Criteria: Version 3.1. ( $2^{\text {nd }}$ ed). Gland, Switzerland and Cambridge, UK: IUCN.

James, K., Ebert, D.A., Long, D.J. \& Didier, D.A. (2009). A new species of chimaera, Hydrolagus melanophasma sp. nov. (Chondrichthyes: Chimaeriformes: Chimaeridae), from the eastern North Pacific. Zootaxa, 2218, 59-68.

Kemper, J.M., Ebert, D.A., Compagno, L.V.J. \& Didier, D.A. (2010). Chimaera notafricana sp. nov. (Chondrichthyes: Chimaeriformes: Chimaeridae), a new species of chimaera from southern Africa. Zootaxa, 2532, 55-63.

Kemper, J.M., Ebert, D.A., Naylor, G.J.P. \& Didier, DA. (2015). Chimaera carophila (Chondrichthyes: Chimaeriformes: Chimaeridae), a new species of chimaera from New Zealand. Bulletin of Marine Science, 91(1), 1-18.

Krefft, G. (1990). Chimaeridae. In J.C. Quéro, C. Hureau, A. Karrer, A. Post, \& L. Saldanha (Eds). Check-list of the fishes of the eastern tropical Atlantic (pp. 111113). Paris: UNESCO.

Kucharczyk, H., Kucharczyk, M., Stanisławek, K., \& Fedor, P. (2012). Application of PCA in Taxonomy Research - Thrips (Insecta, Thysanoptera) as a Model Group. In P. Sanguansat (Ed.) Principal Component Analysis - Multidisciplinary Applications, InTech, pp. 111-126.

Kyne, P.M., \& Simpfendorfer, C.A. (2007). A Collation and summarization of available data on deepwater Chondrichthyans: Biodiversity, life histories and fisheries. Biodiversity, Life History and Fisheries IUCN SSC Shark specialist Group for the Marine Conservation Biology Institute.

Last, P.R., White W.T. \& Séret, B. (2016). Taxonomic status of muskrays of the Neotrygon kuhlii species complex (Myliobatoidei:Dasyatidae) with the description of three new species from the Indo-West Pacific. Zootaxa, 4083(4), 533-561.

Licht, M., Schmuecker, L., Hanel, R., Bartsch, P., \& Paeckert, M. (2012). Contribution to the molecularphylogenetic analysis of extant holocephalan fishes (Holocephali: Chimaeriformes). Organisms, Diversity and Evolution, 12 (4), 421-432. 
Linnaeus. C., (1758). Systema naturae per regna tria naturae, secundum classes, ordinus, genera, species, cum characteribus, differentiis, synonymis, locis. Tomus I. Editio decima, reformata. Impensis Direct. Laurentii Salvii, Holmiae.

Lloris, D. (1986). Ictiofauna demersal y aspectos biogeograficos de la costa Sudoccidental de Africa (SWA/NAMIBIA) Monografias de zoologia marino. Instituto de Ciencias del Mar, Barcelona. Consejo Superior de Investigaciones Cientificas 1, 429.

Lombard A.T., Reyers B.,Schonegevel L.,Cooper J., Smith-Adao L., Nel D.,Froneman W.,Ansorge I.,Bester M.,Tosh C.,Strauss T., Akkers T.,Gon O., Leslie R., \& Chown S., (2007). Conserving pattern and process in the southern Ocean: designing a Marine Protected Area for the Prince Edward Islands. Antarctic Science, 19(1), 39-54.

Luchetti, E.A., Iglésias, S.P. \& Sellos, D.Y. (2015) Chimaera opalescens n. sp., a new chimaeroid (Chondrichthyes: Holocephali) from the north-eastern Atlantic Ocean. Journal of Fish Biology, 79, 399-417.

Macpherson, E., \& Roel, B.A. (1987). Trophic relationships in the demersal fish community off Namibia. South African Journal of Marine Science, 5, 585-596.

Moura, T., Figueiredo, I., Bordalo-Machado, P., Almeida, C. \& Gordo, L.S. (2005). A new deep-water chimaeroid species, Hydrolagus lusitanicus n. sp., from off mainland Portugal with a proposal of a new identification key for the genus Hydrolagus (Holocephali: Chimaeridae) in the north-east Atlantic. Journal of Fish Biology. 67, 742-751.

Marshall, J.C., Arevalo, E., Benavides, E., Sites, J.L., \& Sites, J.W. (2006). Delimiting species: Comparing methods for mendelian characters using lizards of the Sceloporus grammicus (Squamata:Phrynosomatidae) complex. Evolution, 60, 1050-1065.

Mayr, E. (1942). Systematics and the Origins of Species from the Viewpoint of a Zoologist. New York: Columbia University Press.

Moore, J.A., Vecchione, M., Bollette, B.B., Gibbons, R., Hartel, K.E., Galbraith, J.K., Turnipseed, M., Southworth, M., \& Watkins, E. (2003). The diversity of Bear Seamount, New England Seamount Chain: results of Exploratory Trawling. Journal of Northwest Atlantic Fisheries Science, 31, 363-372. 
Moura, T., Figueiredo, I., Bordalo-Machado, P., Almeida, C., \& Gordo, S. (2005) A new deep-water chimaeroid species, Hydrolagus lusitanicus n. sp., from off mainland Portugal with a proposal of a new identification key for the genus Hydrolagus (Holocephali: Chimaeridae) in the north-east Atlantic. Journal of Fish Biology, $67,742-751$.

Moura, T., Silva, M.C. \& Figueiredo, I. (2015). Barcoding deep-water Chondrichthyans $\mathrm{f}$ rom mainland Portugal. Marine and Freshwater Research, 66, 508-517. http://dx.doi.org/10.1071/MF14095

Naylor, G.J.P., Ryburn, J.A., Fedrigo, O. \& Lopez, J.A. (2005). Phylogenetic relationships among the major lineages of modern elasmobranchs. (pp. 1-25). In W.C. Hamlett (ed.). Reproductive biology and phylogeny of Chondrichthyes: sharks, batoids and chimaeras, Volume 3. Enfield: Science Publishers, Inc.

Naylor, G.J.P., Caira, J.N., Jensen, K., Rosana, A.M., White, W.T., \& Last, P.R. (2012). A DNA-sequence-based approach to the identification of shark and ray species and its implications for global elasmobranch diversity and parasitology. Bulletin of the American Museum of Natural History, 367, 1-262.

Neer, J.A., \& Cailliet, G.M. (2001) Aspects of the life history of the Pacific electric ray, Torpedo californica (Ayres). Copeia, 842-847.

Nixon, K.C., \& Wheeler, Q.D. (1990). An amplification of phylogenetic species concept. Cladistics, 6, 211-223.

Norman, J.R. (1935). Coast fishes. Part 1. The South Atlantic 'Discovery Reports', 12, $1-58$.

Novikov, N.P. (2002). Ecology of the ratfish Hydrolagus africanus (Gilchrist) from the Madagascar and Mozambique submarine ridges. Journal of Icthyology, 42(3), 271-274.

Padial, J.M., Miralles, A., De la Riva, I., \& Vences, M. (2010). The integrative future of taxonomy. Frontiers in Zoology, 7(16), 1-14.

Pakhomov, E.A., Bushula, T., Kaehler, S., Watkins, B.P., \& Leslie, R.W. (2006). Structure and distribution of the slope fish community in the vicinity of the subAntarctic Prince Edward Archipelago. Journal of Fish Biology, 68, 1834-1866. 
Parin, N.V., Timokhin, I.G., Novikov, N.P., \& Shcherbachev, Y. (2008). On the Composition of Talassobathyal Ichthyofauna and Commercial Productivity of Mozambique Seamount (the Indian Ocean). Journal of Ichthyology, 48(5), 361366.

Pauly,D., Alder, J., Bennett, E., Christensen, V., Tyedmers, P., \& Watson, R. (2003) The future for fisheries. Science, 302, 1359-1361.

Quaranta, K.L., Didier, D.A., Long, D.J. \& Ebert, D.A. (2006). A new species of chimaeroid, Hydrolagus alphus sp. nov. (Chimaeriformes:Chimaeridae) from the Galapagos Islands. Zootaxa 1377, 33-45.

Reichert, A.N., Lundsten, L. \& Ebert, D.A. (2016). First North Pacific records of the pointy nose blue chimaera, Hydrolagus cf. trolli (Chondrichthyes: Chimaeriformes: Chimaeridae). Marine Biodiversity Records, 9 (90). DOI 10.1186/s41200-016-0095-5

Reum, J.C.P., Paulsen, C.E., Pietsch T.W., \& Parker-Stetter S.L. (2008). First record of an albino Chimaeriform fish, Hydrolagus colliei. Northwestern Naturalist, 89, 60-62.

Richards, R.A. (2010). The Species Problem. Cambridge: Cambridge University Press.

Roa, R., Ernst, B., \& Tapia, F. (1999). Estimation of size at sexual maturity: an evaluation of analytical and resampling procedure. Fisheries Bulletin, 97, 570580 .

Roel, B.A. (1987) Demersal communities off the west coast of South Africa. South African Journal of Marine Science, 5, 575-584.

Sabaj M.H. (ed.) (2016). Standard symbolic codes for institutional resource collections in herpetology and ichthyology: an Online Reference. Version 6.5 (16 August 2016). Electronically accessible at http://www.asih.org/, American Society of Ichthyologists and Herpetologists, Washington, DC.

Shafer, H.B., \& Thomson, R.C. (2007). Delimiting Species in Recent Radiations. Systematic Biology, 56(6), 869-906.

Shcherbachev, Y., Dolganov, V.N., \& Timokhin, I.G. (1982). Deepwater cartilaginous fish (Chondrichthyes) from the waters of the southern hemisphere. Poorly Studied fish of the Open Ocean, 6-31. 
Simpfendorfer, C.A., Heupel, M.R., White, W.T., \& Dulvy, N.K. (2011). The importance of research and public opinion of conservation management of sharks and rays: a synthesis. Marine and Freshwater Research, 62, 518-527.

Smith, J.L.B. (1949). The Sea Fishes of southern Africa. Cape Town, South Africa: Central News Agency Ltd.

Smith, J.L.B. (1961). The Sea Fishes of southern Africa. Cape Town, South Africa: Central News Agency Ltd.

Smith, J.L.B. (1965). The Sea Fishes of southern Africa. (5th ed.). Cape Town, South Africa: Central News Agency Ltd.

Soto, J.M.R., Vooren, C.M. (2004). Hydrolagus matallanasi sp. nov. (Holocephali, Chimaeridae) a new species of rabbitfish from southern Brazil. Zootaxa, 678, $1-10$.

Stevenson, D. E., Orr, J.W., Hoff, G.R. \& McEachran, J.D. (2007) Field guide to sharks, skates, and ratfish of Alaska. Fairbanks: Alaska Sea Grant College Program, University of Alaska Fairbanks.

Stamatakis, A. (2014) RAxML version 8: a tool for phylogenetic analysis and postanalysis of large phylogenies. Bioinformatics, 30(9), 1312-1313.

Straube, N., Leslie, R.W., Clerkin, P.J., Ebert, D.A., Rochel, E., Corrigan, S., Li, C.,\& Naylor, G.J.P. (2015). On the occurrence of the southern Lanternshark, Etmopterus granulosus, off South Africa, with comments on the validity of $E$. compagnoi. Deep-sea Research II, 115, 11-17.

Van der Peer, Y. (2009). Phylogenetic inference based on distance methods. In P. Lemey, M. Salemi, \& A. Vandamm (eds). The Phylogenetic Handbook: a Practical Approach to Phylogenetic Analysis and Hypothesis Testing. (pp. 142-180). Cambridge University Press.

Veríssimo, A., Cotton, C.F., Buch, R.H., Gullart, J., \& Burgess, G.H. (2014). Species diversity of the deep-water gulper sharks (Squaliformes: Centrophoridae: Centrophorus) in North Atlantic waters -current status and taxonomic issues. Zoological Journal of Linnean Society, 172, 803-830. 
Walovich, K.A., Ebert, D.A., Long, D.J. \& Didier, D.A. (2015). Redescription of Hydrolagus africanus (Gilchrist, 1922) (Chimaeriformes: Chimaeridae), with a review of southern African chimaeroids and a key to their identification. African Journal of Marine Science, 37(2), 157-165.

Walovich, K.A., Ebert, D.A. \& Kemper, J.M. (2017). Hydrolagus erithacus sp. nov. (Chimaeriformes: Chimaeridae), a new species of chimaerid from southeastern Atlantic and southwestern Indian oceans. Zootaxa,4226 (4): 509-520.

Ward, R.D., Hanner, R., \& Herbert, P.D.N. (2009). The campaign to DNA barcode all fishes, FISH-BOL. Journal of Fish Biology, 74, 239-356.

Weigmann, S. (2016). Annotated checklist of the living sharks, batoids and chimaeras (Chondrichthyans) of the world, with a focus on biogeographical diversity. Journal of Fish Biology, 88 (3), 837-1037. doi:10.1111/jfb.12874

Wheeler, Q.D., \& Meier, R. (Eds.). (2000). Species Concepts and Phylogenetic Theory. New York: Columbia University Press.

Winston, J.E. (1999). Describing Species, Practical Taxonomic Procedure for Biologists. New York: Columbia University Press.

White, W.T., \& Last, P.R. (2012). A review of the taxonomy of Chondrichthyan fishes: a modern perspective. Journal of Fish Biology, 80, 901-917.

White, W.T., Ebert, D.A., Naylor, G.J.P., Ho, H., Clerkin, P., Verissimo, A., \& Cotton, C.F. (2013). Revision of the genus Centrophorus (Squalifores: Centrophoridae): Part 1 -Redescription of Centrophorus granulosus (Blotch \& Schneider), a senior synonym of C. acus Garman and C. niaukang Teng. Zootaxa, 3752(1), 35-7. 


\section{Appendices}

\section{Appendix 1}

Key to Southern African Chimaeroid Species

1a. Snout plough-shaped; trunk pale silver with several dark spots; heterocercal tail; large anal fin preceding caudal fin; male pelvic claspers unbranched and tube-like without fleshy denticulate tip ..........................Callorhinchus capensis

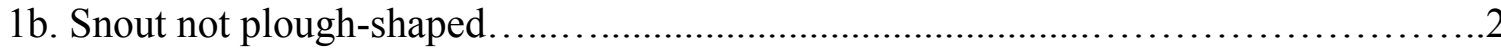

2a. Elongate, spear-shaped snout; male pelvic claspers unbranched, slender rods with denticulate bulbous tip; body even brown with no distinct markings................... 3

2b.Blunt fleshy snout; male pelvic claspers branched with fleshy denticulate lobes at

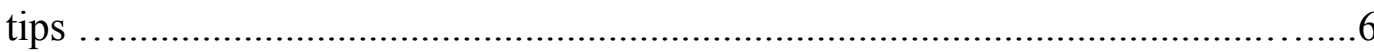

3a.Toothplates with smooth shearing blades; tubercles present on dorsal caudal fin; dorsal surface of head not arched about snout profile.

3 b. Toothplates with raised hypermineralised tritors on surface; tubercles not present on dorsal caudal fin; dorsal surface of head arched about snout profile. .5

4a. Snout broad and paddle-shaped; even dark brown body colour; caudal tubercle count $40-46$ Rhinochimaera africana

4b. Snout narrow and conical; body colour pale, whitish to grey-brown; caudal tubercle count 19-33. Rhinochimaera atlantica

5a. Separate anal fin preceding ventral lobe of caudal fin Neoharriotta pinnata

5b. No anal fin present Harriotta raleighana

6a. Anal fin present, separated from caudal fin by small notch........ Chimaera notafricana 6b. Anal fin absent, ventral caudal fin is continuous along entire length....................7 
7a. Medium-bodied; brown to tan in colour; second dorsal fin slightly indented at centre; males with lateral patch of denticles on the prepelvic tenaculum

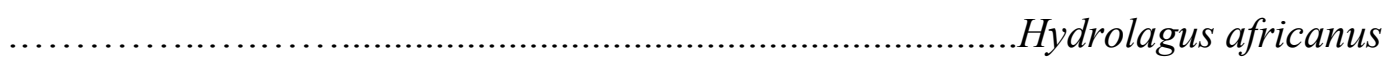

7b. Large-bodied; second dorsal fin uniform along entire length....................................8

8a. Three to five medial pre-pelvic tenaculae spines; color variable from dark brown to light tan and lilac; small, rounded pelvic fins.................. Hydrolagus affinis 8 b. Five to seven medial pre-pelvic tenaculae spines; uniform black color............................................... Hydrolagus erithacus 
Appendix 2

Material Examined

Hydrolagus affinis (NA) (13 specimens): AMNH 78355, adult female, $1080 \mathrm{~mm}$ TL, 740 mm BDL, Tenerife Island, Eastern Central Atlantic, 28 6'16. 15’ N, 16 8'39. 77 W, 01 Oct 1986; AMNH 78358, adult male, $1035 \mathrm{~mm}$ TL, $690 \mathrm{~mm}$ BDL, Tenerife Island, Eastern Central Atlantic, $28^{\circ}$ 6’16’5’'N, $16^{\circ} 8^{\prime} 39.77$ W, 01 Oct 1986; AMNH 78365, adult male, $980 \mathrm{~mm}$ TL, $655 \mathrm{~mm}$ BDL, Tenerife Island, Eastern Central Atlantic, $28^{\circ}$ 6'16.15’N, 16 8'39.77'W, 01 Oct 1986; AMNH 78367, adult male, $1122 \mathrm{~mm}$ TL, 760 mm BDL, Tenerife Island, Eastern Central Atlantic, $28^{\circ} 6^{\prime} 16.15^{\prime} \mathrm{N}, 16^{\circ} 8^{\prime} 39^{\prime} 77^{\prime \prime} \mathrm{W}, 01$ Oct 1986; AMNH 78368, adult male, 1045 mm TL, $721 \mathrm{~mm}$ BDL, Tenerife Island, Eastern Central Atlantic, $28^{\circ}$ 6'16.15'N, 16 8'39.77W, 01 Oct 1986; AMNH 78378, adult female, $1185 \mathrm{~mm}$ TL, $760 \mathrm{~mm}$ BDL, North Atlantic Ridge, 4649'18.0"N 2736'18.0"W; AMNH 78379, immature male, $920 \mathrm{~mm}$ TL, $568 \mathrm{~mm}$ BDL, North Atlantic Ridge, 464' 18.0"N 2736'18.0"W; AMNH 78380, adult female, 1215+ mm TL, 840 mm BDL, North Atlantic Ridge, 46²9'18.0"N 2736'18.0"W; ANSP 174645 (1 of 3), adult male, $1080 \mathrm{~mm}$ TL, $700 \mathrm{~mm}$ BDL, Northwestern Atlantic Ocean; ANSP 178569, adult male, $1002 \mathrm{~mm}$ TL, $657 \mathrm{~mm}$ BDL, Davis Strait, North Atlantic Ocean, 63 37' N, 56 37' W, 1415 m, 7 Nov 2001; USNM 38021, adult male, 945 mm TL, 624 mm BDL, Nova Scotia, Canada, 44 30' 00"N, 58 30' 00"W, 366 m; USNM 94399, adult female, 1121+mm TL, 853 mm BDL, Browns Bank, Massachusetts, USA; USNM 387795, immature male, 996 mm TL, 653 mm BDL, Bear Seamount, Atlantic Ocean, 39 '55'21.36’N, 67²5'55.91'”W, 1197 m, 19 Apr 2005

Hydrolagus affinis (SA) (12 with morphs, 3 genetics): SAM 33063A, mature male, 781+

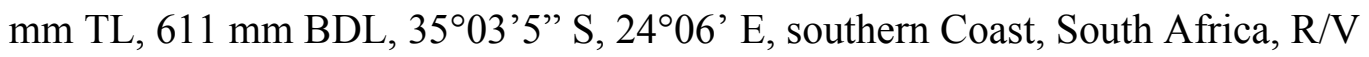
Africana, 1006m, 28 Sept 1993; SAM 33063B, mature male, $947 \mathrm{~mm}$ TL, $629 \mathrm{~mm}$ BDL, 3503' 5' S, 2406' E, southern Coast, South Africa, R/V Africana, 1006m, 28 Sept 1993; SAM 33198, mature male, 1000 mm TL, 700 mm BDL, 32³7'5.8794"S, 16² $26^{\prime}$ 12.1194"E, Western Cape, South Africa, 1009 m; SAM 33205, mature male, $841 \mathrm{~mm}$ TL, 582 mm BDL, 32³7'5. 8794"S, 16² 26' 12.1194"E, Western Cape, South Africa, 1009 m; SAM 33297A, mature male, 935 mm TL, 613 mm BDL, 35²1'S, 24.013'E, southern Coast, South Africa, R/V Africana, 915 m, 4 April 1993; SAM 33297B, mature male, 800+ mm TL, 597 mm BDL, southern Coast, South Africa, R/V Africana, 915 m, 4 April 1993; SAM 33297C, mature male, 882 TL, 607 mm BDL, southern Coast, South 
Africa, R/VAfricana, 915 m, 4 April 1993; SAM 34238, female, 1069 mm TL, 719 mm

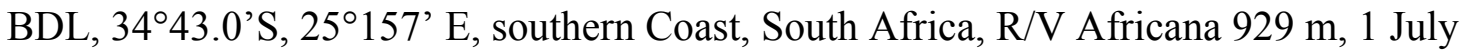
1994; SAM 34435, female, $930 \mathrm{~mm}$ TL, $585 \mathrm{~mm} \mathrm{BDL}, 42^{\circ} 02^{\prime} \mathrm{S}, 0.47^{\circ} \mathrm{E}$, Discovery Seamount, South Africa, $1500 \mathrm{~m}$; SAM 34933, mature male, $851 \mathrm{~mm}$ TL, 536 mm BDL, 3003.6'S, 14²2.2'E, Western Cape, South Africa, R/V Iris, 1056 m, 12 July 1998; SAM 34934, mature male, $905 \mathrm{~mm}$ TL, $584 \mathrm{~mm}$ BDL, 30¹5.4'S, 14³1'E, Western Cape, South Africa, R/V Iris, 1023 m, 12 July 1998; SAIAB xxxx/GN 14842, mature male, $902+\mathrm{mm}$ TL, 710mm BDL, South Africa, 35³'S, 241' 'E, $924 \mathrm{~m}$; GN 16944, female, 636mm* BDL, 1,120mm CTL, South Africa, 360 08.36’ S, $22^{\circ} 23.66 \mathrm{E}, \mathrm{R} / \mathrm{V}$ Africana, 997 m, 21 April 2015; GN 16843, female, 553mm* BDL, 1,000mm CTL, South Africa, $36^{\circ} 08.36^{\prime} \mathrm{S}, 22^{\circ} 23.66 \mathrm{E}, \mathrm{R} / \mathrm{V}$ Africana, $997 \mathrm{~m}, 21$ April 2015

Hydrolagus africanus (42 specimens): CAS 241488, 3 male, 1 female, Western Cape, South Africa, 3459'38.4" S, 018²0'04.8" E, 631 m, 10 Feb 2015; CAS 241490, 1 male, 1 female, Western Cape, South Africa, 31²7'33.0"S 1552'07.2"E, 543 m, 28 Feb 2015; CAS 241491, male, Western Cape, South Africa, 3056'57.6"S 15²7'53” E, 725 m, 5 Mar 2015; CAS 241492, 2 male, Western Cape, South Africa, 30¹9'20.4"S 145'38.4"E, 511 m, 6 Mar 2015; CAS 241493, female, Western Cape, South Africa, 30¹9'20.4"S 1454'38.4"E, 511 m, 6 Mar 2015; SAIAB 186459, adult female, 393+ mm TL, 321 mm BDL, Durban, South Africa, 30 05.244' S, 31²2.969' E, 25 Aug 2010; SAIAB 14040A, adult female, $620 \mathrm{~mm}$ TL, $293 \mathrm{~mm}$ BDL, Mombasa, Kenya, 4 $16^{\prime}$ 59.99” S, 40 6' 59.99” E, 10 Dec 1908; SAIAB 14040B, adult male, 655 mm TL, 413 mm BDL, Mombasa, Kenya, 4 16' 59.99” S, 40 6' 59.99” E, 10 Dec 1908; SAIAB 17324A, adult male, $459 \mathrm{~mm}$ TL, $285 \mathrm{~mm}$ BDL, Durban, South Africa, 29 51' 0" S, $31^{\circ}$ E, Sept 1967; SAIAB 25211, adult male, 790 mm TL, 325 mm BDL, 22 Jan 1984; SAIAB 25712, adult male, $443 \mathrm{~mm}$ TL, $304 \mathrm{~mm}$ BDL, Western Cape, South Africa, $28^{\circ}$ $22^{\prime} 59.99^{\prime \prime} \mathrm{S}, 14^{\circ} 25^{\prime}$ 18" E, 3 Feb 1986; SAIAB 17325, adult female, 407 mm TL, 285 mm BDL, Durban, South Africa, $29^{\circ} 51^{\prime} 0^{\prime \prime}$ S, $31^{\circ}$ E, Sept 1967; SAIAB 81688, adult male, $646 \mathrm{~mm}$ TL, 308 mm BDL, Mozambique, 26 10.5' S, 34 7.5' E, 29 Sept 2007; SAM 33058, adult female, $744 \mathrm{~mm}$ TL, $364 \mathrm{~mm}$ BDL, Port Elizabeth, South Africa, 34 25' 0.11" S, 25 56' 59.99" E, 309 m; SAM 33412A, adult male, $773 \mathrm{~mm} \mathrm{TL}, 330 \mathrm{~mm}$ BDL, Lüderitz, Namibia, $27^{\circ} 22^{\prime} 12^{\prime \prime} \mathrm{S}, 14^{\circ} 16^{\prime} 11.99 " \mathrm{E}, 475 \mathrm{~m}$; SAM 33412B, adult male, 735 mm TL, 295 mm BDL, Lüderitz, Namibia, 27²2' 12" S, 14 16' 11.99"E, 475 m; USNM 438927, male, Western Cape, South Africa, 31³4'55.8"S 1551'41.4"E, 563 m, 28 Feb 2015; USNM 438929, male, Western Cape, South Africa, 31 27'33.0"S 15'52'07.2"E, 543 m, 28 Feb 2015; USNM 438930, female, South Africa, 33³0'31.2"S $17^{\circ} 20^{\prime} 04.2^{\prime \prime E}, 561 \mathrm{~m}, 20$ Feb 2015; USNM 438931, female, South Africa, 3134'55.8"S 
1551'41.4"E, 563 m, 28 Feb 2015; USNM 438932, male, Western Cape, South Africa, $30^{\circ} 19^{\prime} 20.4^{\prime \prime S} 14^{\circ} 54^{\prime} 38.4^{\prime \prime E}, 511 \mathrm{~m}, 6$ Mar 2015;

H. africanus material measured by D. Didier: SAM 34412, 5 F, 16 M, 418-838 mm TL,

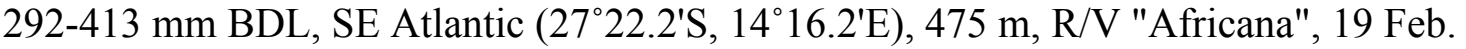
1988; SAM 34413, 2 F, 1 M, 770-828 mm TL, 315-337 mm BDL, SE Atlantic (35²0'S, $\left.18^{\circ} 45^{\prime} \mathrm{E}\right) 473$ m, R/V "Africana"; SAM 34414, 2 M, 568-847 mm TL, 389-404 mm BDL, SE Atlantic ( $\left.32^{\circ} 27.7^{\prime} \mathrm{S}, 16^{\circ} 33^{\prime} \mathrm{E}\right) 485 \mathrm{~m}, \mathrm{R} / \mathrm{V}$ "Africana"; SAM 34415, $3 \mathrm{~F}, 446-857 \mathrm{~mm}$ TL, 340-461 mm BDL, SE Atlantic (27 27.4'S, $\left.14^{\circ} 25^{\prime} \mathrm{E}\right) 425 \mathrm{~m}, \mathrm{R} / \mathrm{V}$ "Africana"; SAM 34416, M, $762 \mathrm{~mm}$ TL, $336 \mathrm{~mm}$ BDL, SE Atlantic (30 $\left.5.1^{\prime} \mathrm{S}, 14^{\circ} 50.3^{\prime} \mathrm{E}\right) 484 \mathrm{~m}, \mathrm{R} / \mathrm{V}$ "Africana"; SAM 34417, 2 F, 1 M, 633-977 mm TL, 388-465 mm BDL, SE Atlantic (30³5.2'S, 15¹9.5'E) 490 m, R/V "Africana"; SAM 34418, M, 649 mm TL, $390 \mathrm{~mm}$ BDL, SE Atlantic ( $\left.30^{\circ} 0.5^{\prime} \mathrm{S}, 14^{\circ} 53.6^{\prime} \mathrm{E}\right) 461 \mathrm{~m}, \mathrm{R} / \mathrm{V}$ "Africana", 20 July 1986; SAM 34419, 4 F, 1 M, 537-844 mm TL, 377-431 mm BDL, SE Atlantic (29 3.6'S, 14²6'E) 454 m, R/V "Africana"; SAM 34420, M, 612 mm TL, 395 mm BDL, SE Atlantic (30 5'S, 14 54.1'E) 465 m, R/V "Africana"; SAM 34421, M, 641 mm TL, 407 mm BDL, SE Atlantic (31 $\left.{ }^{\circ} 47^{\prime} \mathrm{S}, 16^{\circ} 13^{\prime} \mathrm{E}\right) 438 \mathrm{~m}, \mathrm{R} / \mathrm{V}$ "Africana", 21 Jan. 1985; SAM 34422, F, 694 $\mathrm{mm}$ TL, $282 \mathrm{~mm}$ BDL, SE Atlantic (30 6'S, 14 46'E) $497 \mathrm{~m}$, R/V "Africana, 27 Jan. 1985; SAM 33194, 1 F, 3 M, 544-871 mm TL, 227-361 mm BDL, SE Atlantic $\left(30^{\circ} 14.9^{\prime} \mathrm{S}, 14^{\circ} 58^{\prime} \mathrm{E}\right) 464 \mathrm{~m}, \mathrm{R} / \mathrm{V}$ "Africana"; A4785048, F, 940mm TL ; A4373046, M 649 mm TL, ; SAM 269976, F 984 mm TL ; SAM 27581, F, 610 mm TL ; SAM 21925, F, 533 mm TL ; SAM 21924, F, 608 mm TL; SAM 26324, M 682 mm TL; SAM 26325, F, 436mm TL ; SAM 21923, M, 761mm TL ; SAM 21926, F, 897 mm TL ; no tag,M,513 mmTL. SAM 34498, 6 F, 229-236mm TL, SE Atlantic (30²8’S, $15^{\circ} 12^{\prime}$ E), 400m, R/V 'Africana', 5 Feb.1996; CAS 229761, M, 230mm TL.

Hydrolagus erithacus ( 9 specimens): SAIAB 200578, adult male, $1290 \mathrm{~mm}$ TL, $790 \mathrm{~mm}$ BDL, Discovery Seamount, SE Atlantic Ocean, $43^{\circ} 46 \mathrm{~S}, 01^{\circ} 21 \mathrm{~W}$, SAIAB 200579, adult female, $1357 \mathrm{~mm}$ TL, $869 \mathrm{~mm}$ BDL, Discovery Seamount, SE Atlantic Ocean, $43^{\circ} 43 \mathrm{~S}$ $01^{\circ} 23 \mathrm{~W}$; SAM 34432, adult female, $1220 \mathrm{~mm}$ TL, $765 \mathrm{~mm}$ BDL, R.S.A Seamount, SE Atlantic Ocean, 39 $9^{\circ}$ 40' S, $6^{\circ}$ 40' W, 470-972 m; SAM 34434, adult male, 1185+ mm TL, 863 mm BDL, SW Indian Ocean, 44 46’S, 36² 18’E, 1097 m, 31 Jan 1997; SAM 34723, immature male, $1169 \mathrm{~mm}$ TL, $775 \mathrm{~mm}$ BDL, Marion Island, SW Indian Ocean, 46 ${ }^{\circ} 49^{\prime}$ $0.11^{\prime \prime S}, 37^{\circ} 43^{\prime} 59.87^{\prime \prime}$ E, $1000 \mathrm{~m}$; SAM 35442, adult male, $1324 \mathrm{~mm}$ TL, $842 \mathrm{~mm}$ BDL, Marion Island, SW Indian Ocean, 46 $49^{\prime} 0.11^{\prime \prime S}, 37^{\circ} 45^{\prime} \mathrm{E}, 20$ Feb 2000; SAM 34724, adult female, $1442 \mathrm{~mm}$ TL, $915 \mathrm{~mm}$ BDL, Marion Island, SW Indian Ocean, 44 46' $0.12 " \mathrm{~S}, 36^{\circ} 17^{\prime} 59.99 " \mathrm{E}, 600 \mathrm{~m}$; SAM 35446, adult female, 1399+ mm TL, $945 \mathrm{~mm}$ 
BDL, Schmit-Ott Seamount, SE Atlantic Ocean; SAM 35447, adult female, 1405 mm TL, 915 mm BDL, Schmit-Ott Seamount, SE Atlantic Ocean

Hydrolagus pallidus (1 specimen): ANSP 178019, immature male, $1010 \mathrm{~mm}$ TL, 800 mm BDL, Outer Hebrides, Scotland, United Kingdom, 57 30’ N, $9^{\circ} 30^{\prime}$ W, R/V Galibier

Hydrolagus purpurescens (2 specimens): AMNH 3, adult female, $1321 \mathrm{~mm} \mathrm{TL}, 826 \mathrm{~mm}$ BDL, Honshu Island, Japan, 28 Mar 1903; USNM 051594, Type Specimen, adult female, 868 mm TL, 514 mm BDL, Hawaiian Islands, USA, 26 Sept 1904

Hydrolagus trolli (7 specimens): ANSP 177750, adult female, $1020 \mathrm{~mm}$ TL, 610 BDL, Northwest Chatham Rise, New Zealand, 42 32' 6" S, 176 30' 48" E, 1481 m, 16 June 1990; ANSP 177751, adult male, 985 mm TL, 626 mm BDL, Veryan Bank, Chatham Rise, New Zealand, 44 39' 48" S, 176 41' 0" E, 1153 m, 4 Nov 1986; ANSP 177752 (2 of 2), immature male, $715 \mathrm{~mm}$ TL, $418 \mathrm{~mm}$ BDL, Bounty Trough, New Zealand, 3954'06"S, 174²6'06"E, 1356 m, 23 Nov 1989; ANSP 177754 (1 of 2), adult male, $1010 \mathrm{~mm}$ TL, $658 \mathrm{~mm}$ BDL, Chatham Rise, New Zealand, $42^{\circ} 31^{\prime} 12^{\prime \prime} \mathrm{S}, 178^{\circ} 30^{\prime} 30^{\prime \prime} \mathrm{W}$, 1452 m, 16 June 1992; ANSP 177754 (2 of 2), immature male, $920 \mathrm{~mm}$ TL, $562 \mathrm{~mm}$ BDL, Chatham Rise, New Zealand, 42 31' 12" S, $178^{\circ} 30^{\prime} 30^{\prime \prime} \mathrm{W}, 1452$ m, 16 June 1992; ANSP 177755 (1 of 2), adult female, 1036 mm TL, 685 mm BDL, Chatham Rise, New Zealand, 42 41' 38" S, 172 38' 2" E, 1694 m, 21 May 1994; ANSP 177755 (2 of 2), adult female, $930 \mathrm{~mm}$ TL, $564 \mathrm{~mm}$ BDL, Chatham Rise, New Zealand, 42 ${ }^{\circ} 41^{\prime}$ 38" S, $172^{\circ} 38^{\prime} 2^{\prime \prime} \mathrm{E}, 1694$ m, 21 May 1994

Hydrolagus mirabillis (1 specimen): SAM 33633, female, 363 mm TL, 183.37 mm BDL

Note. List of all specimens examined including museum code (see page 8 for list) and identification number, and catch metadata. 
Appendix 3

Morphological Measurements Definitions and Abbreviations

\begin{tabular}{|c|c|c|}
\hline $\begin{array}{c}\text { Trait } \\
\text { Abbreviation }\end{array}$ & Trait & Trait Description \\
\hline BDL & Body length & $\begin{array}{l}\text { Dorsal edge of gill opening to origin of } \\
\text { dorsal lobe of caudal fin }\end{array}$ \\
\hline $\mathrm{CDH}$ & Dorsal caudal fin height & $\begin{array}{l}\text { Maximum height of dorsal lobe of caudal } \\
\text { fin }\end{array}$ \\
\hline CDM & $\begin{array}{l}\text { Dorsal caudal margin } \\
\text { length }\end{array}$ & Origin to insertion of dorsal caudal lobe \\
\hline CLB & Clasper base width & \\
\hline CLL & Lateral clasper length & $\begin{array}{l}\text { Length of lateral clasper branch from fork } \\
\text { to tip }\end{array}$ \\
\hline CLM & Medial clasper length & $\begin{array}{l}\text { Length of medial clasper branch from fork } \\
\text { to tip }\end{array}$ \\
\hline CLT & Total clasper length & Pelvic fin base to tip \\
\hline $\mathrm{CPH}$ & Caudal peduncle height & $\begin{array}{l}\text { Measured at origin of dorsal lobe of caudal } \\
\text { fin }\end{array}$ \\
\hline CTL & Total caudal length & $\begin{array}{l}\text { Origin of dorsal caudal lobe to end of } \\
\text { caudal filament }\end{array}$ \\
\hline $\mathrm{CVH}$ & Ventral caudal fin height & $\begin{array}{l}\text { Maximum height of ventral lobe of caudal } \\
\text { fin }\end{array}$ \\
\hline CVM & Ventral caudal margin & Origin to insertion of ventral caudal lobe \\
\hline D1B & First dorsal fin base length & \\
\hline $\mathrm{D} 1 \mathrm{H}$ & First dorsal fin height & Maximum height of first dorsal fin \\
\hline D1P1 & & $\begin{array}{l}\text { Origin of first dorsal fin to origin of } \\
\text { pectoral fin }\end{array}$ \\
\hline D1P2 & & $\begin{array}{l}\text { Origin of first dorsal fin to origin of pelvic } \\
\text { fin }\end{array}$ \\
\hline $\mathrm{D} 2 \mathrm{AH}$ & $\begin{array}{l}\text { Second dorsal fin } \\
\text { anterior height }\end{array}$ & $\begin{array}{l}\text { Maximum height of anterior third of } \\
\text { second dorsal fin }\end{array}$ \\
\hline
\end{tabular}




\begin{tabular}{|c|c|c|}
\hline $\mathrm{D} 2 \mathrm{~B}$ & $\begin{array}{l}\text { Second dorsal fin base } \\
\text { length }\end{array}$ & \\
\hline $\mathrm{D} 2 \mathrm{MH}$ & $\begin{array}{l}\text { Second dorsal fin mid } \\
\text { height }\end{array}$ & $\begin{array}{l}\text { Maximum height of middle third of second } \\
\text { dorsal fin }\end{array}$ \\
\hline $\mathrm{D} 2 \mathrm{P} 1$ & & $\begin{array}{l}\text { Origin of second dorsal fin to origin of } \\
\text { pectoral fin }\end{array}$ \\
\hline $\mathrm{D} 2 \mathrm{P} 2$ & & $\begin{array}{l}\text { Origin of second dorsal fin to origin of } \\
\text { pelvic fin }\end{array}$ \\
\hline $\mathrm{D} 2 \mathrm{PH}$ & $\begin{array}{l}\text { Second dorsal fin } \\
\text { posterior height }\end{array}$ & $\begin{array}{l}\text { Maximum height of posterior third of } \\
\text { second dorsal fin }\end{array}$ \\
\hline DCS & Dorsal-caudal space & $\begin{array}{l}\text { Insertion of second dorsal fin to origin of } \\
\text { dorsal caudal lobe }\end{array}$ \\
\hline DSA & Dorsal spine height & \\
\hline EYH & Eye height & \\
\hline EYL & Eye length & \\
\hline FTL & $\begin{array}{l}\text { Frontal tenaculum } \\
\text { total length }\end{array}$ & Rear end of base to anterior tip \\
\hline HDL & Head length & Snout tip to dorsal opening of gill \\
\hline IDS & Interdorsal space & Distance between first \& second dorsal fins \\
\hline IOA & $\begin{array}{l}\text { Distance between } \\
\text { infraorbital and angular } \\
\text { canal }\end{array}$ & $\begin{array}{l}\text { Straight line distance from junction of the } \\
\text { oral and infraorbital canal to the junction } \\
\text { of the oral and angular canal }\end{array}$ \\
\hline LNC & Nasal canal length & Straight line distance from right to left side \\
\hline $\mathrm{LRC}$ & Rostral canal length & \\
\hline OCL & $\begin{array}{l}\text { Distance between main } \\
\text { trunk canal \& } \\
\text { supratemporal canal }\end{array}$ & $\begin{array}{l}\text { Measured from their junctions with the } \\
\text { infraorbital and postorbital canals, } \\
\text { respectively }\end{array}$ \\
\hline ONC & $\begin{array}{l}\text { Distance from anterior } \\
\text { oronasal fold to center of } \\
\text { nasal canal }\end{array}$ & \\
\hline OTM & $\begin{array}{l}\text { Distance between } \\
\text { preopercular canal \& } \\
\text { main trunk canal }\end{array}$ & $\begin{array}{l}\text { Measured from the preopercular canal and } \\
\text { main trunk canal junction with the } \\
\text { infraorbital canal }\end{array}$ \\
\hline
\end{tabular}




\begin{tabular}{|c|c|c|}
\hline P1AM & $\begin{array}{l}\text { Pectoral fin anterior } \\
\text { margin }\end{array}$ & \\
\hline $\mathrm{P} 1 \mathrm{BH}$ & Pectoral fin base height & $\begin{array}{l}\text { Height of pectoral fin from body to farthest } \\
\text { end of fin base }\end{array}$ \\
\hline P1BW & Pectoral fin base width & $\begin{array}{l}\text { Width of pectoral fin base from origin of } \\
\text { anterior margin to insertion of inner margin }\end{array}$ \\
\hline P1FW & Pectoral fin width & $\begin{array}{l}\text { Maximum width across pectoral fin } \\
\text { perpendicular to anterior margin }\end{array}$ \\
\hline $\mathrm{P} 2 \mathrm{AM}$ & Pelvic fin anterior margin & \\
\hline $\mathrm{P} 2 \mathrm{BH}$ & Pelvic fin base height & $\begin{array}{l}\text { Height of pelvic fin from body to farthest } \\
\text { end of fin base }\end{array}$ \\
\hline P2BW & Pelvic fin base width & $\begin{array}{l}\text { Width of pelvic fin base from origin of } \\
\text { anterior margin to insertion of inner margin }\end{array}$ \\
\hline P2FW & Pelvic fin width & $\begin{array}{l}\text { Maximum width across pelvic fin } \\
\text { perpendicular to anterior margin }\end{array}$ \\
\hline PCL & Precaudal length & $\begin{array}{l}\text { Snout tip to origin of dorsal lobe of caudal } \\
\text { fin }\end{array}$ \\
\hline PCS & Pelvic-caudal space & $\begin{array}{l}\text { Insertion of pelvic fin to origin of ventral } \\
\text { caudal lobe }\end{array}$ \\
\hline PD1 & Pre-first dorsal length & Snout tip to origin of first dorsal fin \\
\hline PD2 & Pre-second dorsal length & Snout tip to origin of second dorsal fin \\
\hline POB & Pre-orbital length & Snout tip to anterior edge of orbit \\
\hline POR & Pre-oral length & Snout tip to end of upper labial fold \\
\hline PP1 & Pre-pectoral fin length & $\begin{array}{l}\text { Snout tip to origin of pelvic fin anterior } \\
\text { margin }\end{array}$ \\
\hline PP2 & Pre-pelvic fin length & $\begin{array}{l}\text { Snout tip to origin of pelvic fin anterior } \\
\text { margin }\end{array}$ \\
\hline PPS & & $\begin{array}{l}\text { Posterior base of pectoral fin to anterior } \\
\text { base of pelvic fin }\end{array}$ \\
\hline PRN & Prenarial length & Snout tip to anterior end of nasal apertures \\
\hline SPS & & $\begin{array}{l}\text { Distance from anterior base of spine to the } \\
\text { center of the supratemporal canal }\end{array}$ \\
\hline STL & Supratemporal canal length & $\begin{array}{l}\text { Measured across the head from its } \\
\text { junctions with the postorbital canal }\end{array}$ \\
\hline
\end{tabular}




\begin{tabular}{cll} 
SVL & Snout-vent length & Snout tip to vent opening \\
\hline TBH & $\begin{array}{l}\text { Frontal tenaculum } \\
\text { bulb height }\end{array}$ & \\
\hline TBL & $\begin{array}{l}\text { Frontal tenaculum bulb } \\
\text { length }\end{array}$ & \\
\hline TBW & $\begin{array}{l}\text { Frontal tenaculum bulb } \\
\text { width }\end{array}$ & Snout tip to termination of caudal filament \\
\hline TL & Total length & $\begin{array}{l}\text { Ventral edge of gill opening to vent } \\
\text { opening }\end{array}$ \\
\hline TRL & Trunk length & $\begin{array}{l}\text { Measured at halfway point of frontal } \\
\text { tenaculum length }\end{array}$ \\
\hline TSW & $\begin{array}{l}\text { Frontal tenaculum stalk } \\
\text { width }\end{array}$
\end{tabular}

